Florida International University FIU Digital Commons

6-13-2014

\title{
Vocabulary Learning through Use of the Picture- Word Inductive Model for Young English Learners in China: A Mixed Methods Examination Using Cognitive Load Theory
}

Xuan Jiang

Florida International University, xjian002@fiu.edu

DOI: $10.25148 /$ etd.FI14071150

Follow this and additional works at: https://digitalcommons.fiu.edu/etd

\section{Recommended Citation}

Jiang, Xuan, "Vocabulary Learning through Use of the Picture-Word Inductive Model for Young English Learners in China: A Mixed Methods Examination Using Cognitive Load Theory" (2014). FIU Electronic Theses and Dissertations. 1528.

https://digitalcommons.fiu.edu/etd/1528 


\section{FLORIDA INTERNATIONAL UNIVERSITY}

Miami, Florida

VOCABULARY LEARNING THROUGH USE OF THE PICTURE-WORD

INDUCTIVE MODEL FOR YOUNG ENGLISH LEARNERS IN CHINA: A MIXED

METHODS EXAMINATION USING COGNITIVE LOAD THEORY

A dissertation submitted in partial fulfillment

of the requirements for the degree of

DOCTOR OF PHILOSOPHY

in

CURRICULUM AND INSTRUCTION

by

Xuan Jiang

2014 


\section{To: Dean Delia C. Garcia \\ College of Education}

This dissertation, written by Xuan Jiang, and entitled Vocabulary Learning through Use of the Picture-Word Inductive Model for Young English Learners in China: A Mixed Methods Examination Using Cognitive Load Theory, having been approved in respect to style and intellectual content, is referred to you for judgment.

We have read this dissertation and recommend that it be approved.

\begin{tabular}{r} 
Joanne Sanders-Reio \\
Leonard Bliss \\
\hline Kyle Perkins,Co-Major Professor \\
Eric Dwyer,Co-Major Professor
\end{tabular}

Date of Defense: June 13, 2014

The dissertation of Xuan Jiang is approved.

Dean Delia C. Garcia

College of Education

Dean Lakshmi N. Reddi

University Graduate School

Florida International University, 2014 
致谢词

经过四年的不解努力，我终于完成了这篇博士论文。如今回望，心里满是感 激。

首先要感谢我的父母，山牛、海燕，把能给予的和不能给予的都给了我。在 1999 年家境衰落、双亲下岗的困境中做出过人的决定 : 卖房供我上大学 ; 在 2010 年我因赴美留学向原工作单位申请停薪留职未果时，紧衣缩食为我赔付巨额违约 金。

其次要感谢我的外公外婆，贺括、胡滨。我受他们二人的关爱和影响，自小 树立理想。秉承他们的治学严谨, 我在学业上勇于进取、学术上严于律己、专业 上刻苦奋进。外公外婆不仅精神上鼓励我、支持我，在经济上、生活上也给了我 莫大的帮助。在我极其困苦的高中和大学七年生涯中, 外公外婆用不多的退休工 资承担了我一半的教育费用。在外公外婆的影响带动下, 我的舅舅阿姨 (海啸、 海英、海涛、玉霞、永兴、王静 ) 也非常支持我教育上的每一次进步, 他们的爱 是我不懈的动力源。

再次要感谢我的公婆, 少铭、全胜。他们无私地把对枫的爱分享到我的身上。 我的资格考试、论文开题答辩、及毕业论文答辩都是公婆二人在美国期间顺利通 过的。没有他们对我们经济上的支持和生活上的照顾, 我是很难在四年之内完成 博士课程拿到学位的。

最后要感谢我的女儿李糖和老公李枫。如果没有枫，我不会毅然决然地赴美 读博, 也从未想过自己能有更高的人生价值及取得更高的成就。枫不仅是我的伯 乐, 也是我的知音！在我的每篇文章交稿前, 他都会耐心阅读给予评论; 在我的 
每次演讲前，他都会模拟现场让我复述答疑、有所准备。他参加我的所有会议演 讲、庆祝我的每篇文章发表、出席我的开题和论文答辩。他言语和行动体现出的 爱将让我更加无畏于前方人生之路可能的坎坷和崎岖。女儿糖的诞生是在我博士 学习期间的意外惊喜。从怀孕、生产、到哺乳，我没有耽误一节课程、没有错过 一次会议、没有一年学术空档期。这些都是糖带给我的无限动力。我因为糖而多 了个母亲的角色反而使我更有责任、更加成熟。 


\section{ACKNOWLEDGMENTS}

I am about to graduate from the $\mathrm{Ph} . \mathrm{D}$. program in Curriculum and Instruction at Florida International University (FIU). Retrospecting my four-year study, I would like to thank many people at and beyond this institute, all of whom have assisted me in some way along my dissertation journey.

Firstly, I would like to thank Dr. Perkins and Dr. Dwyer, as my co-major professors. Dr. Perkins inspired me to review literature about Cognitive Load Theory early in my first semester of the program, which ended up being the theoretical framework for my dissertation. Dr. Dwyer led me to develop my dissertation idea from the very beginning stage (as a small hut) into the final dissertation manuscript (as a huge mansion), adding bricks of contexts and conceptual framework and cement of tables, charts, connecting sentences and other reader-friendly visuals.

Secondly, I would like to thank Dr. Leonard Bliss and Dr. Sanders-Reio, both of whom are my dissertation committee members. They spent their time in reviewing my proposal and dissertation drafts and giving me verbal and written comments, meeting with me to answer my methodological and theoretical questions about the dissertation, and giving my guidance for my future career, academic publications, and other occurrences.

Thirdly, I would like to thank Dr. Reio, Dr. Linda Bliss, Dr. Newman and Caprila, or the entire team known as Office of Graduate Studies in the College of Education. Caprila always reminded me of my paperwork and deadline, and checked and processed those files for every of my advancements in the program. Dr. Linda Bliss and Dr. 
Newman scrutinized the dissertation topic, purpose, research questions, methods, and structure for me in their Dissertation Boot Camp, where I benefited a lot from their challenges and questions. Dr. Linda Bliss reviewed my proposal and dissertation before defense, which I guess must have taken more time since I am not a native English speaker. Dr. Reio attended my dissertation proposal defense and dissertation defense, where he listened attentively and gave constructive suggestions. In addition to the formal occasions, he also asked me about my academic progress and gave me advice at times. Fourthly, I would like to thank Feng Li, Manuel Vilchez and Natalie Paul for their persistent efforts and time in reviewing my drafts. I also would like to thank my 48 participants and at a large, 230 student subjects. Without all of them mentioned above, I could not have my dissertation done with such efficiency.

Last but not least, possibly true to other doctoral students, my dissertation journey did not happen in a vacuum; instead, it was interwoven with other aspects of my life, such as my academic network, interactions with peers, faculty members, librarians and staff at FIU, unexpected incidents and accidents, the physical conditions and emotions of my family members. Thus, in this sense, I would like to thank all of the people who encouraged, cared or helped me, my family members who shared my joys and tears, and all of the difficulties, frustrations and tragedies which molded me into a mature and brave human. 


\begin{abstract}
OF THE DISSERTATION
VOCABULARY LEARNING THROUGH USE OF THE PICTURE-WORD

INDUCTIVE MODEL FOR YOUNG ENGLISH LEARNERS IN CHINA: A MIXED

METHODS EXAMINATION USING COGNITIVE LOAD THEORY

by
\end{abstract}

Xuan Jiang

Florida International University, 2014

Miami, Florida

Professor Eric Dwyer, Co-Major Professor

Professor Kyle Perkins, Co-Major Professor

English has been taught as a core and compulsory subject in China for decades.

Recently, the demand for English in China has increased dramatically. China now has the world's largest English-learning population. The traditional English-teaching method cannot continue to be the only approach because it merely focuses on reading, grammar and translation, which cannot meet English learners and users' needs (i.e., communicative competence and skills in speaking and writing).

This study was conducted to investigate if the Picture-Word Inductive Model (PWIM), a new pedagogical method using pictures and inductive thinking, would benefit English learners in China in terms of potential higher output in speaking and writing. With the gauge of Cognitive Load Theory (CLT), specifically, its redundancy effect, I investigated whether processing words and a picture concurrently would present a cognitive overload for English learners in China. 
I conducted a mixed methods research study. A quasi-experiment (pretest, intervention for seven weeks, and posttest) was conducted using 234 students in four groups in Lianyungang, China (58 fourth graders and 57 seventh graders as an experimental group with PWIM and 59 fourth graders and 60 seventh graders as a control group with the traditional method). No significant difference in the effects of PWIM was found on vocabulary acquisition based on grade levels. Observations, questionnaires with open-ended questions, and interviews were deployed to answer the three remaining research questions. A few students felt cognitively overloaded when they encountered too many writing samples, too many new words at one time, repeated words, mismatches between words and pictures, and so on. Many students listed and exemplified numerous strengths of PWIM, but a few mentioned weaknesses of PWIM. The students expressed the idea that PWIM had a positive effect on their English teaching.

As integrated inferences, qualitative findings were used to explain the quantitative results that there were no significant differences of the effects of the PWIM between the experimental and control groups in both grade levels, from four contextual aspects: time constraints on PWIM implementation, teachers' resistance, how to use PWIM and PWIM implemented in a classroom over 55 students. 


\section{TABLE OF CONTENTS}

CHAPTER

PAGE

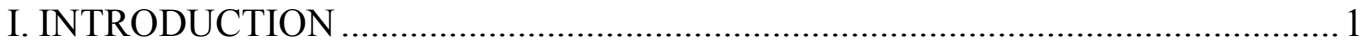

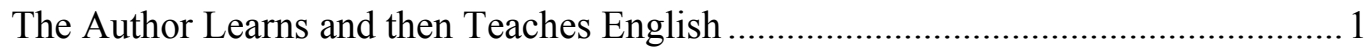

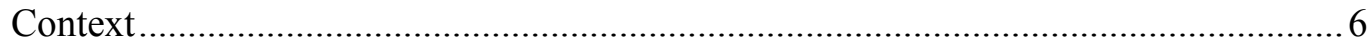

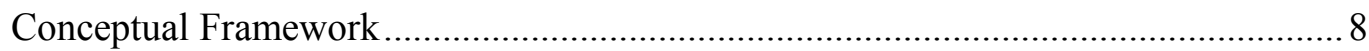

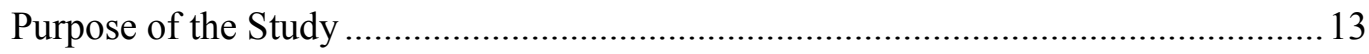

Statement of the Research Questions and Hypotheses ............................................... 13

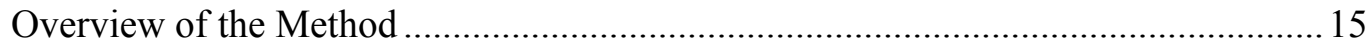

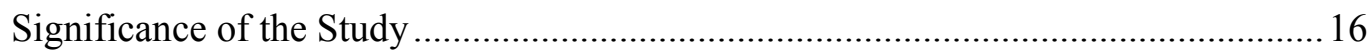

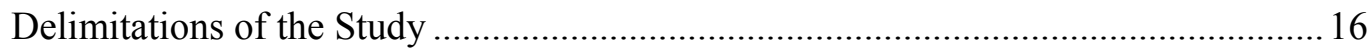

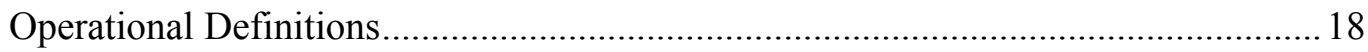

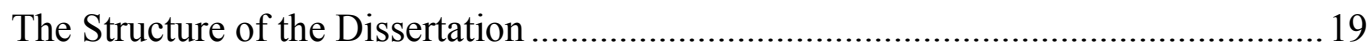

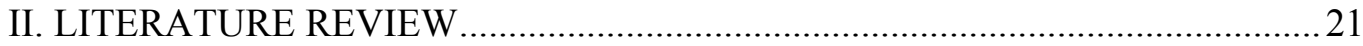

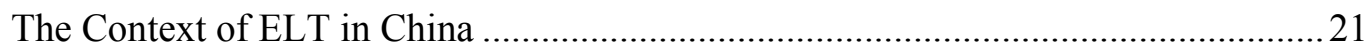

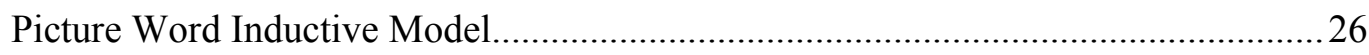

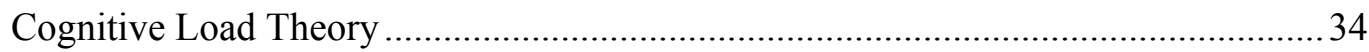

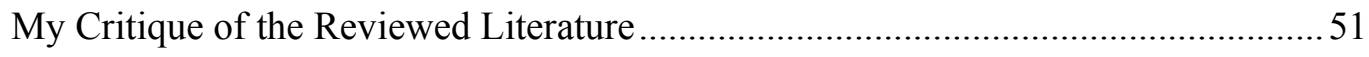

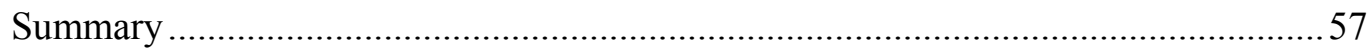

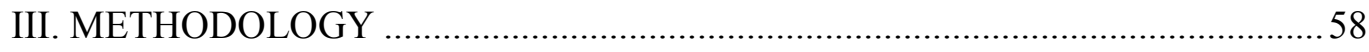

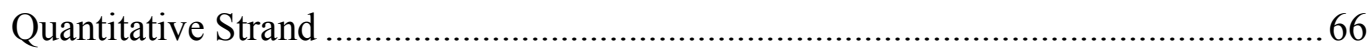

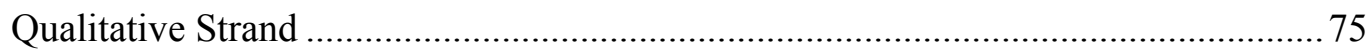

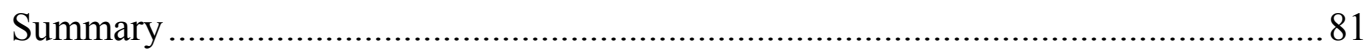

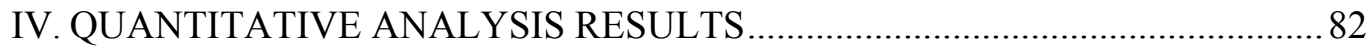

Language Knowledge Established in the Posttest ..................................................... 85

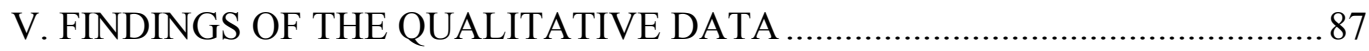

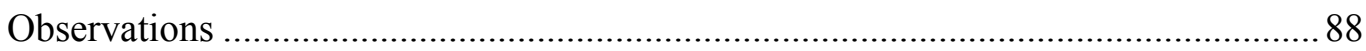

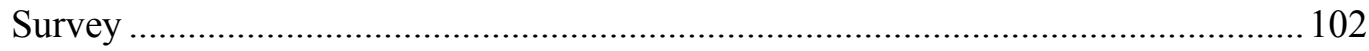

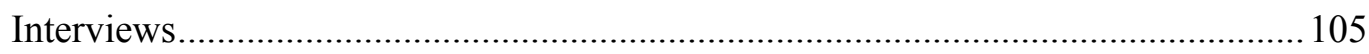

Answers to Research Question : In what instances do participants feel cognitively overloaded when they practice using PWIM? ...................................................... 127

Answers to Research Question : What are student participants' perceptions of

PWIM as to its strengths and weaknesses?

Answers to Research Question : Do participants feel PWIM is affecting their English 
learning? If so, do they consider this a positive effect or negative effect? And why?

VI. INTEGRATED INTERFERENCE 134

Time Constraints on PWIM Implementation........................................................ 134

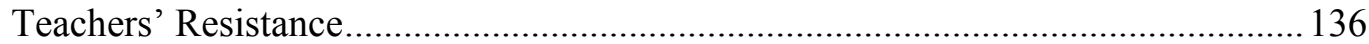

It is More about How to Use it, not Just What to Use ........................................... 139

PWIM Implemented in a Classroom of Over 55 Students ..................................... 140

More Contextual Factors Playing their Roles - Review of the Literature Review ... 141

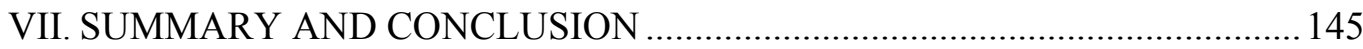

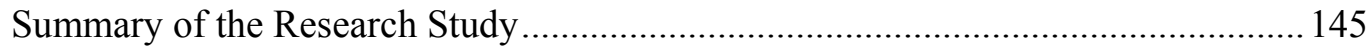

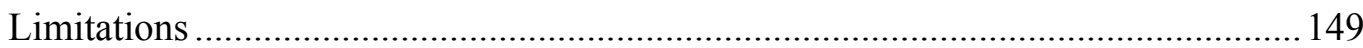

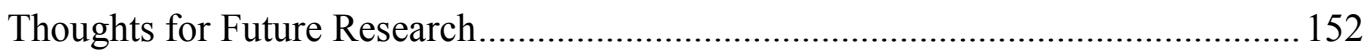

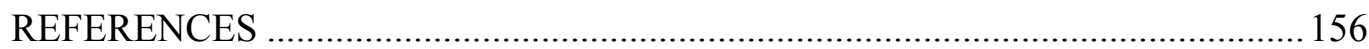

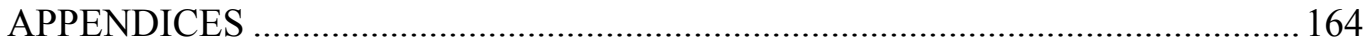

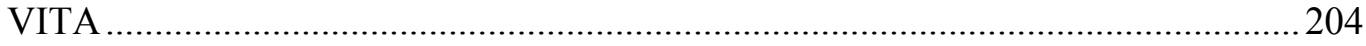




\section{LIST OF TABLES}

TABLE

PAGE

Table 1: Three Levels of Word Knowledge ….......................................................... 4

Table 2: Research Hypothesis of the Four Groups ................................................. 15

Table 3: Three Phases of a Multiphase Mixed Methods Study ...................................58

Table 4: Percentage of Correct Answers from the Pretest and Posttest.......................83

Table 5: Changes Made from Calhoun's PWIM for the Experimental Group in Grade

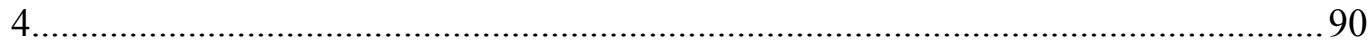

Table 6: Changes Made from Calhoun's PWIM for the Experimental Group in Grade

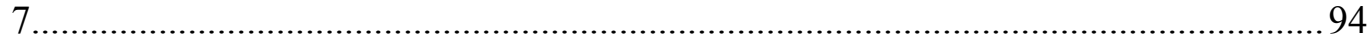

Table 7: Selected Interviewees' Name Codes and Pseudonyms .............................. 106

Table 8: Cognitive Overload Circumstances for Fourth and Seventh Graders ......... 128

Table 9: What Literature Says and What I Found/Felt—Context ............................ 142

Table 10: What Literature Says and What I Found/Felt — Use of PWIM................. 143 


\section{LIST OF FIGURES}

FIGURE

PAGE

Figure 1: Illustration of information processing model 10

Figure 2: The model of the conceptual framework.................................................... 13

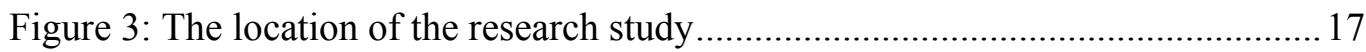

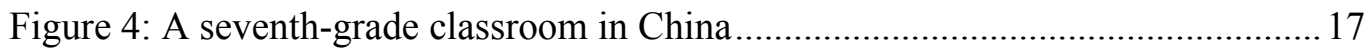

Figure 5: A demonstration of PWIM using a picture ............................................. 30

Figure 6: Connections of speaking and writing using PWIM................................... 32

Figure 7: Information into and between WM and LTM .......................................40

Figure 8: The textbook "Fun with English 4A" in fall semester for fourth graders ....51

Figure 9 The textbook "English 7A" in fall semester of seventh graders ...................51

Figure 10: Literature review and research questions ….........................................56

Figure 11: Literature review, research questions and research design ......................6 62

Figure 12: Parallel mixed methods design with two strands ....................................63

Figure 13: Mixed methods design with two strands and three phases.........................64

Figure 14: Percentage of correct answers from the pretest and posttest for each cell. 85

Figure 15: Timetable of implementing PWIM in the elementary school ................... 89

Figure 16: PWIM picture for fourth Graders — Unit 1 ............................................ 93

Figure 17 Timetable of implementing PWIM in the middle school...........................94

Figure 18: PWIM picture for seventh Graders-Unit 4 .......................................... 97

Figure 19: Strength of PWIM reported by the seventh Graders ............................. 130 
Figure 20: Recent groups distribution and future groups distribution......................152 


\section{LIST OF ACRONYMS}

CL cognitive load

CLT cognitive load theory

EFL English as a foreign language

ELT ...English language teaching

ESL English as a second language

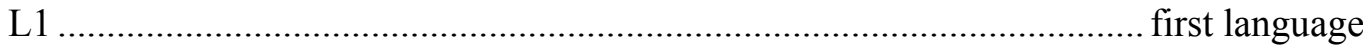

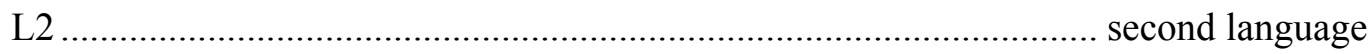

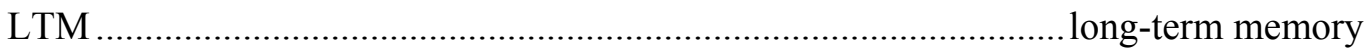

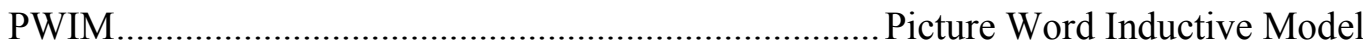

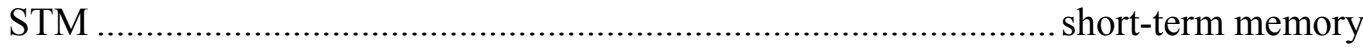

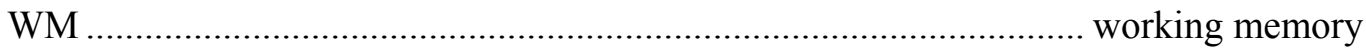




\section{CHAPTER I}

\section{INTRODUCTION}

\section{The Author Learns and then Teaches English}

I grew up in Lianyungang, a coastal, medium-sized city in Jiangsu, China. The province has been economically and educationally advancing for centuries. Back in the 1990s during my 6-year English learning experiences in secondary schools, I did not see many visuals accompanying the texts in my English textbooks. Moreover, all my English teachers were Chinese, sharing the same first language (L1) and cultural heritage, rigidly adhering to the textbooks in teaching (i.e., they used the textbooks as the only material, and they taught based on the unified syllabus), and reflecting Yang's (2000) notion of a "teacher-centered textbook-analysis-based Grammar-Translation Method" (p. 19; 以教师为中心、以教科书分析为基础的语法翻译法). Thus, during my 10 years of systematic and institutional English education (i.e., 6-years of secondary and 4-years of post-secondary education), I had few chances to experience the effect of pictures on my English learning, from either the curriculum or instruction. As a result, at least in my mind, I felt I had even fewer opportunities to learn inductive thinking or any connection between reading and writing. Instead, I learned English in a disconnected way, primarily through drilling and repetition, in the way many English learners had been studying in China for ages. 
As an undergraduate English major, I was taught English partially by the audio lingual method. In the late 1990s, in an audio lab of cassettes and tape-recorders, I was asked to follow what the speakers said after listening to a tape and imitate their tones and rhythm, developing (theoretically) phonetic awareness between pronunciations and spellings and collecting information from those dialogues. Sometimes, my Chinese English teacher gave us a transcript of what we would hear, which I found helpful in terms of correct spelling but not helpful at all with regard to accurate pronunciation and information collection. For some dialogues spoken quickly with demanding content (e.g., news of launching a satellite from an advanced English listening program using Voice of America), the written text of the transcripts seemed to have a counter-effect on my attention. I chose to cover the text while listening, in order to concentrate on the dialogue. Then I examined the text, checking spellings and collected information. Now I realize that the text appeared to have a redundancy effect ${ }^{1}$ on me when I was listening to the tape. At that time, both verbal and text information was presented to my brain to be processed at the same time, which may actually have impeded my acquisition of accurate pronunciation and information collected from listening. In that case, the extra written text may have been redundant to me.

After I graduated with a Bachelor's degree in Legal English, I became an English instructor and taught college comprehensive English to Chinese non-English-major college students in the 2000s. Students told me that they found learning vocabulary as their biggest challenge. On the one hand, they needed to pass a

\footnotetext{
${ }^{1}$ The redundancy effect will be discussed in further detail in Chapter 2.
} 
national English test requiring a command of approximately 4,000 English words. Failure to pass the test resulted in the students' not obtaining any corresponding diploma, even if they had passed all other previous college courses. With such a backdrop, my students had yet one additional problem: They felt unempowered with any strategy for remembering or using the new words they studied. They reported to me regularly that they found remembering meanings of new words presented in a random and isolated display tremendously difficult. They said they had too many new random words at one time; thus, drilling and repetition were not working anymore. Sometimes, they said that even if they already knew textual meanings, they felt it was even harder to use them to match different contexts (i.e., the connotations of new words). For instance, one student explained with consternation the word suspect, which has the same literal meaning as doubt after being translated into Chinese as 怀 疑, or huaiyi. As a result of the Grammar-Translation Method from their previous English learning experiences (Yang, 2000, p. 19), students had insufficient experience from which they could choose a correct and appropriate synonym accordingly. In other words, they might recognize these words in readings, but they could not use the words in their writing. As a result, when instructed to write a theme-based or assigned essay in the writing part of the exam, some students simply left it blank.

Armbruster, Lehr, and Osborn (2003) distinguished different levels of knowing words, naming the stages as unknown, acquainted, and established levels (p. 43), as shown in Table 1. My students seemed to be more at the acquainted stage, as words were often somewhat familiar to them, but not yet at the established stage where they 
could "immediately recognize" and use the words correctly (Armbruster et al., 2003, p. 43).

Table 1

Three Levels of Word Knowledge

\begin{tabular}{ll}
\hline $\begin{array}{l}\text { LEVEL OF WORD } \\
\text { KNOWLEDGE }\end{array}$ & DEFINITION \\
\hline Unknown & $\begin{array}{l}\text { The word is completely unfamiliar and its meaning is } \\
\text { unknown. } \\
\text { Acquainted }\end{array}$ \\
$\begin{array}{l}\text { The word is somewhat familiar; the student has some idea of } \\
\text { its basic meaning. } \\
\text { Established }\end{array}$ & $\begin{array}{l}\text { The word is very familiar; the student can immediately } \\
\text { recognize its meaning and use the word correctly. }\end{array}$ \\
\hline
\end{tabular}

(Source: Armbruster et al., 2003, p. 43)

Without consolidating the words from the acquainted level to the established level, my students were more likely to forget the pronunciation, spelling, and meanings of those words sooner while they ceaselessly added on more and more words to study. As a result, with the larger vocabulary field to tackle, previously studied words seemingly reverted to the unknown stage. As a consequence, students became less motivated or interested in enlarging their vocabulary since they found memorizing the words fruitless. As a result, I felt helpless as I saw these scenarios over and over, all I could tell them was to work harder and memorize the words again and again and again.

Over the years, I found myself searching for an approach which could bridge reading with writing, make new words meaningful and alive to learners, and scaffold the contextual uses of new words. One day, I happened upon the picture-word induction model (PWIM) in a textbook for a doctoral class, EDG 7362 Instruction: 
Theory and Research (Joyce, Weil, \& Calhoun, 2009). When I first read about PWIM, I realized that it was the approach that I was looking for, because PWIM could make words become alive by having students use them inductively and build paragraphs from those words. I could not wait to implement it in English language teaching (ELT) in China. Then, with such an initial emotional impulse fading away, I wondered whether PWIM might even be effective in the context of China in spite of its many successful scenarios in Native English and English as a Second Language (ESL) learning contexts. Before I had a chance to study PWIM in China empirically, I started to review the literature to seek the theoretical possible reasons of its effectiveness or ineffectiveness.

Theoretically, I did not identify the possible reasons why PWIM may or may not be effective until I started studying Cognitive Load Theory (CLT) and its redundancy effect. The redundancy effect means that information presented does not "contribute to schema acquisition or automation" and "interferes with learning" (Sweller, 2010, p. 30). I felt that using CLT might explain the degrees of PWIM effectiveness, since CLT deals with how much information can be processed at one time in working memory (WM) and PWIM delivers both verbal information and images to any learner's brain to be processed at the same time. In the same vein, vocabulary acquisition may actually be impeded, because the additional cognitive load which PWIM imposes would take up the limited resources in the WM, causing cognitive overload, and the extra images may be redundant to English language learners. My English-learning experience of being presented with listening and reading may go hand in hand with PWIM, which presents pictures and texts 
concurrently. Both of them are linked with cognitive overload ${ }^{2}$ and the redundancy effect.

\section{Context}

English has been taught as a core subject in China for decades, making China now the largest population of English learners and users: approximately 440 million English-learning and English-using people in China (for details, see Crystal, 2008, pp. 4-5). And for decades, English teaching in China promoted a strong linguistic focus on grammar, reading, and translations, with a method called "teacher-centered textbook-analysis-based grammar-translation” (Yang, 2000, p. 19; 以教师为中心、以 教科书分析为基础的语法翻译法). This traditional approach, a form of direct instruction, typically starts with teacher demonstrations followed by student practice and memorization (Yang, 2000). However, this traditional method is not the only English teaching approach implemented nowadays because English learners and users in China need more competence and skills (e.g., writing, speaking, and communicative competence), due principally to economic, political, and social influences including the Open-Door Policy in 1979 (Galbraith \& Lu, 2000); the entry into the World Trade Organization (WTO) in 2000 (Wang \& Robertson, 2004); the Olympic Games in Beijing in 2008 (Zhang \& Daun, 2010), as well as decades of globalization and domestic economic reforms.

\footnotetext{
${ }^{2}$ Cognitive load will be discussed in further detail in Chapter 2.
} 
As an example, recently designated (i.e., nationally unified) syllabi at the university level are based on the notional function approach, communicative language teaching, and learner-centeredness (Nunan, 2003). These constructivist approaches are revolutionary in the sense that they are student-centered and involve active learning, compared to the traditional behaviorist, teacher-centered and passive learning version.

All these socio-political and economic factors have driven ELT into producing English learners with communicative competence (i.e., using English in an appropriate way for both oral and written communications in real-life settings). PWIM, as a new ELT approach that seemingly had never been used in China before, might be essential to the ongoing new English education, which enables learners to manage the meaning and use of new words, empowers learners from passive learning to active learning by speaking and writing, and helps learners write up paragraphs step by step from adding up words, phrases and sentences.

\section{Conceptual Framework}

\section{Picture-Word Inductive Method}

One teaching approach that seemingly combines both constructivism and behaviorism is PWIM (Wang, Lin, \& Spalding, 2008). PWIM focuses on the learners' own understanding of pictures, in concert with the meaning of words, phrases, sentences, and paragraphs (Wang et al., 2008), which is congruent with constructivist ideas of learning (von Glasersfeld, 1987). It also, however, results in learning in the 
form of isolated concepts, words, sentences, phrases, and paragraphs, which are suggested as knowledge in behaviorism (Skinner, 1968).

PWIM is a teaching approach based on Calhoun's (1999) research on early literacy. The fundamental tenet of PWIM is its use of "pictures as a stimulus for language experience activities" in classrooms to teach young beginners learning to read and write (Joyce et al., 2009, p. 130). Calhoun suggested that PWIM be used to teach several skills as an integrated whole simultaneously, beginning with the phonetic and structural components of language, for example, the pronunciation and the spelling of a word. Students using PWIM see the item, listen to the teacher's pronunciation, and then pronounce the word to reinforce word recognition. PWIM also covers explicit instruction and induction, as well as an immediate assessment of students' needs and comprehension. Calhoun suggested that a teacher can arrange any individual activity, as well as small-group and large-group activities, with a PWIM format. She also suggested that PWIM can be modified and applied to older beginners (Calhoun, 1999). However, until now, there have been only a few research studies of PWIM (Calhoun, 1999; Feng, 2011; Swartzendruber, 2007; Wong, 2009), and none of them have been conducted with any English as a Foreign Language (EFL) learner in Mainland China. This study was an initial attempt to examine the effectiveness of PWIM in a Chinese context, which helps fill the gap in the research knowledge of the effect of PWIM in an EFL context and with older beginners. This study was undertaken to give more bottom-up practical factors of implementing and effectiveness of a new English teaching method (PWIM) in a certain context, thus possibly pushing the discipline of 
English language teaching forward.

\section{Cognitive Load Theory}

Cognitive Load Theory (CLT) is one of the most influential theories in instructional design and a highly effective guide in designing learning materials. CLT focuses on the processing of information aspects and the inherent limitation of working memory (WM), also known as short-term memory (STM), and deals with the STM's storage and transfer of incoming stimuli to long-term memory (Atkinson \& Shiffrin, 1968). The STM receives input from the sensory memory and the long-term memory (LTM).

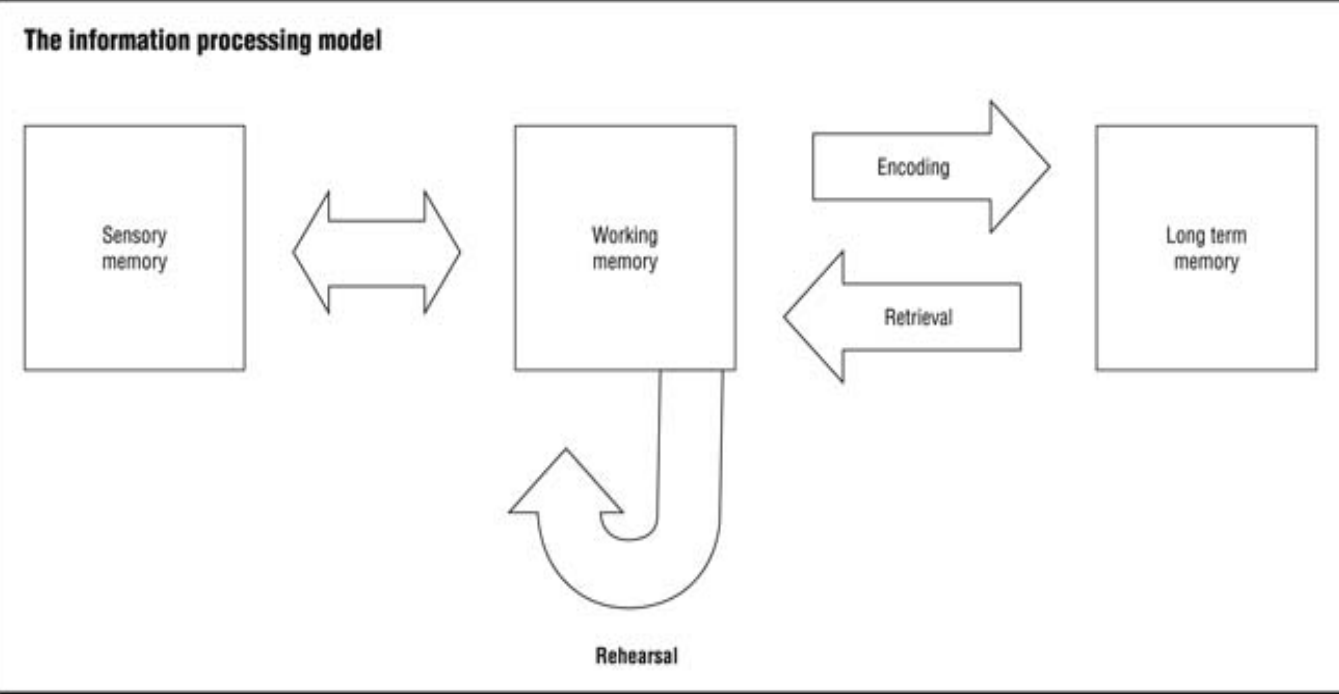

Figure 1. Illustration of information processing model (Source: GGS Information Services. Cengage Learning, Gale, 2013).

Although it is limited, WM is vital to CLT concerns as it is viewed as "the seat of consciousness" (Sweller, 2004, p. 12) where small amounts of information are stored 
while LTM stores relatively permanent and large amounts of information (de Jong, 2010; Sweller, 2004). Two aims of CLT are to encourage learners' cognitive activities and further optimize their intellectual performance. CLT has been increasingly applied since the 1990s in several instructional contexts including language instruction, math instruction, animation learning, and multimedia design (Craig, Gholson, \& Driscoll, 2002; Kalyuga, Chandler, \& Sweller, 1999; Mayer \& Moreno, 2010; Torcasio \& Sweller, 2010).

\section{The Redundancy Effect}

As a result, CLT may have been appropriate for examining the effectiveness of using PWIM with regard to cognitive load, cognitive overload, and the redundancy effect. Indeed, findings from empirical studies have shown different cognitive load (CL) effects. Sweller summarized and listed 12 such CL effects in a table (2010, p. 30, see Appendix A), including the split-attention effect, the modality effect, the redundancy effect, the expertise reversal effect, and so forth. Eight of the 12 fall into a set of effects known as extraneous $C L$; two, namely, element interactivity and isolated/interacting effects, are designated as primarily intrinsic $C L$; and variable examples and imagination fall into a group labeled germane $C L^{3}$.

Among the 12 effects, the redundancy effect has been studied in the field of

${ }^{3}$ Please see Chapter 2 literature review beginning on page 37 and 38 for details of the three types of CL. 
language teaching and learning. The redundancy effect occurs when information presented does not "contribute to schema acquisition or automation" and "interferes with learning" (Sweller, 2010, p. 30), such as my personal experiences of processing listening and reading English materials concurrently. There have been at least four studies of the redundancy effect in language learning. Two of these studies (Diao, Chandler \& Sweller, 2007; Diao \& Sweller, 2007) fall in the domain of EFL teaching, in which EFL students were presented with written and spoken text simultaneously. These two studies emphasized the effect of combining written and spoken texts. A third empirical study (Torcasio \& Sweller, 2010) was conducted in the field of English as a native language with the researchers examining the effect of using illustrations in the beginning stage of teaching reading. The fourth study (Plass, Chun, Mayer, \& Leutner, 2003) was conducted in the context of German as a second language learning, more specifically with respect to reading with multimedia aids and the influence of verbal and spatial abilities. Findings from all the four studies demonstrated the redundancy effect in which redundant information adds to processing time and processing load; however, none of the researchers (Diao et al., 2007; Diao \& Sweller, 2007; Plass et al., 2003; Torcasio \& Sweller, 2010) have ever investigated the effects of the concurrent presentation of pictures and texts in an EFL teaching context such as China, which has the largest English-speaking and English-using population in the world.

In terms of the PWIM, a consideration of the redundancy effect may be important. In a foreign language class, a teacher could possibly present a picture along 
with words, and doing so may cause the redundancy effect for learners.

As the result of these considerations, I used cognitive load theory (CLT) to examine the effectiveness of using PWIM to teach Chinese students English vocabulary; in particular, I used cognitive load and the redundancy effect to investigate the effectiveness of using PWIM to teach Chinese students English vocabulary in the context of Mainland China. CLT, effective in designing instruction and learning materials, was appropriate as a guiding theory which was applied to PWIM as an instructional approach. The following figure is a model of the conceptual framework of the current research study.

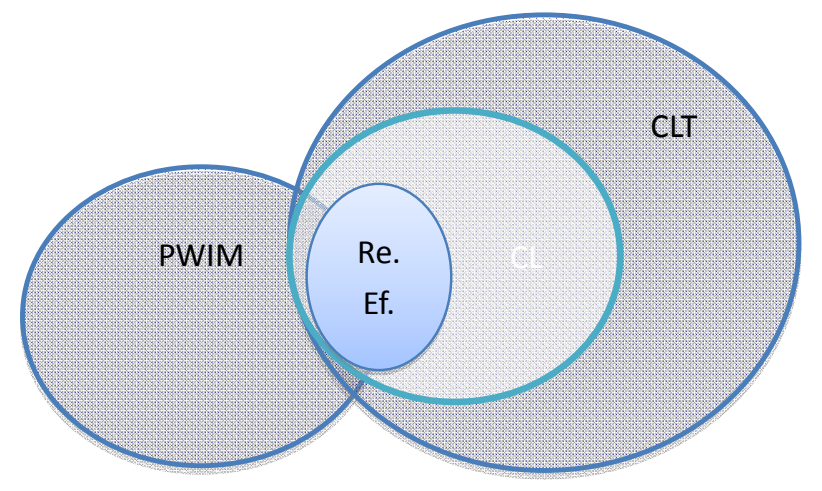

Figure 2. The model of the conceptual framework. Re. = redundancy, $\mathrm{Ef}=$ effect, $\mathrm{CL}=$ cognitive load.

\section{Purpose of the Study}

With the theoretical, empirical and contextual gap mentioned above, the purpose of this study was to investigate the effectiveness of using PWIM to teach Chinese students English vocabulary in Mainland China, through the gauge of CLT. 
Specifically, the redundancy effect in CLT was used to investigate whether processing words and a picture concurrently created a cognitive overload to English learners in China.

\section{Statement of the Research Questions and Hypotheses}

Given that PWIM was new to English learners in Mainland China, this research addressed research questions regarding which EFL learners, fourth graders who learn to read or seventh graders who read to learn, would benefit most from PWIM. Specifically, this research involved the investigation of the following research questions:

(a) What are the effects of the PWIM on vocabulary acquisition? Are there differential effects of PWIM on vocabulary acquisition based on grade level?

(b) In what instances do participants feel cognitively overloaded when they are in the practice stage using PWIM?

(c) What are student participants' perceptions of PWIM as to its strengths and weaknesses?

(d) Do participants feel PWIM is affecting their English learning? If so, do they consider this a positive effect or negative effect? And why?

The first research question is based on two research hypotheses: (a) The mean of the percentage of correct answers in the posttest for the PWIM group of fourth graders 
(experimental group) is significantly lower than the mean of the percentage of correct answers in the posttest of students taught with traditional methods (control group) the percentage of correct answers in the pretest is used as a covariate; (b) The mean of the percentage of correct answers in the posttest for the PWIM group of seventh (experimental group) is significantly higher than the mean of the percentage of correct answers in the posttest of students taught with traditional methods (control group) the percentage of correct answers in the pretest is used as a covariate. The are shown in the table below.

Table 2

Research Hypothesis of the Four Groups

Grade $4(1)$

Grade 7 (2) Experimental (1) Control (2)

\begin{tabular}{|l|l|}
\hline 11 & 12 \\
\hline 21 & 22 \\
\hline
\end{tabular}

Statistically, the first research hypothesis was $\mathrm{H}_{1}: \mu_{11}<\mu_{12}$, and the null hypothesis was $H_{0}: \mu_{11} \geq \mu_{12}$. The second research hypothesis was $H_{1}: \mu_{21}>\mu_{22}$, and the null hypothesis was $\mathrm{H}_{0}: \mu_{21} \leq \mu_{22}$. 


\section{Overview of the Method}

This research study utilized a mixed methods approach. Data were collected from students' tests, questionnaires, and interviews. Vocabulary test grades were analyzed by two-way analysis of covariance (ANCOVA) to determine if differences of means existed between EFL students having been taught by PWIM (experimental group) and students having been taught by the traditional method (control group).

Test data were also analyzed to see whether the effectiveness of using PWIM to teach Chinese students English vocabulary varied with grade level. Data collected from questionnaires and interviews were analyzed to identify students' viewpoints concerning PWIM in terms of cognitive (over)load.

\section{Significance of the Study}

This study may be the first to implement mixed methods with respect to an examination of PWIM and would also be the first one to apply CLT to PWIM, which may contribute to the existing handful of research studies of PWIM, presenting more research evidence concerning the effectiveness of using PWIM.

Moreover, this study would have been a pioneer study in terms of the sample and context, that is, fourth graders in a public elementary school and seventh graders in a public secondary school in a coastal city in China. As a result, had the results been favorable with respect to PWIM, replicated studies across Mainland China would be needed before any positive results inform policy decisions about English 
instruction for the entire nation. If positive results from replicated studies corroborate with the findings of the current study, officials can consider PWIM as a new teaching approach to be introduced and implemented in Mainland China, which has the world's largest English-learning population, thus possibly enhancing the current teaching methodology in terms of helping learners acquire English literacy and develop inductive thinking effectively.

\section{Delimitations of the Study}

For this study, I chose EFL learners in Mainland China, rather than English as a Second Language (ESL) learners or EFL learners in other parts of the world. Participant learners were from public schools in a developed city, Lianyungang, along the coast of China (see Figure 3 for geographic location of the research study). Subjects were not representative of all Chinese EFL learners because learners' English proficiency varied geographically. The teachers who volunteered their classes may have different teaching levels from other teachers, so they were not representative of all Chinese EFL teachers.

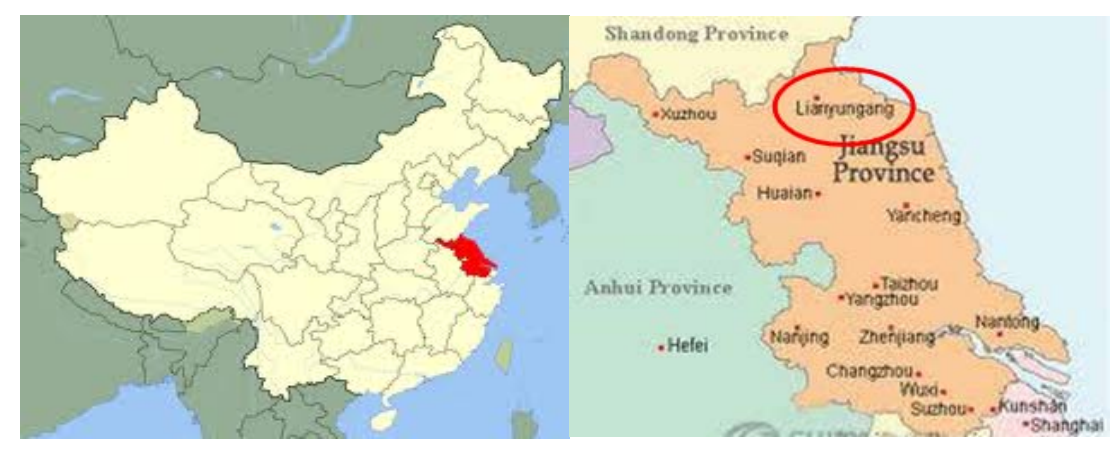

Figure 3. The location of the research study 
(Source: Jiangsu top 8 make great performances, 2011 and City feature: Lianyungang, Jiangsu province, n.d.).

Another delimitation of this research study was the grade levels of the participants. I chose grade level Four and Seven only in the study. The subjects were not representative of all Chinese EFL learners in different grade levels.

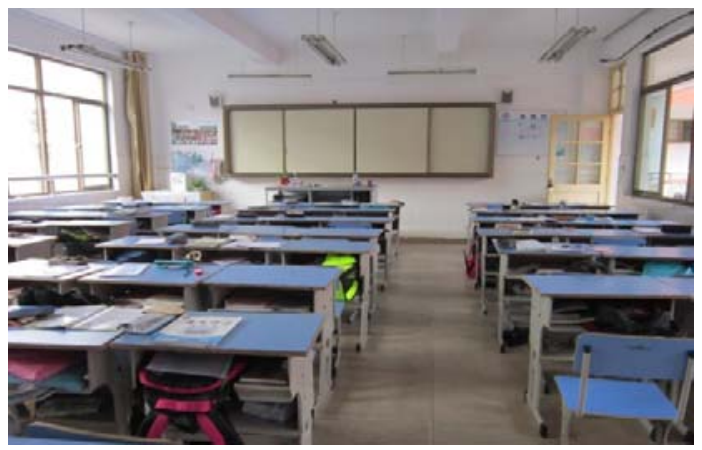

Figure 4. A seventh-grade classroom in China

(Source: Author, 2013)

\section{Operational Definitions}

Cognitive Load (CL) is also called relative condition efficiency operationally, as calculated by combining mental effort ratings with performance scores to obtain information. The method is based on the standardization of raw scores for mental effort and task performance to $z$-scores (Paas \& van Merriënboer, 1993).

Cognitive Overload means WM "capacity is exceeded" (de Jong, 2010, p.118) or the required WM capacity exceeds available WM. 
English as a foreign language (EFL) means learners learn English in a community where English is not the first language. In the current study it means English learners in China.

Mainland China refers to the part of China, excluding Taiwan, Hong Kong, and Macao.

Picture word inductive model (PWIM) is an instructional strategy in which pictures are used "as a stimulus for language experience activities" in classrooms to teach young beginners learning to read and write (Joyce et al., 2009, p. 130; see Calhoun, 1999, p. 23 for the 10 steps in detail).

The redundancy effect means that information presented does not "contribute to schema acquisition or automation" and "interferes with learning" (Sweller, 2010, p.30)

\section{The Structure of the Dissertation}

The first chapter of this dissertation started with the background, the purpose and the research questions of the study. Following that, the significance and the delimitations of the study were presented.

The second chapter focuses on the related literature review on PWIM and CLT as well as applying PWIM in Mainland China in an EFL context. Three major areas are discussed: (a) the contextual factors of implementing PWIM in Mainland China; 
(b) PWIM as an instructional approach to enhance vocabulary acquisition and inductive thinking; and (c) CLT as theoretical framework.

Chapter 3 explains the research methodology of this study. The mixed methods design, participants, the materials used in the participating classes, the design of this study, the procedure of the quasi-experiment, and the procedures of data collection and analysis are fully discussed.

Chapter 4 provides findings of the quantitative data to answer the first research question. Analyzed by ANCOVA, the results from each group were compared to examine the effectiveness of using PWIM.

Chapter 5 provides findings of the qualitative data. The data from observations, questionnaires, and interviews were analyzed and categorized into several themes. The answers to the three remaining research questions are put at the end of this chapter.

Chapter 6 provides meta inference from the results of both quantitative and qualitative components in this mixed methods study. The interference from the quasi-experiment, observations, questionnaires, and interviews are integrated in order to inform and explain each other.

The last chapter (Chapter 7) presents a concluding summary of the study. The concluding chapter starts with a summary of this mixed methods study and then discusses its limitations. It ends with thoughts for future research studies. 


\section{CHAPTER II}

\section{LITERATURE REVIEW}

The purpose of this mixed-methods research study was to examine the effectiveness of using PWIM to teach Chinese students English vocabulary using CLT in Mainland China as an EFL context. It also aimed to explore the participants' opinions about PWIM. Accordingly, this chapter discusses three key aspects through a selection of reviewed literature. The three areas to be discussed are contextual factors of English language teaching (ELT) in China, the Picture-Word Inductive Model (PWIM) and Cognitive Load Theory (CLT), most specifically CLT's redundancy effect.

\section{The Context of ELT in China}

English as a foreign language has been taught as a compulsory subject in China for many years. English teaching in China has its peculiar cultural, social and political context; thus, China has experienced its own particular history of English textbooks and syllabi changes.

\section{English Teaching in China}

Historically, English has been taught as a compulsory subject with a strong emphasis on grammar, translation, and reading, mainly through direct instruction approaches (Yang, 2000). Such traditional teaching approaches are characterized by 
systematic study of grammar, extensive use of Chinese-English translation, and persistent memorization of syntactic patterns and vocabulary $(\mathrm{Hu}, 2002)$. The teacher-centered teaching style often starts with teacher demonstrations (i.e., reading a paragraph out loud from a textbook, writing down new words and phrases on a blackboard, and explaining the form and meaning of those new words), followed by student practice (i.e., following the teacher to pronounce those words, taking notes from the blackboard and trying to read the paragraph in chorus) and memorization of the spelling after class (Yang, 2000). Such has been the tradition for many years; however, the traditional approach has failed to develop an adequate level of EFL learners' communicative competence (i.e., the ability to use English for authentic verbal and textual communications) in China. Millions of EFL learners taught by this traditional approach can read, but cannot speak or write well. As a result, new English teaching approaches, focusing on bridging reading with writing and transforming learners from passive to active agents, have recently entered Chinese classrooms. In 2001, the National Academy of Education Administration in China (NAEA), known as the highest education authority in China, issued the National Standards for Teaching English Subject (NETES), which states that the utilization and practical application of English has been neglected and that "the new textbooks need to take students' study interests, life experience, and their cognition knowledge into consideration" (Pp. 1-2). This new attitude may be observed as a shift in education policy and accordingly in textbook reform, one catering toward a view of constructivism, compared to the traditional behaviorist-based ones. 
This English education reform, however, has had top-down constraints in various facets, for instance, national syllabi and a centralized approach. Such homogeneity or unity cannot be realized without repercussions. For example, Nunan (2003) observed that English teaching varies geographically and economically, and therefore there seems to be a general division between the wealthier coastal regions and the interior land, as well as between urban and nonurban areas. In fact, a gap can be seen among the students' English proficiency, teachers' credentials, and resources, as well as the number of native English teachers per school. Some top schools in Beijing and Shanghai have begun math and science classes in English, but some elementary schools in remote areas don't have English classes at all, in spite of the September 2001 national policy requiring that English be taught to third graders in all elementary schools that have qualified English teachers (Nunan, 2003). The cities of Beijing and Shanghai have also begun to develop their own English textbooks (Niu-Cooper, 2012); thus, they are pioneers in designing local textbooks rather than adopting the national ones.

The 2001 policy mandated that the age for compulsory English be lowered from 11 to 9 years old. According to the official rhetoric, elementary pupils receive two or three 40-minute English classes per week. Students in secondary and high schools have five or six 45-minute English lessons every week (Nunan, 2003). The suitably qualified teachers mentioned in this regulation refer to Chinese students English teachers with formal English teaching education (Wang et al., 2008). Elementary English teachers typically receive a credential in English education from 
three-year normal schools and as do secondary teachers in four-year colleges or universities (Wang et al., 2008). However, while these rules are in place, such compulsory introduction of English classes, as a national policy, may not be feasible for all classrooms due to the factors mentioned before (Nunan, 2003).

\section{Resistance to Change}

As mentioned earlier, some innovative teaching approaches have recently been introduced into English education in China. However, school principals and teachers may feel uncomfortable and unsafe when they are informed of change. This feeling occurs when "change... upsets the pattern" people are accustomed to, thereby thrusting people into new perceptions and challenging people's way of dealing with life (Evans, 1996, p. 27). Such feelings are more likely to register with those educational practitioners who are already satisfied with the situation they are in (Feng, 2011). Resistant teachers feel awkward or even embarrassed when they, like learners, have to relearn new approaches to teaching in front of their students because they want to maintain the image of being experts rather than novices (Shor \& Freire, 1987). They even fear the consequences of their own change proposals when they think of the risks to their careers if "they express opposite ideology...[or] engage in opposition politics...” (Shor \& Freire, 1987, p. 53).

Students may similarly be accustomed to the traditional teaching methods and resistant to change. Their resistance to change may also be rooted in Chinese culture specifically. Chinese culture has been largely influenced by Confucius (Jiang, 2011), 
and Confucian philosophy has led to the teacher-centered approach. It has also, as Scollon (1999) pointed out, correspondingly exerted an ideological impact on students' ways of thinking, teachers' and students' roles, objectives of education, and behaviors of teachers and students. According to Scollon (1999), Confucius prioritized gaining wisdom and complying with morality over rhetorical reasoning, with morality referring only to the moral code that a teacher uses to communicate with students. Confucian philosophy also attaches great importance to "group identity and harmony maintenance," which may seem to be a predominant target for Chinese students (Scollon, 1999, p. 10). Under the influence of the Confucian education philosophy, what teachers say is authoritative and true, and these truths should be repeated and remembered instead of being questioned by students, as "Docility, passivity, and conformity" are what education demanded of its students in this Confucian heritage culture (Yen, 1987, p. 52).

Students under the influence of Confucian heritage culture for years are more likely to be passive thinkers without any consciousness of inductive reasoning. Scollon (1999) undertook a case study to identify the cultural constructs that underlie the viewpoints on the purposes of education in Chinese classrooms and that influence the behaviors of students and teachers. She observed that the cultural notions stemming from Confucius affect learning processes tacitly (Scollon, 1999). Chinese EFL learners influenced by historically dominant Confucian traditions tend to be disabled from using rhetorical reasoning (Jiang, 2011). 


\section{Challenges of Change in Traditional English Teaching Approaches}

Under the impact of the Confucian philosophy in China, books are considered integral to "knowledge, wisdom and truth" (Maley, 1990, p. 97). The role of the teacher is to be authoritative as the source of knowledge (Yu, 2008). This view results in the "teacher-centered textbook-analysis-based Grammar-Translation Method" of English teaching in China for years (Yang, 2000, p. 19; 以教师为中心、以教科书 分析为基础的语法翻译法). As for English teaching policy, national or regional syllabi dictate the English curriculum and teaching policy (Wang, 1998). Wang (1998) stated that English is taught in the current traditional method, which focuses on grammatical mistakes and form correctness. Some new teaching approaches may be known to teachers, but their implementation can be severely constrained by stress resulting from simulation tests and many test-preparation exercises in the highly exam-oriented society in China.

In addition to test-generated stress and little syllabus freedom, teachers may feel that innovative approaches are too new to use in the future teaching. Even if they overcome their emotional timidity or hesitation, they need to be cognitively and technically prepared for the implementation.

\section{Picture Word Inductive Model}

The Picture Word Inductive Model (PWIM) is based on early literacy and was designed by Calhoun (1999) as a major component of a language arts curriculum for 
beginning readers. PWIM is "an inquiry-oriented language arts strategy that uses pictures containing familiar objects and actions to elicit words from children's listening and speaking vocabularies" (Calhoun, 1999, p. 21). It was originally designed for small groups, and individuals from kindergarten through sixth grade. However, Calhoun (1999) suggested that teachers can arrange large-group activities using PWIM as well. She also suggested that the PWIM can be modified and used with older beginners (Calhoun, 1999).

PWIM has several purposes. It is used to lead students into "inquiring about words, adding words to their sight-reading and writing vocabularies, discovering phonetic and structural principles, and using observation and analysis in their study of reading and writing" (Calhoun, 1999, p. 21). A goal of implementing PWIM is to enable young readers to think inductively and generalize awareness of phonetic and structural rules by building sight vocabularies, learning structural analysis of words and sentences, and writing sentences and paragraphs (Calhoun, 1999). Another purpose of the strategy is to develop learners' vocabulary concepts and paragraphs and sentence structures in general content subject matters, including mathematics, reading, science, and social science. The ultimate goal of this strategy is to enable language beginners to become powerful language learners (Calhoun, 1999).

\section{PWIM in Class}

PWIM has many successful scenarios in classrooms (Calhoun, 1999; Joyce \& Showers, 2002; Joyce et al., 2009). Calhoun claims that its successful applications 
are closely related to prescribed and detailed steps for implementation, an

instructional sequence incorporating cycling and recycling through the following 10

instructional steps:

1. Select a picture.

2. Ask students to identify what they see in the picture.

3. Label the picture parts identified. (Draw a line from the identified object or area, say the word, write the word; ask students to spell the word aloud and then to pronounce it.)

4. Read and review the picture word chart aloud.

5. Ask students to read the words (using the lines on the chart if necessary) and to classify the words into a variety of groups. Identify common concepts (e.g., beginning consonants, rhyming words) to emphasize with the whole class.

6. Read and review the picture word chart (say the word, spell it, say it again).

7. Add words, if desired, to the picture word chart and to the word banks.

8. Lead students into creating a title for the picture word chart. Ask students to think about the information on the chart and what they want to say about it.

9. Ask students to generate a sentence, sentences, or a paragraph about the picture word chart. Ask students to classify sentences; model putting the sentences into a good paragraph.

10. Read and review the sentences and paragraphs (Calhoun, 1999, p. 23).

Joyce and Showers (2002) and Joyce et al. (2009) gave a more detailed description of the process of the PWIM, compared with Calhoun's (1999) initial research. They named three specific stages in which teachers are facilitators, questioners, and organizers (Wang et al., 2008).

In step one, called "students' development of language," students identify objects, actions, and qualities in large photographs, "shaking out" the words from the picture and using the vocabularies they naturally develop (Joyce et al., 2009, p. 131). The teacher draws lines from the relevant items in the picture to words that are spelled. The students then follow the teacher to spell the words. The more words they are 
able to spell, the more lines the teacher draw, thus generating a "substantial sight vocabulary" (p. 132).

During step two — "the process of learning to read and write" — the teacher puts these words on large vocabulary cards and gives each student a set of smaller cards with the same words on them (Joyce et al., 2009). Students study the words using their small cards and go to the picture dictionary to identify words they don't recognize. Teachers also use students' cards to lead them to study the words. On the basis of the phonetic and structural features of the words, students can classify their new words by inductive thinking through modeling and practice. All of the new words are spelled correctly by the teacher and written down in the picture dictionary. Next, the teacher models by producing sentences about the picture, and the students dictate the sentences using the words in the picture. Thus high-frequency sight vocabularies are added to students' existing schema through regular repetition.

The final step of PWIM is called "the reading and writing connection" (Joyce et al., 2009, p. 133). In this phase, the teacher constructs a paragraph out of those sentences and discusses how they make up the paragraph (thinking aloud during writing). Each week the teacher chooses a sample of students to examine their word recognition - in other words, how many they can recognize out of context. Throughout the cycle, students continuously classify words and eventually the sentences in terms of spellings, pronunciations, meanings and other features, and students practice reading the words, the sentences, and the paragraph. This stage 
also involves parents, who "need to read at least five books each week to their children" (p. 137).

\section{Vocabulary Learning through Pictures}

PWIM embraces the development of visual perception, which is vital to children's literacy acquisition, in the following manner (Astorga, 1999; Clay, 2001; Joyce, Calhoun, \& Hopkins, 2002). During instruction with the PWIM, students are shown a picture and are asked to identify items in the picture or "shake out" the words of the picture. The picture as a visual image has a significant role in PWIM to develop children's literacy. The following figure is an example.

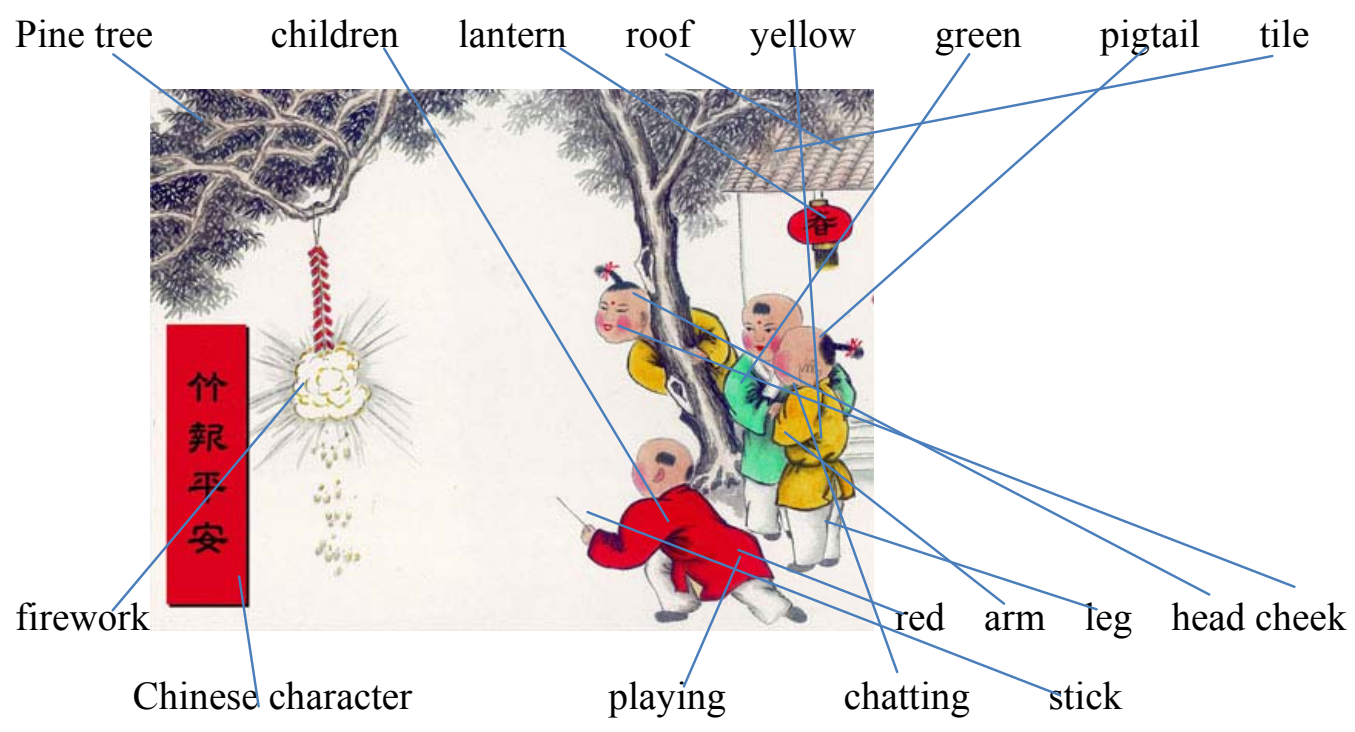

Figure 5. A demonstration of PWIM using a picture

(Source: Top 10 things to do during Chinese spring festival. n.d.) 
Children can learn by reading and communicating using the picture and by deconstructing and interpreting the image (Calhoun, 1999; Wong, 2009). Hence, this learning process is encouraged in the model (Calhoun, 1999; Wong, 2009).

Joyce and Weil (2004) showed how pictures may serve as important stimuli for connecting learners' life experiences to their language learning in the classroom. The teacher writes each identified word on chart paper outside the picture and draws a line from the word to the item in the picture, essentially creating a picture-word dictionary which the students can employ to connect words with corresponding pictures. Joyce and Weil claim that such a kind of connection contributes to developing new ideas and learning vocabulary.

Wong (2009) demonstrated that vocabulary learning is also achieved through connections via dual channels of speaking and writing. Shaking out the words and spelling the words, she says, brings "awareness to the letters in the word and connection between the spoken words onto written text” (Wong, 2009, p. 9). Reading out, spelling out, and writing down these words on the picture-word dictionary is the first step for children to know the phonetic and morphological form of the words. After they become more familiar with this mode of instruction, they start to write phrases, short sentences and later long ones about the pictures independently or with the assistance of teachers and more competent peers. This writing process involves learning form, meaning and use of those words. Gradually, these vocabularies should be stored, as Calhoun (1999) suggests, in students' long-term memory and eventually become a part of their prior knowledge, which will 
be used to learn new words. Using the picture in Figure 5 as an example, the connections of speaking and writing can be realized in the following flow chart in the

Figure 6.

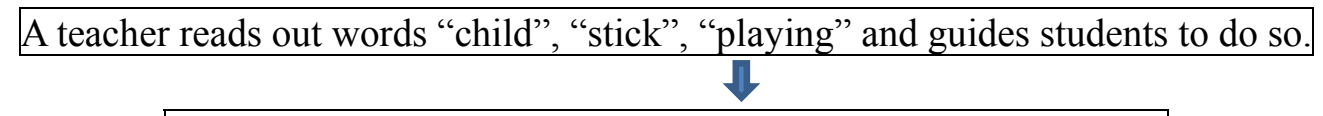

The teacher spells out those words and guides students to do so.

The teacher writes down those words, and students do so to practice their spellings.

The teacher guides students to write down phrases "a child in red" and "playing with

a stick".

\section{$\checkmark$}

The teacher leads students to write down: A child in red is playing with a stick.

Figure 6. Connections of speaking and writing using PWIM

\section{Thinking Inductively}

Inquiry-oriented induction is another key feature of PWIM. Inductive

thinking or induction promotes learners' awareness of language development (Astorga, 1999; Clay, 2001; Joyce et al., 2002). Induction in PWIM refers to developing new ideas through building parallelism among unrelated information, ideas, and artifacts (Joyce, Weil, \& Calhoun, 2004). This type of thinking assists students noticing and inferring with patterns and relationships within the language - elements which should enable them to apply and transfer such learning to novel words. They also suggest that such induction empowers students to generalize language rules, for example, how to structure sentence as in building up the sentence, "A child in red is playing with a 
stick". Students may draw generalizations after numerous PWIM activities cycling and recycling the sequences mentioned above.

\section{The Research Gap of PWIM}

It should be noted that PWIM has received wide recognition and application in educational institutes. In spite of its delicate narrations, true-to-life scenarios and wide popularity, PWIM has its weaknesses in terms of research studies.

First, there are only a few research articles and books about PWIM studies since Calhoun's (1999) research, most of which are written or co-written by Calhoun or Joyce. Evidently, Calhoun and Joyce are the two major proponents of this model thus PWIM narrated and evaluated by them cannot avoid possible biases.

Second, PWIM is not the only intervention in the learners' language development in those research studies, so it cannot be inferred from the results that PWIM alone contributes to the learners' language development. For example, parents also seem to play a role in the scenario, who "need to read at least five books each week to their children" in English as their native language (Joyce et al., 2009, p. 137). Another example is Swartzendruber's (2007) study, in which PWIM and other scaffolding strategies were used as experimental treatments in the classroom. In a qualitative research study, Feng (2011) introduced PWIM and cooperative learning into English classes in Taiwan. The researcher then interviewed participant teachers. After the data collection and analysis, Feng reported that the teachers thought both PWIM and cooperative learning were effective in improving learners' literacy. They 
did not point out whether PWIM was the only factor enhancing early literacy for their students.

Third, research studies of PWIM are even fewer when the studies are narrowed down to ESL or EFL learners. There is only one quantitative research study (Swartzendruber, 2007) found in the literature review. Swartzendruber (2007) conducted a quasi-experiment study with 35 second graders in a Midwestern U.S. city with both ESL learners and native English speakers (NESs). Results indicated that there were statistically significant differences between the control and experimental groups on the final assessment. Scaffolding and explicit connections to concepts and words appeared to be beneficial to both ESLs and NESs. The only qualitative research found was in Feng's (2011) dissertation, in which the participant teachers reported that their fourth to sixth grade students had increased English vocabulary through PWIM and cooperative learning. Thus, one might infer that ESL and EFL research studies of PWIM are underrepresented. If PWIM is used as an experimental treatment, then CLT will be used as a tool to determine whether PWIM entails a cognitive overload when information is processed.

\section{Cognitive Load Theory}

Cognitive Load Theory (CLT) has become one of the most influential theories in guiding instructional design and learning materials. CLT enables professionals to discuss teaching approaches based on the knowledge of human cognitive architecture. 
Human cognitive architecture (Torcasio \& Sweller, 2010) is composed of a natural information processing system, which collects information provided by the sensory memory, creates novel information, stores it, and is able to disseminate it over a long distance and time. The cognitive architecture pays attention to the role of working memory (WM) in creating and storing information to be transferred to and stored in long-term memory (LTM) for following use (Torcasio \& Sweller, 2010). A large store of information from imitating, reading, or listening is held in LTM. The larger amount of information in LTM can be used by WM to deal with the external interactivity for the processing of information (de Jong, 2010). WM is severely limited in capacity, that is, processing a finite amount of new information at a time, suggested to be $7 \pm 2$ in terms of numbers (Miller, 1956), and $4 \pm$ with respect to words (Cowan, 2001; Feldon, 2010; Janssen, Kirshner, Erkens, Kirschner, \& Paas, 2010). It is also limited in duration, that is, a few seconds without rehearsal before the information is lost (Peterson \& Peterson, 1959). Most important, however, is that CLT guides us to what ultimately yields real learning. In other words, learning means storing information in LTM to be used later, which is to say, if "nothing has been stored in LTM, nothing has been learned" (Torcasio \& Sweller, 2010, p. 660).

\section{Historical Background of CLT}

CLT was founded by Sweller (1988). Sweller's major objective in promoting this theory was to inform the design of instruction and instructional materials in order to promote learners' skill and knowledge acquisition. To promote this acquisition, 
Sweller states that the designed instruction should optimize the use of WM capacity and avoid cognitive overload. Overload means that the WM capacity required to conduct a cognitive operation exceeds available WM (de Jong, 2010).

Sweller (1988) correlated cognitive load with the amount of information processed in WM, a notion based on Miller's (1956) well-known "magical number." Miller's (1956) work suggested that WM can hold no more than about 5 to 9 elements or chunks of information that have not been previously learned or combined (i.e., novel or unfamiliar information). However, what many people do not know about the "magical number" is that this number may be a substantial overestimated (Feldon, 2010). Cowan (2001) put forward another finding that, apart from simple numbers, one's WM can usually hold no more than approximately 4 chunks of unrelated information. Cowan's (2001) finding has been recognized by many researchers (e.g., Feldon, 2010; Janssen et al., 2010). Additionally, WM is also limited in duration; Peterson and Peterson (1959) assigned a group to repeat a stimulus aloud and another group to keep silent in their experiment. After different recall intervals (i.e., three, nine, and 18 seconds), participants in both groups were able to only partly memorize the given sets of unfamiliar combinations of letters. The silent group performed even worse. Peterson and Peterson (1959) found that those letters can only be held in memory for a few seconds without verbal rehearsal. In the following section, cognitive load will be discussed, including its definition and types. 


\section{Types of Cognitive Load}

Feldon (2010, p. 18) defined CL as "the number of separate chunks (schemas) processed concurrently" in WM in learning or performing a task, plus "the resources necessary to process the interaction between them." Based on the interrelation of instruction formats and CL, CLT presumes that the total CL must stay within WM limits if learning is to occur (Sweller, 2005). There are three independent sources of CL in learning: intrinsic, extraneous, and germane cognitive load.

Intrinsic cognitive load. Feldon (2010) gave a clear definition of the three different sources of cognitive load, in which intrinsic load means "the inherent complexity of the material to be learned" (p.18). Sweller (2010) in his most recent article defined intrinsic CL as the number of elements concurrently processed in WM to "understand and learn material under instruction" (p. 41). It is due to a large number of elements processed in WM simultaneously (Mayer \& Moreno, 2010). For instance, Chinese EFL learners in Grade 7 need to learn a new word "Halloween" in the Unit 3 of their textbooks. To understand and learn the new word is intrinsic cognitive load to them.

Extraneous cognitive load. Extraneous load refers to "information in the instructional environment" that occupies WM space but has no assistance in understanding or solving the problem, no contribution to learning (Feldon, 2010, p. 18; Mayer \& Moreno, 2010). Sweller (2010) depicted extraneous load as interacting elements, which should be reduced by the devised principles of CLT. For instance, 
when Chinese EFL seventh graders learn a new word "Halloween," they also see a pumpkin in their textbooks. Without cultural background knowledge about this Western tradition, the picture of pumpkin may not help them understand the word “Halloween," which exerts extraneous CL.

Germane cognitive load. Germane load is the effort put in the "necessary instructional scaffolding" and in "learning concepts that facilitate further content learning” (Feldon, 2010, p. 18). Sweller (2010) pointed out the dynamic relations of germane load, WM and intrinsic load. He assumed that germane load will increase with the rising use of WM resources devoted to dealing with intrinsic CL. Mayer and Moreno (2010) also pinpointed that germane load is caused by motivating learners to make effort toward understanding and learning. In the case of helping those seventh-grader English learners understand "Halloween" which does not exist in Chinese culture, English teachers may use some Chinese festivals to start, including the Spring Festival (春节,Chunjie), the Dragon Boat Festival(端午节,Duanwujie) and Grave-sweeping Day (清明节,Chingmingjie). Then teachers introduce Halloween and compare this Western festival with Chinese festivals. Teachers may even go further to guide students list their understanding of differences and similarities. Such scaffolding or facilitating from teachers are germane CL.

Taking these three types of CL together, a learning task presented to learners may exert different levels of CL upon different individuals due to their level of relevant prior knowledge—-schema (Feldon, 2010). Perhaps most importantly though, is the case when there is too much to process. In other words, when CL 
exceeds WM's capacity to process it, learners will have substantial difficulties in learning; indeed there will be overload. The example would be that the word "Halloween" could be overload to fourth graders because they have not developed phonetic awareness and cannot see the three chunks of the word in terms of syllables - a syllabus being the base for any Chinese character. To them, Halloween has nine letters instead of three chunking segments and may probably exceed their WM capacity to process the spelling. CLT aims to avoid overload of learners' cognitive systems and optimize the use of WM, in detail, by reducing extraneous CL so as to promote use of cognitive resources into germane CL, or by supplying appropriate prior knowledge content to students so that the intrinsic load of the new material does not occupy all the available WM resource (Beckmann, 2010; de Jong, 2010; Feldon, 2010; Mayer \& Moreno, 2010). However, it should be noticed that if additional activities designed to enhance germane CL exceed learners WM limitations, the germane load could become an extraneous load and debilitate learning as well (de Jong, 2010).

\section{Five Principles of CLT}

There are five basic principles to all natural information processing systems:

the information store principle, the borrowing and reorganizing principle, the randomness as genesis principle, the narrow limits of change principle, and the environment organizing and linking principle. The flow chart below is helpful to understand the five principles. 


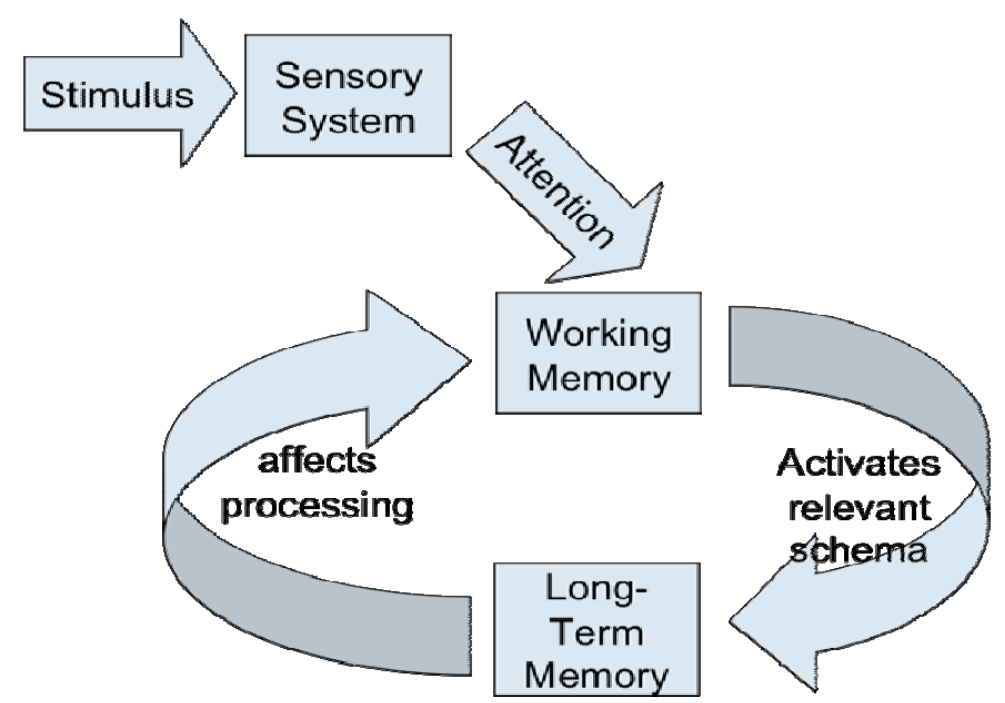

Figure 7. Information into and between WM and LTM (Morgan, 2013)

Information store principle: long-term memory. The information store

principle accounts for LTM and suggests that a huge amount of information is stored in LTM. CLT presumes information stored in LTM can guide the cognitive activity (Diao \& Sweller, 2007; Sweller, 2010; Torcasio \& Sweller, 2010). An example of this principle in ELT is the words in an established level (Armbruster et al., 2003), which learners have recognized and used correctly.

Borrowing and reorganizing principle. A large bulk of information is stored in LTM, but where does the information come from? The borrowing principle proposes that the great deal of information stored in LTM is obtained by imitating what other people do, listening to what they say, or reading what they write, that is., information is borrowed from other people's LTM (Diao \& Sweller, 2007; Sweller, 2010; Torcasio \& Sweller, 2010). However, the information borrowed does not keep exactly the same form as the original one, instead, it is altered, constructed and 
reorganized (Sweller, 2010; Torcasio \& Sweller, 2010). An ELT example is how English learners learn English. They read and listen to borrow others' knowledge. They may construct their own knowledge of those words. Take Halloween, for example: Chinese English learners may internalize Halloween as a ghost festival (just as with Grave-sweeping Day) with treats to children (similar to the Spring Festival), and decorated with pumpkins (just like the Lantern Festival).

Randomness as genesis principle: learning through problem solving. The randomness as genesis principle states that through problem solving, novel information is created. When an EFL learner deals with a task, for instance, how to celebrate Thanksgiving for his/her U.S. friends in China, his/her old knowledge in the LTM includes the concept of Thanksgiving and how to celebrate Chinese traditional festivals. The learner does not have already-existing information, but he/she may transmit the existing information and randomly generate new information. If this trial turns out successful (test of effectiveness), the new information is likely to be stored in the LTM (Diao \& Sweller, 2007; Sweller, 2010; Torcasio \& Sweller, 2010).

Narrow limits of change principle: working memory. The narrow limits of change principle accounts for limited capacity and duration of WM, which have been demonstrated by Cowan (2001), Miller (1956), and Peterson and Peterson (1959), when dealing with novel information (Torcasio \& Sweller, 2010). Hereinafter, this principle suggests that information must be carefully structured to avoid causing overload on WM (Sweller, 2010). It should be noted that when and only when beginners deal with unfamiliar information, information goes through the process in 
the limited WM first and then leads to changes in LTM. Thus any alterations to LTM are "small and incremental" (Diao \& Sweller, 2007, p. 79). An example mentioned above is the new word "Halloween," which may cause cognitive overload for EFL fourth graders who have not developed phonetic awareness yet.

Environment organizing and linking principle. Although the narrow limits of change principle requires a very limited capacity of WM when dealing with novel information, there are no known limits to the amount of information that can be processed by WM if that information from LTM is structured and organized. Narrow limits only apply to new, not-yet-organized, and unrelated information. However, the environment organizing and linking principle applies to previously organized and structured information for external interaction (Diao \& Sweller, 2007; Sweller, 2010; Torcasio \& Sweller, 2010). If EFL fourth graders have already known and used the word "Halloween" or other related words (pumpkin, costumes, trick or treat, etc.) correctly, there are no known limits of the words processed in the WM for external interaction, as in any in-class activity such as brainstorming.

In all, these principles constitute a natural information system, provide a foundation for human cognitive architecture and underlie the core of CLT and instructional design.

\section{Measurement of CL}

The five principles of CLT constitute the essence of designing instructional formats and make CLT highly effective in the instructional design of teaching and 
learning materials; however, it is not free from problems. One particular issue is how to measure CL appropriately. Such a question and its answer become important as we consider how cognitive overload may debilitate changes in learners' LTM (i.e., may reduce learning, as defined by storage in LTM).

Early in 1993, Paas and van Merriënboer took the initiative in developing a construct, known as relative condition efficiency, which helps researchers measure perceived mental effort. They used this calculation approach for combining mental effort ratings with performance scores to obtain information on the relative condition efficiency. The method was based on the standardization of raw scores for mental effort and task performance to $z$-scores. Group mean $z$-scores were graphed and compared with a one-way analysis of variance (ANOVA). Relative condition efficiency was calculated as the perpendicular distance to the line that was presumed to represent an efficiency of zero. Paas and van Merriënboer (1993) concluded that this method might be a valuable addition to research on the training and performance of complex cognitive tasks. The approach has been acknowledged as a well-known subjective method and introduced many times in the following research in CLT. Still, de Jong (2010) contended that the primary problem with this measurement of CL was that there is no direct measurement of CL, i.e., CL measures are always presented as relative.

Fredericks, Choi, Hart, Butt, and Mital (2005) applied the ergonomic approach to seek a quantitative neurophysiological expression of cognitive load, i.e., using the rate-pressure product (RPP) as a measure of both heart rate (HR) and blood pressure. 
An increase in HR and blood pressure represents the responses of cardiovascular system to both physical and cognitive occupational workload. The findings from this study suggested that RPP might be used as an objective measure to separate the components of cognitive workload and cognitive stress in combined tasks. This is a typical example of objective measures of CL classified by Brunken, Seufert and Pass (2010).

A study conducted by de Jong (2010) used three different techniques to measure CL: self-reports through questionnaires, physiological measures (e.g., heart rate variability), and secondary tasks analysis. Based on the table as to classification of CL measures by Brunken et al. (2010, p. 193, see Appendix B), de Jong (2010) combined subjective and objective CL measurement.

One may then observe from the three cases above (de Jong, 2010; Fredericks et al., 2005; Paas \& van Merriënboer, 1993) and Brunken et al.’s (2010) table that there is neither a single standardized method nor a common CL measurement. Various approaches of CL measurement cannot be generalized simply as good or bad, because they all have advantages and disadvantages (i.e., less direct thus relative, or objective but not feasible in the current study). Choosing which one to deploy then depends highly upon the specific research questions in individual research (Brunken et al., 2010). 


\section{Effects of CL}

Listed in Sweller's (2010, p. 30, see Appendix A) table are 12 CL learning effects: eight of them are primarily from extraneous CL, namely, worked-example effect, completion effect, split-attention effect, modality effect, redundancy effect, expertise reversal effect, guidance fading effect, and goal free effect; two essentially come from intrinsic $\mathrm{CL}$, that is, isolated/interacting elements effect and element interactivity effect; the remaining two are called variable examples effect and imagination effect mainly root in germane CL. The CL effects show practical and instructional implications of CLT, making CLT more concrete to educators; thus, they are essential in this report.

Taken together, the five sections above synthesize the history development of CLT, describe the types of CL, depict the main principles underlying the current CLT, unveil the measurement of $C L$, and highlight the effects of $C L$ in relation to the following empirical studies which mainly discuss about the effect.

\section{The Redundancy Effect}

Although there are $12 \mathrm{CL}$ effects, only the redundancy effect was explained in this study. The redundancy effect occurs when learners are required to attend to information that is presented in addition to necessary information and irrelevant to the task (Sweller, 2005). For instance, EFL learners were presented with the written and spoken text concurrently with the expectation to acquire reading or listening 
competency (Diao et al., 2007; Diao \& Sweller, 2007; for details read the following section), or reading learners were given both text and interrelated pictures simultaneously (Torcasio \& Sweller, 2010; for details read the following section).

CLT explains that by eliminating this unnecessary information, the extraneous cognitive load may be lessened, the capacity of WM may be freed, and then the task can be more easily performed.

\section{Empirical Studies about the Redundancy Effect}

This section synthesized the findings of four recent empirical studies conducted by the leading researchers, related to applying CLT to language teaching, showing the redundancy effect which has been depicted above.

Plass et al. (2003) were the first to research CL in reading with multimedia aids and the influence of students' respective verbal and spatial abilities in a foreign language context. They presumed that multimedia learning processes are under the constraints of limited WM. As a result, they conducted a study of reading a 762-word German story presented by a multimedia computer program with 152 English-speaking college students in a second-year German course. The stimulus material was presented under four different conditions: (a) no annotations, (b) verbal annotations, (c) visual annotations, or (d) both verbal and visual annotations - for 35 key words in the story. Subjects were prescreened for their verbal and special abilities. When students received visual annotations for vocabulary words, low-verbal and low-spatial ability students performed worse than high-verbal and 
high-spatial ability students in the recall of word translations; however, when they received verbal annotations, no group significantly outperformed another. All learners performed worst in text comprehension when they received visual annotations. In general, visual annotations were found to be redundant for second language learners' reading comprehension, which confirmed the researchers' assumption.

Diao et al. (2007) aimed at investigating the effect of written text on comprehension of spoken English as a foreign language, i.e. presenting written text and listening simultaneously. They used three instructional formats: listening with auditory materials only, listening with a full, written script, and listening with simultaneous subtitled text. Then they compared learners' language comprehension and found that listening with the presence of a script and subtitles led to better understanding of the scripted and subtitled passage but poorer performance on a subsequent auditory passage than listening with the auditory materials only. These findings indicated that where the intent was learning to listen, the use of a full script or subtitles had detrimental effects on the construction and automation of listening comprehension schemas. The findings can be analyzed by the theoretical framework of CLT and explained that if WM resources are used to process scripts and subtitles rather than listening comprehension, fewer resources would be available to comprehend the listening materials and required changes to LTM would decrease.

Diao and Sweller (2007) looked into simultaneous presentations of written and spoken text, examining the effect of concurrent written and spoken presentations and 
investigate whether the redundancy effect exists in EFL reading comprehension. They chose 117 first-year Chinese undergraduates and applied two instructional formats to them: (a) written presentation, and (b) written presentation concurrent with spoken presentation. Then they compared learners' reading comprehension both at a lexical level and at the level of text comprehension. Examination of translation scores, subjective mental load ratings, and free recall performance suggested that simultaneous written and spoken presentations turned out to be less effective than mere written presentation. The results demonstrated the redundancy effect that redundancy information interfered with learning, suggesting that when the unnecessary processes of information imposes a heavy load on WM, WM then may have fewer resources to process information and to send it to LTM. In other words, there is less learning under such conditions.

The study most related to this dissertation was conducted by Torcasio and Sweller (2010), which dealt with text and image in reading in English language teaching. Torcasio and Sweller examined the effect of using illustrations in the process of learning to read, which belongs to a beginning stage of reading by carrying out three experiments: Experiment One compared reading materials composed of texts only with materials composed of both texts and informative illustrations (describing the content of the texts); Experiment Two compared the informative illustrations with uninformative illustrations; and Experiment Three compared uninformative illustrations with no illustrations. The results indicated the following: 
(a) that reading proficiency improved more with reading materials using no illustrations than those with texts and informative illustrations in Experiment One;

(b) that reading proficiency improved more under the condition of using uninformative illustrations in Experiment Two than using informative illustrations; and

(c) that reading proficiency differed slightly with reading materials using uninformative illustrations or not using illustrations in Experiment Three.

In terms of CLT, Torcasio and Sweller attributed the findings to redundancy effect and suggested that the use of illustrations cannot universally benefit younger learners because the illustrations increased the processing load. As a result, Torcasio and Sweller (2010) reached a milestone in differentiating texts without images, texts with closely correlated images, and texts with non-correlated images: a result indicating that it was "the nature of the illustrations" rather than illustrations themselves that caused the redundancy effect (p. 662). Their work also showed that the higher element interactivity (i.e., the relation between images and texts) was, the higher the unnecessary load on WM, thus indicating that learning was less likely to happen (Paas, Renk1 \& Sweller, 2003, p. 2). However, they did not pinpoint the distinctions of reading and learning to read, the two different development stages. Meanwhile, they focused on reading of English as the first language, not EFL reading. 
The redundancy effect is not only demonstrated by those comparison studies mentioned above, but also demonstrated in the studies where eliminating the redundant material enhanced learning, including the studies by Chandler and Sweller (1991, 1996), Craig, Gholson, and Driscoll (2002), Kalyuga, Chandler, and Sweller (1999), Mayer, Heiser, and Lonn (2001), Mayer, Bove, Bryman, Mars, and Tapangco (1996), and Sweller and Chandler (1994).

\section{Significance of CLT in Instructional Practice}

One may conclude from the theoretical underpinnings and empirical studies regarding redundancy effect that instructional designs are likely to be random in their effectiveness without knowledge of human cognitive architecture. One cannot interpret the results of such studies without knowing about WM and LTM. CLT links the design characteristics of instruction to human cognitive architecture, thus providing an appropriate theoretical base resulting in a diverse set of instructional designs. Not only does human cognitive architecture seemingly influence instructional design, instructional design also sheds light on human cognitive architecture. When considered in terms of instructional design principles, the overwhelming importance of LTM to all perspectives of human cognitive function, as well as the characteristics of WM changing dramatically with increased knowledge in LTM, become strikingly obvious (Sweller, 2004).

In sum, reducing extraneous CL seems to be the linkage of attaching CLT as theoretical framework to instructional designs and procedures such that learning is 
more likely to happen. As a result, this study examines a particular instructional design — PWIM, for early second language literacy—by implementing CL as a gauge.

\section{My Critique of the Reviewed Literature}

\section{ELT in China}

The following pictures are excerpts from the current English textbooks for Grade 4 and 7.

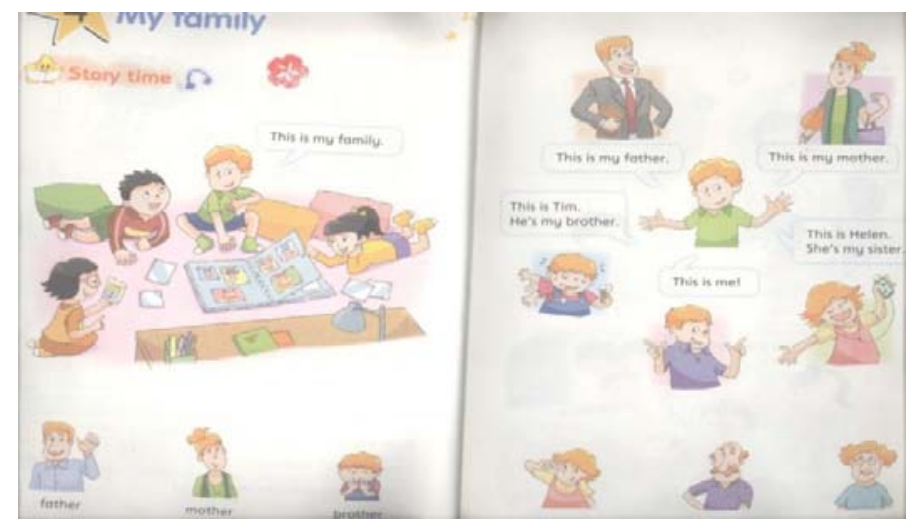

Figure 8. The textbook "Fun with English 4A" in fall semester for fourth graders (Qi \& He, 2004)

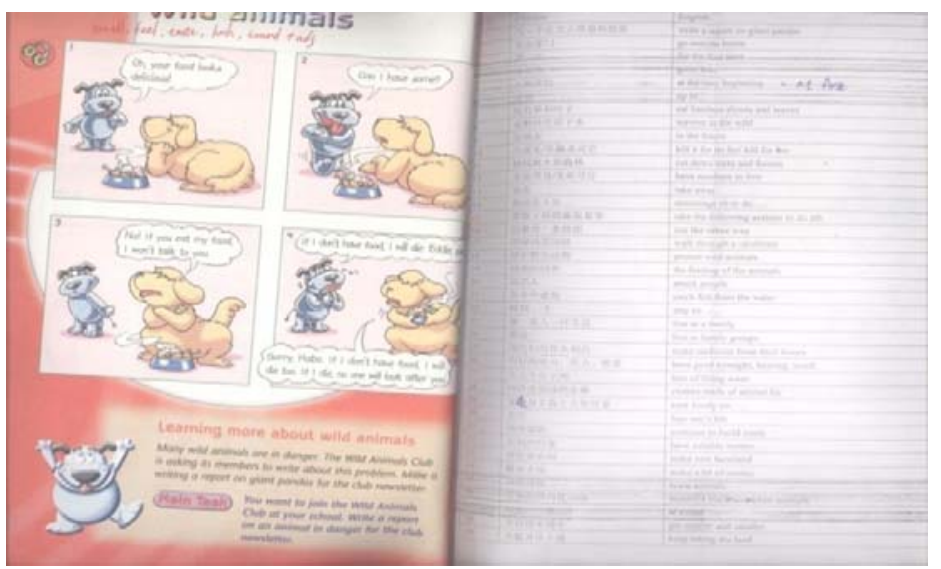

Figure 9. The textbook "English 7A" in fall semester for seventh graders (Dawson, 2001) 
One may see within these excerpts that pictures were integrated into texts in the books, a condition my own textbooks seldom exhibited two decades ago. The English instruction has not been changed as much as the English textbooks in China. In Figure 9, a word list was provided for students to memorize by rote, exactly the same practice as I had when I learned English in my middle school. The list had two columns, one in English and one in Chinese. The English phrases were from the units which had been taught and the translation was strictly one to one, i.e., one English word having only one corresponding Chinese meaning and vice versa.

Traditionally, students were assigned to have their parents or peers check whether they have memorized these words after class. Checkers read a Chinese phrase and students wrote down the English translation or vice versa. The next day, students would be tested with the same procedure. One may infer from the list that the "teacher-centered textbook-analysis-based Grammar-Translation Method" (Yang, 2000, p. 19; 以教师为中心、以教科书分析为基础的语法翻译法) was still predominant in English education in Mainland China. One may also conclude that English instruction has yet not changed with respect to using the new textbooks effectively.

One should also note that Chinese English teachers who have been taught in traditional ways are not prepared to adopt new teaching approaches. The new teaching approaches are different from the way they were taught. There are few training programs with regard to pedagogical methodologies. Nor are there experts to resort to. If English instruction is a continuum with Grammar-Translation 
traditions and new student-centered type approaches at two ends, Chinese English teachers are moving from the traditional end to the student-centered end, slowly forward most of the time but occasionally backward. The backward resistance can result from a top-down syllabus, test-generated stress, and concern about making changes or taking risks, notions which abrade the centuries-long Confucian traditions of maintaining modesty and group harmony.

\section{PWIM for ELT in China}

Even with more pictures in the English textbooks in China, the designed tasks do not make good use of pictures. In other words, pictures are used for simple matching or labeling. Pictures, at least seen from the textbooks as an example, serve as merely background. There is no induction or scaffolding for writing in those tasks. There is no discussion or induction involved to describe the picture or to make a story/scenario based on the picture. Someone may argue that making stories is beyond the capability of fourth graders who have just started to learn English and are still learning to read in Chinese (L1). However, such may not be true of the seventh graders who have already studied English for four years, and who are in the stage of reading to learn as they have substantial mastery of concepts and skills for writing fluently in Chinese.

PWIM is not representative of the existing repertoire of most Chinese English teachers. Historically, Chinese philosophy has established inductive logic in terms of analogical reasoning (Tang, 1997); nevertheless, there is no logic class in public 
education in this modern age. Nor is there a Chinese philosophy class (except for introductions of Marxism) for education-major students in universities. Hence, Chinese English teachers have been disabled from thinking inductively, which is a key component in PWIM. Chinese English teachers may lack cognitive readiness with specific regard to PWIM, which is reflected in the study done by Wang, Lin, and Spalding (2008).

One should also note that native-English-speaking foreign teachers have not brought a noticeable incentive to the change of English instruction in China. They are fewer compared to 440 million English learners in schools in Mainland China (Crystal, 2008, pp. 4-5). Most foreign teachers are native English speakers, but only a number of them are qualified English teachers. For those who have little background knowledge in language education or education in general, PWIM as a recent instructional approach is also new to them. They may speak Standard English but they don't know how to teach English.

Although the requirement to recruit foreign teachers in China is increasing, many people hired to teach do not know how to teach in general, let alone know how to teach Chinese students as a specific ethnic group in Mainland China. In other words, teachers from those English-speaking countries where PWIM has already been in full swing haven't introduced PWIM to China. 


\section{CLT Applied to ELT}

CLT is a powerful theory guiding ELT curriculum and instructional designs. One of its contributions is to inform English teachers how to calibrate an appropriate amount of new information which they may give to English learners at one time, due to the limited capacity of students' WM. If teachers control the amount of "separate chunks (schemas) processed concurrently" (Feldon, 2010, p. 18), then they would avoid students' cognitive overload, on the one hand, and optimize the use of WM capacity on the other hand.

The guidance is rooted in the redundancy effect, which discusses extraneous CL. Extraneous CL refers to interacting elements (Sweller, 2010), which can be pictures to be used in the experiment group in the current study. The redundancy effect occurs when learners attend to some information, namely B, that is in addition to necessary information, namely A, but irrelevant to the task (Sweller, 2005). Many relevant studies (Diao et al., 2007; Diao \& Sweller, 2007; Plass et al., 2003; Torcasio \& Sweller, 2010) showed that A and B together may be less effective than A only . This current study explored the circumstances in which A and B together is better and in which merely $\mathrm{A}$ is better with regard to the students in Grade 4 and Grade 7. The fourth graders were considered as learning to read in English and the seventh Graders were in the stage of reading to learn. 


\section{Conceptual Framework}

After reviewing literature on ELT in China, PWIM, and CLT, I presumed that PWIM may be not effective on all occasions. PWIM as an instructional model may produce cognitive overload to students because students' WM resources are limited and WM must be used to process pictures as well.

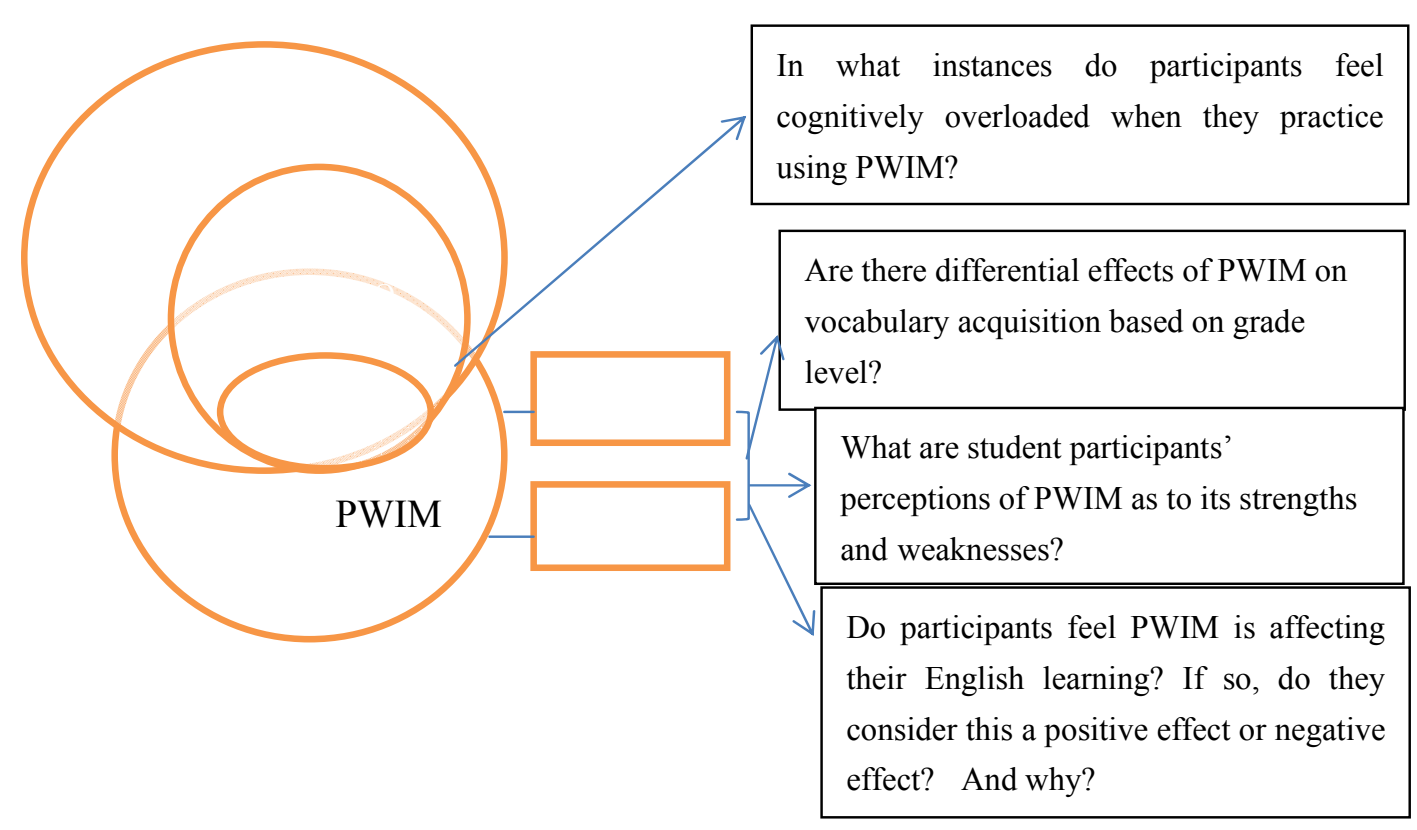

Figure 10. Literature review and research questions (Cog. = Cognitive, O.= Overload, Red. $=$ Redundancy, $\mathrm{E}=$ Effect $)$

Considering ELT in the context of China, I wondered whether PWIM would add or reduce the CL for EFL learners in China when they learned new words. My question was answered by exploring the four research questions:

(a) What are the effects of the PWIM on vocabulary acquisition? Are there differential effects of PWIM on vocabulary acquisition based on grade level? 
(b) In what instances do participants feel cognitively overloaded when they practice using PWIM (i.e., in the intervention stage)?

(c) What are student participants' perceptions of PWIM as to its strengths and weaknesses?

(d) Do participants feel PWIM is affecting their English learning? If so, do they consider this a positive effect or negative effect? And why?

\section{Summary}

This literature review chapter started with a discussion of the ELT context in China. It then provided a theoretical framework, based on empirical studies of CLT and PWIM. The theoretical framework of CLT was used in this study to evaluate the effectiveness of using PWIM to teach Chinese students English vocabulary in terms of extraneous cognitive load and the redundancy effect, both of which have the potential to impede meaningful learning. The contextual details of the current research study showed the possibilities and challenges of introducing PWIM to ELT in Mainland China. 


\section{CHAPTER III}

\section{METHODOLOGY}

Based on a review of the literature, it appears that this study may be the first to examine the effectiveness of using PWIM to teach vocabulary using CLT in the context of Mainland China. In this current study, I took the research questions and contextual factors into consideration. It compared the effectiveness of this instructional approach targeted for fourth graders (learning to read) and seventh graders (reading to learn) as EFL students in vocabulary learning. Due to the nature of PWIM, the research questions and the purpose of the current research (Stake, 2005), I chose mixed methods to probe answers as to the effectiveness of using PWIM to teach Chinese students English vocabulary. Mixed method research is "the collection, analysis, and integration of quantitative and qualitative data in a single or multiphase study" (Hanson, Creswell, Plano Clark, Petska, Creswell, 2005, p. 224). The current research study was a multiphase one (including three phases, for details see Table 3 below).

Table 3

Three Phases of a Multiphase Mixed Methods Study

\begin{tabular}{lll}
\hline Phase One & Phase Two & Phase Three \\
\hline Quantitative + Qualitative & Qualitative & Data analysis and inferences
\end{tabular}


The research design decision also depended on the stated problem and the context (Flyvbjerg, 2011). The four research questions were based on the fact that PWIM was new to English learners in Mainland China, and the question of which kind of EFL learners may benefit most from PWIM. Correspondingly, it was hypothesized that for early elementary learners (fourth graders) in China, PWIM would be less beneficial than traditional method in terms of vocabulary acquisition. It was, however, hypothesized that the situation would be the opposite for early adolescent EFL learners (seventh graders) in middle school, in other words, the PWIM group would outperform the control group. I presumed this difference would be due to the redundancy effect which the seventh graders could deal with and the fourth graders could not. Presumably, the redundancy effect affecting the fourth graders in this research study referred to the same vocabulary information in both text and pictures which would increase extraneous cognitive load and do not contribute to learning. The first question could be answered by an analysis of quantitative data and the remaining three could be answered by qualitative findings. In a nutshell, these were the research questions for this study:

(a) What are the effects of the PWIM on vocabulary acquisition? Are there differential effects of PWIM on vocabulary acquisition based on grade level?

(b) In what instances do participants feel cognitively overloaded when they practice using PWIM (i.e., in the intervention stage)?

(c) What are student participants' perceptions of PWIM as to its strengths and weaknesses? 
(d) Do participants feel PWIM is affecting their English learning? If so, do they consider this a positive effect or negative effect? And why?

The first research question is based on two research hypotheses: (a) The mean of the percentage of correct answers in the posttest for the PWIM group of fourth graders (experimental group) is significantly lower than the mean of the percentage of correct answers in the posttest of students taught with traditional methods (control group) when the percentage of correct answers in the pretest is used as a covariate; (b) The mean of the percentage of correct answers in the posttest for the PWIM group of seventh graders (experimental group) is significantly higher than the mean of the percentage of correct answers in the posttest of students taught with traditional methods (control group) when the percentage of correct answers in the pretest is used as a covariate. The hypotheses are shown in Table 2 (p. 15 of the dissertation).

Statistically, the first research hypothesis is $\mathrm{H}_{1}: \mu_{11}<\mu_{12}$ and the null hypothesis is $H_{0}: \mu_{11} \geq \mu_{12}$. The second research hypothesis is $H_{1}: \mu_{21}>\mu_{22}$ and the null hypothesis is $\mathrm{H}_{0}: \mu_{21} \leq \mu_{22}$.

The stated problem was that the instructional approach of vocabulary teaching in Mainland China needed to be revolutionized along a continuum from traditional grammar -translation to other new methods, such as, PWIM. The context of this research was in a public elementary and a secondary school of all Han Chinese students in Lianyungan, Mainland China. Typical quasi-experiments dealt with the replication or generalization of the results obtained with the sample to the whole 
population (Hitchcock \& Newman, 2013). However, exploring treatment impacts at an individual level would improve our understanding of "how" PWIM worked and “not just if" it worked (Hitchcock \& Newman, 2013, p. 48). That is to say, whatever the quantitative results were, looking at individuals might tell us why these results were as such (i.e., explain and interpret the quantitative data).

The purpose of this study was to investigate the effectiveness of using PWIM to teach English vocabulary to Chinese students using CLT in an EFL context in Mainland China. The research was conducted with the goal that PWIM would be introduced to English teaching in Mainland China if the effectiveness of using PWIM to teach Chinese students English vocabulary was confirmed. This study was about the practicality and adoption of PWIM as a new practice in English education in China; thus qualitative research was vital (Newman \& Hitchcock, 2011, p. 387). The integration of both quantitative and qualitative data collection and analyses, as a practice-oriented approach, theoretically could overcome the possible shortcomings of using either of the research approaches exclusively and could increase the "potential for transferability to similar contexts and groups" (Tashakkori, Brown, \& Borghese, 2010, p. 39). Moreover, mixed methods may have also solved the arbitrariness of cognitive load measurement in this study, as observed in the measurement of other cognitive or psychological constructs, such as stress and coping (Collins, Onwuegbuzie, \& Jiao, 2010). A mixed methods design "allows one to combine the strengths of multiple methods, for a better understanding of both group and individual outcomes" (Hitchcock \& Newman, 2013, p. 48). Thus, in this case, mixed methods 
may have helped us understand whether PWIM worked and why it worked or why it did not work. A mixed method design was chosen to "serve the dual purpose of generalization and in-depth understanding" (Bazeley, 2004, p. 145), that is, to generalize the result of PWIM being (not) effective and to deeply understand PWIM being (not) effective to whom, in which context and the possible reasons (i.e. contextual factors, including recipients, where and why).

In summary, the purpose of this study, the research questions, the problem and the potential arbitrariness of cognitive load and cognitive overload all required the use of both qualitative and quantitative paradigms to collect and to analyze data.

Collected data were then integrated through meta inferences to reach a conclusion, so as to help me answer the four research questions. With the research process as a mixture of concurrent and sequential mixed methods, the paper would be more likely to enhance its trustworthiness and validity (Newman, Newman, \& Newman, 2011).

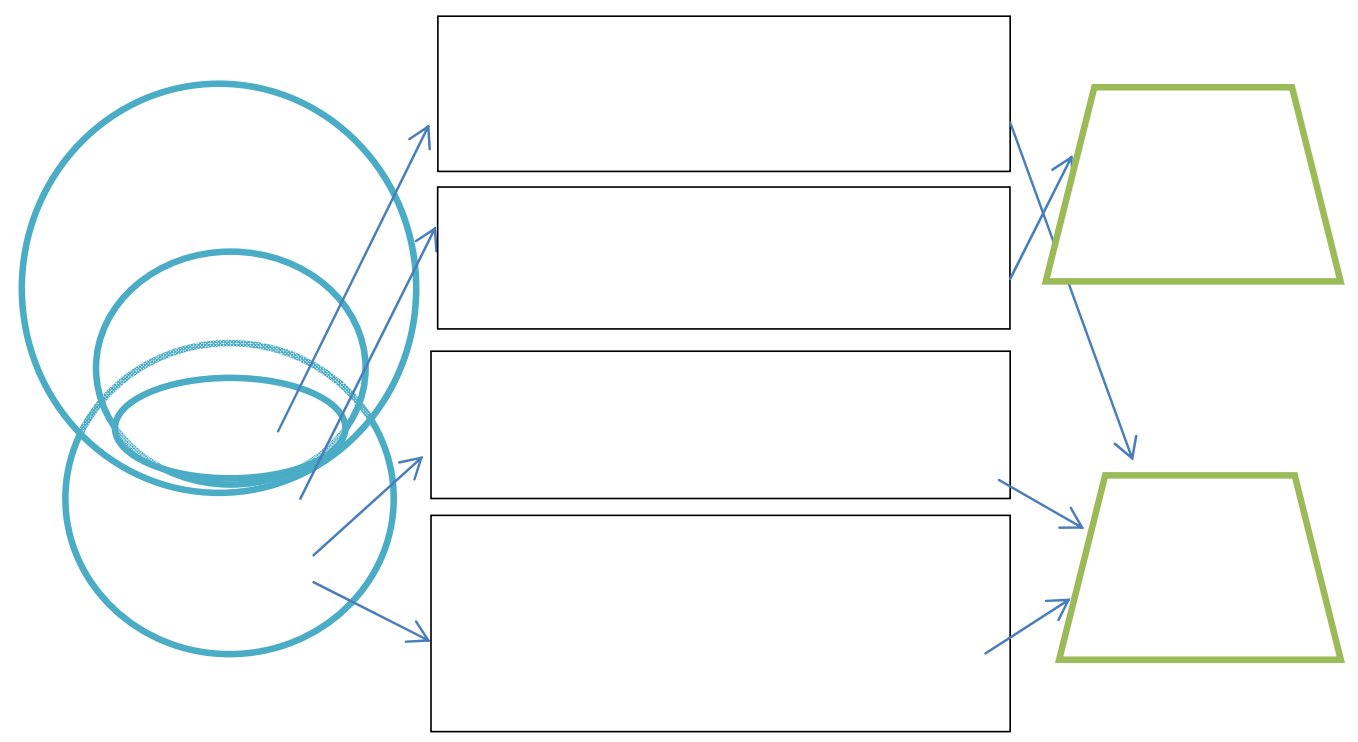

Figure 11. Literature review, research questions and research design. Cog. = Cognitive, $\mathrm{O} .=$ Overload, Red. $=$ Redundancy, $\mathrm{E}=$ Effect 
As a result of these considerations, I decided to implement a combination of concurrent (parallel) and sequential mixed methods design. A sequential mixed methods design has more than two phases. The first phase of the project can be either qualitative or quantitative (Newman et al., 2011, p. 196), so I chose both quantitative (quasi-experiment) and qualitative (observations) research in phase One. These findings from the first stage give clues to make survey and interview questions for the second phase. Based on findings from the two phases, a meta inference or meta interpretation can be made. A meta inference refers to "the judgment a researcher makes about the data that is based on the results of more than one study" (Newman et al., 2011, p. 192). A concurrent mixed methods design also has two strands, one quantitative and one qualitative (Newman et al., 2011). The flow chart below shows a parallel mixed methods design (Tashakkori et al., 2010, p. 45).

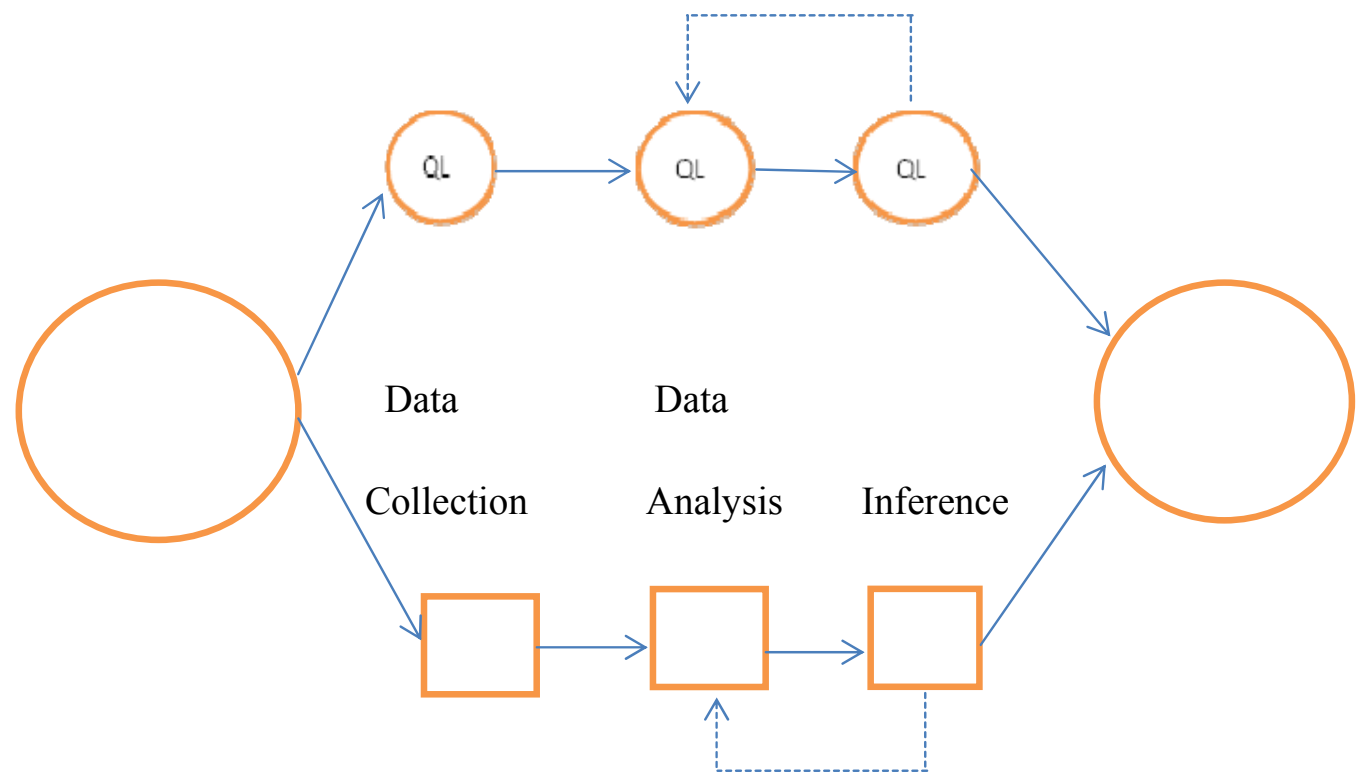

Figure 12. Parallel mixed methods design with two strands. QL= Qualitative; $Q N=$ Quantitative; dashed line represents a feedback loop 
I modified the design (Tashakkori et al., 2010, p. 45) into a combination of concurrent (parallel) and sequential mixed methods design in the following fashion in order to address the research questions in this study.

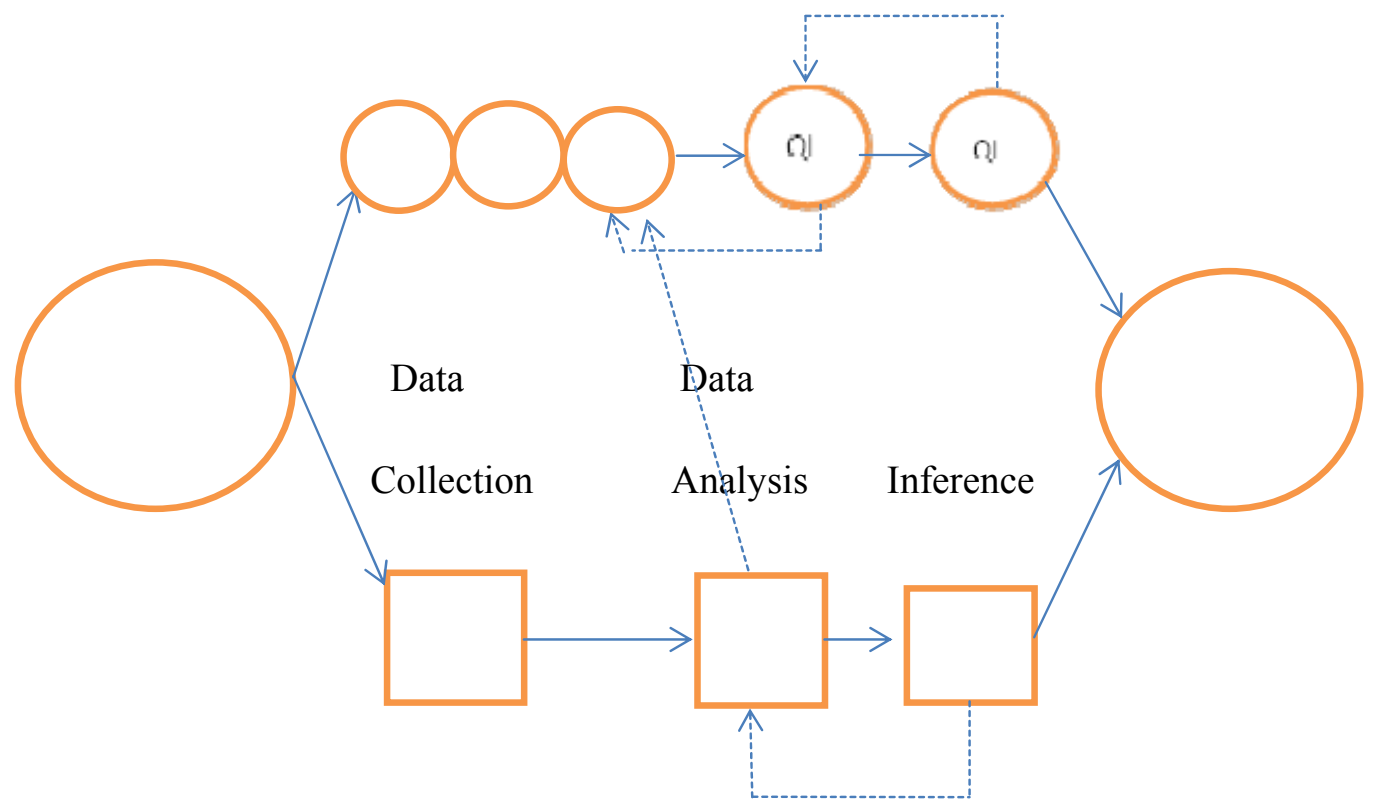

Figure 13. Mixed methods design with two strands and three phases. I= Interviews;

$\mathrm{O}=$ Observations; $\mathrm{QL}=$ Qualitative; $\mathrm{QN}=$ Quantitative; $\mathrm{Q}=$ Questionnaires; dashed line represents a feedback loop.

In the modified design, there were three phases before the meta-inference. In Phase One, I used a quasi-experiment as a quasi-experimental quantitative research design (following the study structure of Torcasio and Sweller, 2010) and conducted observations related to the question "What is being cognitively overloaded like?" as a qualitative research design. During the first stage in parallel to the quasi-experiment, I visited and observed the two classes - experimental groups in both Grades 4 and 7 
when PWIM was implemented as an intervention. In Phase Two, I delivered a questionnaire (seen in Appendix C and Appendix D) and analyzed the data from quasi-experiment and observation. Based on the analyses of the quasi-experiment and questionnaire, I then drew up questions for interviews. I then conducted the interviews. The rationale for conducting interviews in the second phase derived from the possibility that the participating students felt shy or anxious to answer questions in front of a stranger at the beginning of this study. By then, the students in the two experimental groups came to know me a bit because I observed them in their classrooms in Phase One of the study, and they felt more comfortable in these informal interviews. Moreover, asking them PWIM-related questions may have threatened the internal validity of the quantitative part in the first phase, since students in the experimental group may have felt more conscious of PWIM and may have performed better than they would have done without being asked. In Phase Three, I analyzed all the data and made inferences. If necessary, I went back and forth between data analysis and inferences. The current study combined sequential and concurrent design, representing a triangulated explanatory design which would look like Figure 13.

Each phase was carried out separately and relatively independently, but "at the conclusion of the research, meta inferences based on the findings of both studies were developed to facilitate answering of the research questions" (Newman et al., 2011, p.196). The two strands and the three phases were independent but not isolated from each other, in terms of collected data and findings in the later stage called meta 
inferences or meta interpretation. A meta inference is "the judgment a researcher makes about the data" that are being "informed by both the qualitative and quantitative aspects of the research" to explain how "the qualitative-quantitative methods inform each other" (Newman et al., 2011, p.192). It is a "conclusion generated through an integration of the inferences" (Tashakkori et al., 2010, p.45) from the results of both quantitative and qualitative strands of the study (Creswell et al., 2008). The meta inference should be "theoretically consistent" by integrating each strand of mixed methods research study to achieve "integrative efficacy" (Tashakkori \& Teddlie, 2008, p. 115).

\section{Quantitative Strand}

To collect quantitative data, I used a quasi-experimental research design (i.e., samples were not randomized, i.e., cluster convenience sample) in four natural classroom settings to answer the first research question. The current research was based on Torcasio and Sweller's (2010) study procedure for the quantitative section of this study. The precursor study examined text and image in reading in English language teaching for native English speakers who were learning to read. The current study explored the effectiveness of using PWIM to teach Chinese students English vocabulary as a treatment for EFL fourth graders who learned to read and seventh graders who read to learn. Since PWIM was new to both English teachers and EFL learners in those schools, I was the only trainer available to introduce PWIM 
to the teachers involved. There were two teachers, one fourth grade teacher teaching both the experimental group (group 11) and the control group (group 12), and the other seventh grade teacher teaching both the experimental group (group 21) and the control group (group 22). The group distribution can be seen in Table 2 on page 15 . I designed and conducted two training workshops before the implementation of PWIM and provided additional ongoing help if needed, normally before and after class, so that teachers were comfortable and ready to implement PWIM in their classes. After the principals introduced the two English teachers to me, I used my laptop and explained PWIM to them individually. At the end of the first training, I gave them PWIM videos, and the ten steps of PWIM in both English and Chinese version (Calhoun, 1999, p.23; see Appendix E for the Chinese version), so that they could understand this novel method better. We three set an appointment and met together again in a quiet café to reinforce the knowledge of PWIM, asking questions with follow-up discussions and answers. During this casual meeting, I asked the two teachers to teach me PWIM, as if I were their student, to demonstrate their understanding of this new teaching approach. During the implementation, I observed them as well as students. In case of class conflict between the two experimental groups, I asked them to report to me and write down something in their teaching $\log$ (see Appendix F) as a self-report. I also asked them to check whether they used PWIM or not in a given calendar (see Appendix G), so that they would recall PWIM implementation and the students' reactions that I missed, during my follow-up visit. We did not have an extra training during the implementation. 
However, during almost every visit, we discussed PWIM before or after class, mainly in Mandarin Chinese.

\section{Participants}

In the current study, I chose participants who were both early elementary pupils in the stage of learning to read and early adolescents in middle schools who already knew how to read and read to learn in two public schools in Mainland China. The testing criterion was initially planned to refer to Torcasio and Sweller's (2010) study, that is, recognizing words in isolation or from texts. However, I did not have the permission to design tests for the students. Instead, two English teachers made the decisions. Within the beginner group, the fourth graders (117 children in two groups) were chosen at a district key elementary school (i.e. a top-ranking school in the district) in a coastal city. All participants had already received a year of English education. The fourth graders received four 40-minute English classes per week. Within the adolescent group, the 117 EFL seventh graders were chosen at a key secondary school in the same city. The seventh graders received five 45 -minute English lessons every week. They had received at least four years of English education. All participants were Chinese Han (91.5\% as the ethnic majority, not ethnic minority; The World Factbook).

Both the elementary and the secondary English teachers earned a bachelor's degree in 4-year universities. The fourth-grade English teacher (Ivy, pseudonym to her preference) had taught English for 2 years. The seventh-grade English teacher 
(Lily, pseudonym to her preference) had taught English for 9 years in a key high school before she moved to this "A" middle school. The English teachers and other major-subject (i.e., Chinese, math, English) teachers (i.e., Chinese, math, English) can swap minor-subject (i.e., geography, history, music, politics, biology, physical exercises, etc.) classes for their classes. So the real English classes are more than outlined in their class schedules.

\section{Materials}

Both the experiment and control groups in the same grade had the same textbooks and target vocabulary to acquire. The experimental group additionally had three pictures during PWIM practices. I mainly used the Chinese website http://www.baidu.com/ and sometimes http://google.hk to input the target words in the search blank to search images (Google was inconvenient because it went down very often possibly due to the strict censorship). I could not find any single picture to cover all the target vocabulary. Accordingly, I used several pictures. I selected pictures, taking cultural affinity and age appropriateness into account, so that students should be able to use those pictures to retrieve their previous word and world knowledge as a start. I then showed the cooperating teachers all the selected pictures, and the teachers gave me feedback as to further changes or modifications. After getting their approval, I put the pictures on a big piece of paper to make a collage. I emailed the two teachers with picture attachments and asked their approval before I took the collage hardcopies to the field class to implement PWIM (see Appendices H 
to M). The two teachers, who taught two or three classes either in Grade 4 or Grade

7, chose their experimental groups by themselves.

\section{Quasi Experiments}

To answer the first research question "What are the effects of the PWIM on vocabulary acquisition? Are there differential effects of PWIM on vocabulary acquisition based on grade level?", there were two experiments of four groups together to collect data for future comparison.

Pretests and posttests. Before the experiment implementation, pretests were administrated to all groups (Groups 1 and 2 were fourth graders; Group 3 and 4 were seventh graders). Posttests were administrated at the end of the 7-week-long experiment to all groups again. The testing was expected to have unified criteria (following Torcasio \& Sweller, 2010) at both a lexical level and at the level of text comprehension, which were recognizing words in isolation or from texts without any visual aids or pictures, and the words were the same on the posttests and the pretests, decided by the teachers. However, the teachers decided to use a simulated mid-term test from their exercise book as the pre- and posttest (see Appendices $\mathrm{N} \& \mathrm{O}$ ). The testing format of English language for fourth graders (see Appendix N) was mainly spelling and multiple choices, and the format (see Appendix O) for seventh graders was mainly spelling, grammar translation, sentence structure and writing in China. I did not have permission to bring a test (attached $\mathrm{G}$ and $\mathrm{H}$ are the assigned tests in this research study). 
These students were familiar with the test format and form, thus the format did not (presumably) take up their WM resources and helped avoid cognitive overload. PWIM involved reading, writing, inductive thinking, phonetic awareness and vocabulary learning; however, in this current study, it was used mainly for vocabulary learning. Hence, part of the administered tests (see Appendix N \& O) was congruent with the purpose of using PWIM in this research study. The table adapted from Armbruster et al. (2003, p.43; see Appendix P) was used after the posttest by me to show students acquisition of target words by counting words from the acquainted and established columns.

Intervention. The 7-week-long experiments comprised a learning/practicing stage and a test stage. In the learning stage, learners in the same grade level were taught based on the same syllabus and textbooks, with difference of having PWIM or having business-as-usual teaching method in the last 10 minutes of most English classes. The English class in China was integrated in elementary and middle schools, that is, all skills (reading, listening, speaking, writing, grammar and vocabulary) were included as one subject matter. For the rest of the time in class (30 minutes in the Grade 4 and 35 minutes in the Grade 7), the two teachers followed their lesson plans and taught students exactly the same content as other classes. In the current study, PWIM was used to teach participants in the experimental group and there was no rehearsal during the implementation of PWIM. With the same recall intervals, the posttest phase was at the end of the 7-week-long experiment. 
Experiment One. This experiment was designed to examine the effect of using PWIM on vocabulary for beginners learning to read. In group one, 59 fourth graders were taught in the traditional way (以教师为中心、以教科书分析为基础的 语法翻译法) and another 58 counterparts (group two) were taught using PWIM in the learning stage of the experiment. It was hypothesized that group one would outperform group two in the posttest afterwards, in which both groups had texts and pictures as a hint for word spelling.

Experiment Two. This experiment was designed to examine the effect of using PWIM on vocabulary for adolescent EFL learners. In group three 60 seventh graders were taught in traditional way(以教师为中心、以教科书分析为基础的语法 翻译法) and another 57 counterparts in group four were given PWIM in the learning stage of the experiment. It was hypothesized that group four would outperform group three in the posttest afterwards, in which both groups had texts only without any pictures attached.

\section{Internal Validity}

Since the tests were chosen and administered by the two English teachers, I did not have a chance to test the internal validity of the tests. That is to say, it was unknown yet whether the tests could measure the instruction with PWIM intervention and without PWIM. Moreover, using the same questions in the pretest and posttest for one grade level may have a testing effect, which means sensitiveness to certain content resulting that the posttest scores may be artificially inflated or overestimated. 
Different test forms and vocabulary for fourth graders and seventh graders may make the comparison of the effectiveness of using PWIM to teach Chinese students English vocabulary on different graders less convincing. However, sight words and concrete words from the textbooks were chosen, which belonged to the same category of vocabulary. Moreover, choosing all subjects from a regular class ( $n=57-60)$ may have selection bias effect, for instance, sex ratio.

\section{External Validity}

External validity is "the extent to which a study is generalized to other people, groups, or situations" (Newman et al., 2011, p.206). The current study was conducted with respect to the effectiveness of using PWIM to teach Chinese students English vocabulary on fourth graders and seventh graders in a developed city of education in Mainland China. The results of the measurement used to answer the quantitative research question should not be generalized to all EFL learners in China due to the differences of English education resources, time period of English exposure, teachers' qualifications, and so on. Furthermore, the results should not be generalized to all Chinese English learners as well, who may be in an ESL context.

\section{Reliability}

Reliability refers to the "consistency of the measurement instrument" (Newman et al., 2011, p.205). The current study used objective methods of scoring (counting correct answers), and had standardized procedures (pretest, learning stage 
and posttest), in order to enhance its reliability. However, since I was also the trainer to teach the collaboration teachers PWIM and I was not a professional and experienced PWIM user, the teachers did not use PWIM in an identical way; thus, the treatment may be inconsistent. To reduce the possibility of such inconsistency, I gave both teachers Calhoun's (1999) ten instructional steps (p. 23) and an implementation log (Calhoun, 2006; see Appendix G in both English and Chinese) to do self-checking after they taught. I also checked with the individual teacher as to the next step of PWIM.

Additionally, there were documents written in both English and Chinese, including the parent letter, questionnaires, and so forth. To ensure their reliability, there was a translator and a back-translator. Those documents were translated into Chinese and then back-translated to English to assure concordance of the translated information. I performed the translation and the back-translator performed the back-translation without first seeing the original English version of the documents. The back-translator and I reconciled our differences in word choices and decided the more appropriate, concrete and accurate words and expressions in the documents.

\section{Data Analysis}

All quantitative data were entered into an SPSS database (version 19.0). A two-way analysis of covariance (ANCOVA) was conducted on the total correct answers in the pretest and the posttest. Pretest results were a covariate. The prose model of my research hypothesis was that the effectiveness of PWIM varies according 
to different grade levels. To be more specific, I presumed that PWIM would be more effective than business-as-usual method for seventh graders, but less effective than business-as-usual method for fourth graders. In accordance with research Question One, the statistical models were the following:

Full Model Y (Posttest $)=a_{0} U+a_{1}$ PWIM $+a_{2}$ Grade $+a_{3}$ Pretest $+E_{1}$ Restricted Model Y (Posttest) $=\mathrm{a}_{0} \mathrm{U}+\mathrm{a}_{4}$ Grade $+\mathrm{a}_{5}$ Pretest $+\mathrm{E}_{2}$

The $\alpha$ level was set at .05 .

The findings from each group were compared and contrasted to investigate the effect of using PWIM between the experimental and control groups.

\section{Qualitative Strand}

In addition to the quantitative research, observations were conducted in the two experimental groups along the quasi-experiment. After analyzing data from the quantitative research and observations, I decided to use the pre-designed version of the questionnaire and composed questions for the interviews. Questionnaires and interviews were conducted afterwards, so as to give a whole picture of how participants felt when they were taught with PWIM and when they felt cognitively overloaded.

\section{Participants}

The samples of participants in the experimental group were observed in parallel to the quasi-experimental component of the study. The participants who 
responded to the questionnaires and participated in the interviews were a subset of those in the quantitative strand, as a "nested" sampling design (Collins et al., 2007, p.277). After the posttest, I was allowed 20 minutes in a self-learning class (the $7^{\text {th }}$ class for the day in a late afternoon), to explain the questionnaires and the interviews. I asked who wanted to participate and then handed out child assent forms (see Appendix Q in simplified Chinese and Appendix R for its English translation), as well as parent consent forms afterwards (see Appendix S in simplified Chinese and Appendix T for its English translation) to each hand-raising student. I asked each student to take the two forms, read them carefully. I then explained what I said to their parents to get their parents' signature. By this process, I had 30 seventh graders for the survey and interviews.

Since the headmaster of the fourth graders requested that I explain my research study to the students' parents myself, rather than having the students with little knowledge of participating a research study do so for me. As a result, I did so in a post-mid-term-exam parents meeting. I handed out the three paper sheets, introduced myself and my dissertation project and I then waited for the parents' questions. They had questions with respect to the reward, the timing of interviews with their children, and what to ask in the interviews. I answered each query one by one. In return, I asked the parents to discuss the project with their kids after the meeting and hand in the two forms with their signature if their children indeed wanted to participate with the questionnaire and the interview. Later on, I collected signed forms from the fourth graders and ultimately had 18 fourth graders for the follow-up survey and 
interviews. Students who agreed to complete the questionnaires were given hardcopy questionnaires (see Appendix C in simplified Chinese and Appendix D for its English translation) in a class of a minor subject. After collecting and analyzing their answers on the survey, I conducted informal interviews at the convenience and availability of the students.

I guaranteed my participants' confidentiality during and after the research study; thus, I gave each of them a coded ID to be put on their answer sheets. I asked children participants for their consent by explaining the study in a way that they could understand (see Appendix Q in simplified Chinese and Appendix R for its English translation). Since the participants were younger than 18 years old, I asked the custodians of the participants to sign their written consent forms (see Appendix $\mathrm{S}$ in simplified Chinese and Appendix T for its English translation) after I briefly explained my research study to them directly or via their children. I showed and explained my research study proposal (see Appendix $\mathrm{U}$ in simplified Chinese and Appendix V for its English translation) to the custodians. I also notified my participants' custodians that they had the right to say "no" to the form, and that they could decide not to let their children participate at any time during the process of collecting data for any reason, without consequences.

In the data coding, I assigned each participant a coded ID. The electronic data were kept on a USB jump drive with a promise of maintaining it in a secured suitcase for 3 years starting from the date of dissertation defense and would be discarded after that time frame. Other sheets of data (i.e., questionnaires and field 
notes) would be scanned and kept on the same jump drive before being destroyed.

The data were protected with a password, only known by the researcher.

\section{Data collection}

I observed the 115 participants in the experimental group during most of their practice and testing sessions. I took field notes when I observed each of the two classes during the 7-week-long quasi-experiment. Because of class conflicts and traveling time to the school site, I spent two days observing fourth graders and two days observing seventh graders in the experimental group each week. I did not electronically record anything during the observations. However, I took some pictures without participants, with school permission. During my observation, not one single participant took the initiative to talk to me before or after class. I could only note down some moments of their facial expressions and body language, as well as their interaction with peers and teachers, in case that I was able to ask them in the subsequent interviews. In addition to the reason stated above, observations also provided more relevant and personalized questions for the following interviews. For instance, I asked a student's feeling about PWIM after I saw he raised his hands actively during PWIM.

Questionnaires. After their posttest at the end of the experiment, I received parents' and children's permission first and then handed out a questionnaire survey to the participants assenting to participating, using their interpretable language (i.e., Chinese, see Appendix C and Appendix D for its English translation). I did not 
distinguish the language level of the survey for fourth graders and seventh graders, which caused a little confusion for the fourth graders. Some of them internalized the word "influence" as negative (because of their first language influence), and some did not comprehend the term "greatly positive influence on vocabulary learning". The questions included open ones about their feeling of "too much" during learning and testing stages, but just a few of them answered them with enough time permitting. Students wrote down an assigned coded ID that I gave, instead of their names. Interviews. After collecting and analyzing their answers on the survey, I interviewed 18 fourth graders and 30 seventh graders in Chinese one-to-one using a digital recording based on what I had observed and their answers on their questionnaires. As a former student in the public schools in China, I recognized the discipline of routinized school life, so I proposed a maximum of 10 minutes for each interview. My consideration met little resistance or barrier in the field. Since I could only interview them for a maximum of 10 minutes during class breaks, self-learning classes, and minor classes (i.e., geography, history, music, fine arts, physical exercise, and other classes apart from Chinese, Math or English). Seventh-graders were pulled out one by one for maximum 10 minutes each. Fourth graders were pulled out in small clusters of three to five in an attempt to keep the classrooms as uninterrupted as possible. The observations and questionnaire responses helped me with the interview questions. The incongruence of the participants' answers with the difference in their vocabulary acquisition shown from the pretests and posttests was also taken into consideration as interview questions. 
Due to the design of my research questions, the interview data were the main data source.

\section{Trustworthiness Enhancement}

Research journal. Both of my critical reflective journal and my process research journal were important in terms of data collection. The reflective journal was used to check my "assumption, worldviews, biases, theoretical orientation, and relationship to the study that may affect the investigation" (Merriam, 2009, p. 229). My reflective journal included my perception of PWIM in EFL teaching along the process of this project. It was used to check my biased presumption, for instance, that PWIM was effective to certain EFL students. The process journal was utilized to check details of "the methods, procedures, and decision points in carrying out the study", and to establish an audit trail (Merriam, 2009, p. 229). This process journal or audit trail was for the future replication of the current research in terms of methods and procedures.

A detailed description of the settings, participants and the real use of PWIM were given, with an attempt to answer who and under what conditions thought PWIM was effective or not. The thick description could enhance external validity. It was also used for readers to "evaluate the transferability of the findings" (Newman et al.,

2011, p.199). Transferability, from the readers' viewpoint, is to what extent the findings of this research study could be applied to another study (Newman et al., 2011). 


\section{Data Analysis}

I started a preliminary data analysis after collecting data from the observations, so that I could decide to keep or modify my questionnaires (see Appendix C and D). After collecting the data from the questionnaires, I analyzed the data from their answers and interviewed all assented participants. I transcribed those interviews, and translated their answers to questions in both questionnaires and interviews from Chinese into English. Following this transcription, I conducted the coding, found concepts and patterns and developed them into themes through thematic analysis to help answer the three remaining research questions.

\section{Summary}

This chapter explored the methodology of this research study, that is, a mixed methods combining parallel and sequential mixed methods design which was modified from Tashakkori et al.'s $(2010, p .45)$ design. There were three phases in this research study: Phase One, a quasi-experiment study and observations; Phase Two, the use of questionnaires and interviews to collect qualitative data; and Phase Three, data analysis and interpretation to make a meta inference. Findings from quantitative and qualitative data are reported in the following two chapters. The findings answered the research questions raised, addressed the hypotheses put forward, and more importantly, contributed to the empirical arena of CLT and the effectiveness of using PWIM to teach Chinese students English vocabulary in an EFL context. 


\section{CHAPTER IV}

\section{QUANTITATIVE ANALYSES RESULTS}

In this chapter, the first research question "What are the effects of the PWIM on vocabulary acquisition? Are there differential effects of PWIM on vocabulary acquisition based on grade level?" is answered by referring the results obtained from ANCOVA. The pretest results were a covariate, to control for the effect of the pretest on the posttest. In accordance with the research question one, the statistical models were the following:

Full Model Y (Posttest $)=\mathrm{a}_{0} \mathrm{U}+\mathrm{a}_{1}$ PWIM $+\mathrm{a}_{2}$ Grade $+\mathrm{a}_{3}$ Pretest $+\mathrm{E}_{1}$

Restricted Model Y (Posttest) $=\mathrm{a}_{0} \mathrm{U}+\mathrm{a}_{4}$ Grade $+\mathrm{a}_{5}$ Pretest $+\mathrm{E}_{2}$

The $\alpha$ level was set at .05 .

Statistically, the first research hypothesis is $\mathrm{H}_{1}: \mu_{11}<\mu_{12}$ and the null

hypothesis is $\mathrm{H}_{0}: \mu_{11} \geq \mu_{12}$. The second research hypothesis is $\mathrm{H}_{1}: \mu_{21}>\mu_{22}$ and the null hypothesis is $\mathrm{H}_{0}: \mu_{21} \leq \mu_{22}$.

The findings from each group were compared and contrasted to investigate the effect of using PWIM. 
Table 4

Percentage of Correct Answers from the Pretest to Posttest

Tests of Between-Subjects Effects

Dependent Variable: percentage of correct answers in the posttest

\begin{tabular}{|c|c|c|c|c|c|c|}
\hline Source & $\begin{array}{c}\text { Type III Sum of } \\
\text { Squares }\end{array}$ & df & Mean Square & $\mathrm{F}$ & Sig. & $\begin{array}{c}\text { Partial } \\
\text { Eta } \\
\text { Squared }\end{array}$ \\
\hline Corrected Model & $61021.803^{\mathrm{a}}$ & 4 & 15255.451 & 40.522 & .000 & .418 \\
\hline Intercept & 42786.685 & 1 & 42786.685 & 113.650 & .000 & .335 \\
\hline Pretest & 14257.490 & 1 & 14257.490 & 37.871 & .000 & .144 \\
\hline Grade & 4469.931 & 1 & 4469.931 & 11.873 & .001 & .050 \\
\hline Class & .011 & 1 & .011 & .000 & .996 & .000 \\
\hline Grade * Class & 51.227 & 1 & 51.227 & .136 & .713 & .001 \\
\hline Error & 85083.767 & 226 & 376.477 & & & \\
\hline Total & 1489380.952 & 231 & & & & \\
\hline Corrected Total & 146105.571 & 230 & & & & \\
\hline
\end{tabular}

a. R Squared $=.418($ Adjusted R Squared $=.407)$

An ANCOVA was conducted to evaluate whether the percentage of the correct answers in the posttest was significantly different between grade level 4 and 7 , and between the experimental and control groups, with the percentage of the correct answers in the pretest as a covariate. With the alpha set at .05, the percentage of the correct answers in the posttest was significantly different between grade level 4 and 7 , $p=.001<.05$. With the alpha set at .05 , the percentage of the correct answers in the posttest was not significantly different between the experimental and control groups, $p$ $=.996>.05$. That is to say, PWIM had no significant effect or there is no significant difference between the experimental and control groups in both the fourth grade and seventh grade. Given the sample size and difficulties within the study, the results cannot be generalized to a population. It can be inferred that the teacher 
effect didn't seem to matter, at least with respect to these results. Furthermore, the interaction between grade levels and two groups was not significantly different, either, $p=.713>.05$.

The first research question is based on two research hypotheses: (a) The mean of the percentage of correct answers in the posttest for the PWIM group of fourth graders (experimental group) is significantly lower than the mean of the percentage of correct answers in the posttest of students taught with traditional methods (control group) when the percentage of correct answers in the pretest is used as a covariate; (b) The mean of the percentage of correct answers in the posttest for the PWIM group of seventh graders (experimental group) is significantly higher than the mean of the percentage of correct answers in the posttest of students taught with traditional methods (control group) when the percentage of correct answers in the pretest is used as a covariate. The hypotheses are shown in Table 2 on page 15 of this dissertation.

The first research hypothesis is $\mathrm{H}_{1}: \mu_{11}<\mu_{12}$ and the null hypothesis is $\mathrm{H}_{0}: \mu_{11} \geq$ $\mu_{12}$. The second research hypothesis is $H_{1}: \mu_{21}>\mu_{22}$ and the null hypothesis is $H_{0}: \mu_{21} \leq$ $\mu_{22}$. However, the analysis results did not confirm the research hypotheses.

As to the research question "What are the effects of the PWIM on vocabulary acquisition? Are there differential effects of PWIM on vocabulary acquisition based on grade level?", the results did not show any effects of the PWIM on vocabulary acquisition nor any differential effects of PWIM on vocabulary acquisition based on grade level. 


\section{Language Knowledge Established in the Posttest}

The mean of the pretest and the posttest scores for each grade and each class is shown below (see Figure 14), to ascertain whether there were English language achievements. If so, how different the achievements for each cell were.

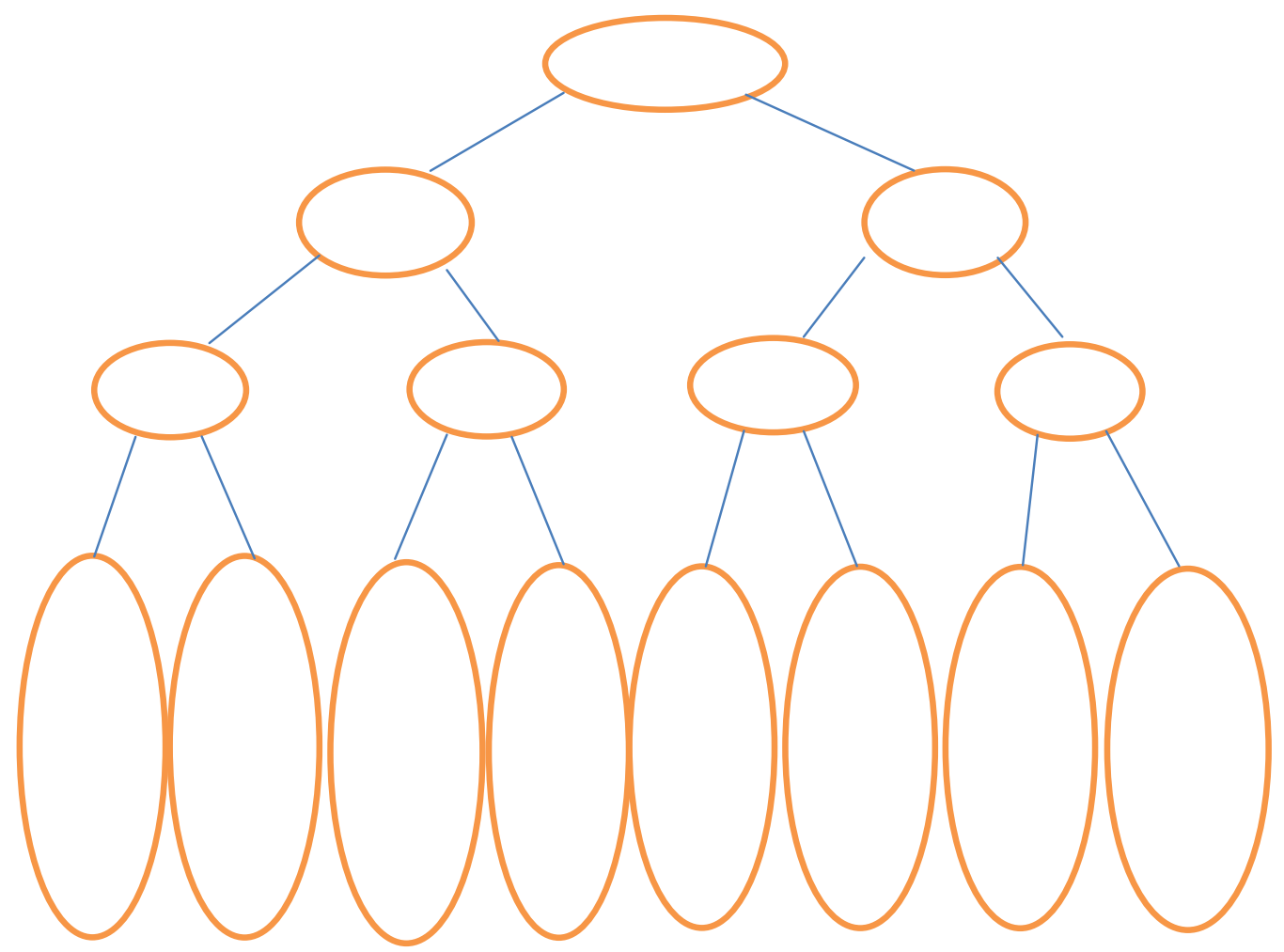

Figure 14. Percentage of correct answers from the pretest and posttest for each cell

As seen from the figure, all of the four groups had English language

achievements over the period of the quasi-experimental study. The mean of the percentage of correct answers in the posttest was 29.5 higher than the mean of the percentage of correct answers in the pretest in the experimental group in Grade 4. The mean of the percentage of correct answers in the posttest was 28.7 higher than the mean of the percentage of correct answers in the pretest in the control group in Grade 
4. The mean of the percentage of correct answers in the posttest was 25.4 higher than the mean of the percentage of correct answers in the pretest in the experimental group in Grade 7. The mean of the percentage of correct answers in the posttest was 22.1 higher than the mean of the percentage of correct answers in the pretest in the control group in Grade 7. Hence, it can be concluded that the English language achievements were slightly better in the experimental groups than in the control groups for both grade levels, but the differences were statistically non-significant. In summary, the quantitative data did not show significant differences of the experimental group with PWIM and control group with traditional methods, with the alpha set at .05 . I will show some interesting phenomena in the qualitative section in the next chapter, although these phenomena, while noteworthy, may not necessarily be generalizable to wider populations. 


\section{CHAPTER V}

\section{FINDINGS OF THE QUALITATIVE DATA}

In this chapter, the qualitative data results provide the answer to research

questions two to four. The three research questions can be seen below:

(b) In what instances do participants feel cognitively overloaded when they practice using PWIM?

(c) What are student participants' perceptions of PWIM as to its strengths and weaknesses?

(d) Do participants feel PWIM is affecting their English learning? If so, do they consider this a positive effect or negative effect? And why?

Before I answer the three research questions, I am going to tell the story of my data collection, because the experience turned out to play a role in the analysis of the data. I personally think that the context through which the qualitative data is obtained is important for readers to have in consideration, when they ultimately take on the specific PWIM-related results. The following narration is my experience of data collecting, following the actual sequences. 


\section{Observations}

The observations were conducted along with the quasi-experimental component. Due to the conflict of class schedules for the four groups, I decided to observe the experimental group only. Even for the experimental group in the Grades 4 and 7, I could not observe all PWIM sessions due to the different locations of the two public schools, class time conflict and commuting time. As I observed the two classes in the experimental group, I focused on the following key issues:

(1) Interactions between teachers and students and among students - whether the English teachers promoted communicative interaction in their English classes or not. How did such classroom climate influence PWIM implementation?

(2) Implemented materials - were the PWIM pictures used in English classes relevant and suitable to students' cultural and linguistic background? Could the pictures trigger students' previous English word knowledge? Did the teachers leave the pictures in the classroom or not? Did students go to see the pictures if they were available in the classrooms?

\section{English Class Observations}

English class observations of the fourth graders. I observed 11 out of the 13 PWIM sessions. Due to the fact that PWIM pictures needed to match the incoming words from each unit, the English teacher, Ivy and I agreed on that there 
would be no PWIM for Unit Three, which was about numbers, 11 to $19 . \quad$ The actual PWIM implementation for each Unit is shown as follows.

\begin{tabular}{|c|}
\hline \multicolumn{1}{|c|}{ Pretest on September $10^{\text {th }}$} \\
\hline Unit 1 PWIM - once \\
\hline Unit 2 PWIM -- 3 times \\
\hline Unit 3 no PWIM (break) \\
\hline Unit 4 PWIM -- 7 times \\
\hline Unit 1 PWIM -- twice by November $6^{\text {th }}$ \\
\hline \\
\hline \\
\hline Posttest on November $6^{\text {th }}$ \\
\hline
\end{tabular}

Figure 15. Timetable of implementing PWIM in the elementary school

For one observation of the class on October 31st, there was no PWIM on that day. During the implementation, there were some changes made, based on agreement between the English teacher ( with psydonym Ivy to her preference) and me, different from PWIM implementation in my dissertation proposal. The table 5 below shows the changes. 
Table 5

Changes Made from Calhoun's PWIM for the Experimental Group in Grade 4

\begin{tabular}{|l|l|}
\hline Date of change & \multicolumn{1}{|c|}{ Content } \\
\hline September $4^{\text {th }}$ & $\begin{array}{l}\text { Instead of two pictures and two rounds, Ivy used three pictures } \\
\text { and PWIM for three rounds }\end{array}$ \\
\hline September $4^{\text {th }}$ & $\begin{array}{l}\text { Instead of finding pictures to cover all targeted vocabulary, Ivy } \\
\text { asked me to put some pictures together to make a collage. I } \\
\text { asked for her approval before printing them out for PWIM. }\end{array}$ \\
\hline September $12^{\text {th }}$ & $\begin{array}{l}\text { Instead of pasting word blocks into sentences, Ivy preferred to } \\
\text { asking students to write down the sentences. }\end{array}$ \\
\hline September $12^{\text {th }}$ & $\begin{array}{l}\text { Instead of using PWIM for every class period, Ivy implemented } \\
\text { PWIM from the } 2^{\text {nd }} \text { period of each unit. }\end{array}$ \\
\hline September $16^{\text {th }}$ & $\begin{array}{l}\text { Instead of using PWIM for the last } 10 \text { minutes in every class } \\
\text { period, Ivy would try to use PWIM for one class session for one } \\
\text { unit( especially the categorization and writing part). }\end{array}$ \\
\hline September $16^{\text {th }}$ & $\begin{array}{l}\text { Instead of using class time to categorize and write using those } \\
\text { words, Ivy prefer to have them at least half done right after her } \\
\text { class, during class break. ( I prepared a word module as a tool, } \\
\text { seen Appendices W, X \& Y) }\end{array}$ \\
\hline September 23 & $\begin{array}{l}\text { Ivy and I decided not to use any picture for Unit 3. Because the } \\
\text { key words in Unit 3 were numbers from 11 to 19, which cannot } \\
\text { be represented by the previous two pictures. }\end{array}$ \\
\hline
\end{tabular}

Ivy taught the fourth grade experimental group and control groups. She felt

concerned about having me in her class. After negotiation, she agreed to let me

observe her class at most twice a week for 10 minutes each during the PWIM

implementation. When she found me sitting outside of her class waiting for the

10-minutes session, she sometimes allowed me to sit in her class beyong PWIM time.

Ivy taught English for 40 minutes of each session, four times a week. But if

Ivy wanted, she could ask other minor-subject (e.g., music, P.E., computer, etc.)

teachers to give her more time for her English subject. Ivy taught in a crowed 
classroom where there was a back blackboard and a front black-white-two-layer board. It seemed that another single student could not fit in the overly crowded classroom. Ivy spoke standard English with a slight Chinese accent. Ivy had a textbook, a textbook guide book, an exercise book, an exercise book guide book, textbook CDs, a laptop, and a loudspeaker as her teaching facilities. Ivy spent a large amount of time on class management, emphasizing discipline and criticizing misbehaved students. She was very strict and rigid, seldom smiled, and demonstrated little tolerance for students' free answers or naughty misbehavoirs (such as pushing, grabbing others' pens, talking to peers when Ivy was teaching). Ivy used Chinese language to explain English words and sentences to reach her linguistic and grammatical goal. She sometimes asked students to translate what she said in Chinese into English or vice versa and asked students to read in chorus several times to consolidate the learnt knowledge. Such drilling and practice was more like audio-lingual. In general, Ivy basically still followed the "teacher-centered textbook-analysis-based Grammar-Translation Method" (Yang, 2000).

In terms of classroom interaction, Ivy was the leading speaker for the entire PWIM process, resulting in one-way, not two-way communication. Generally speaking, Ivy did not promote communicative interactions in her English classes. She had some questions and answers, but most of them were closed-ended questions in the mode of Initiate-Respond-Evaluate (IRE, sometimes even without evaluation). Such questions only had one correct answer, thus Ivy seemingly did not facilitate 
creative thinking or communicative interactions, both of which are to be promoted by PWIM (Calhoun, 1999).

Accordingly, during PWIM implementation in the 13 sessions, the fourth graders could contribute some words to the picture in the brainstorming stage. However, when they moved to the categorization of the sight and text vocabulary and writing stage, they basically followed Ivy's given example. Only a few of the students had their own innovative thoughts of grouping words and turning these words into text. After reading students' categorization and writing, I suddenly felt that PWIM (categorization and writing) constituted another burden on these students, without too much fun. This sudden reflection led to my conclusive thought that Ivy changed PWIM from a student-centered, new-school method into a teacher-centered, old-school way. That is to say, what mattered here was not what to use, but how to use it.

Furthermore, Ivy did not follow the PWIM presentation steps and schedule at times. She combined the categorization and writing stages together because of a time constraint. She put categorization and writing right before the posttest in one teaching session. She even wrote down some words next to the picture before student contributed to save time.

With my bias monitored, I observed that the PWIM pictures that I chose and Ivy agreed were closely relevant to and in the same phase of the units they were learning. The PWIM pictures were suitable to students' cultural and linguistic background as well as to students' interests (i.e., cartoons, characters of their age). 
Thus the pictures could trigger students' previous English word knowledge. Take the first picture for Unit 1 as an example. Ivy told me that when students looked at the picture of different animals for the first time, some students even thought of a phrase "on the farm," which had been taught from their previous semester.

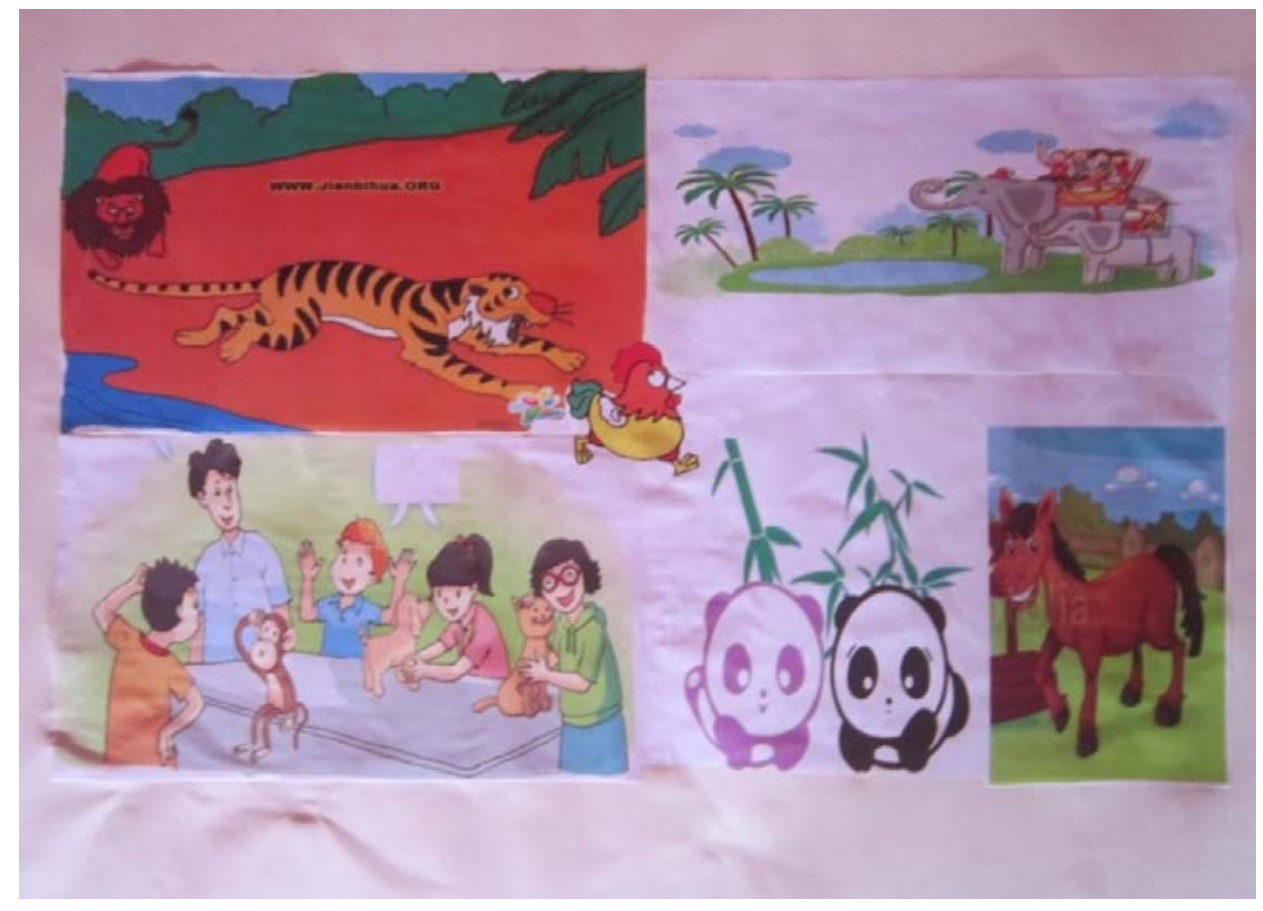

Figure 16 PWIM Picture for Fourth Graders-Unit 1

English class observations of the seventh graders. I observed 12 out of the 18 PWIM sessions. Due to the fact that PWIM pictures needed to match the incoming words from each unit, the English teacher Lily and I agreed that the first PWIM picture would be used for both Unit one and two, since both units talked about activites, using structures including "like doing...," and "be good at doing..." 


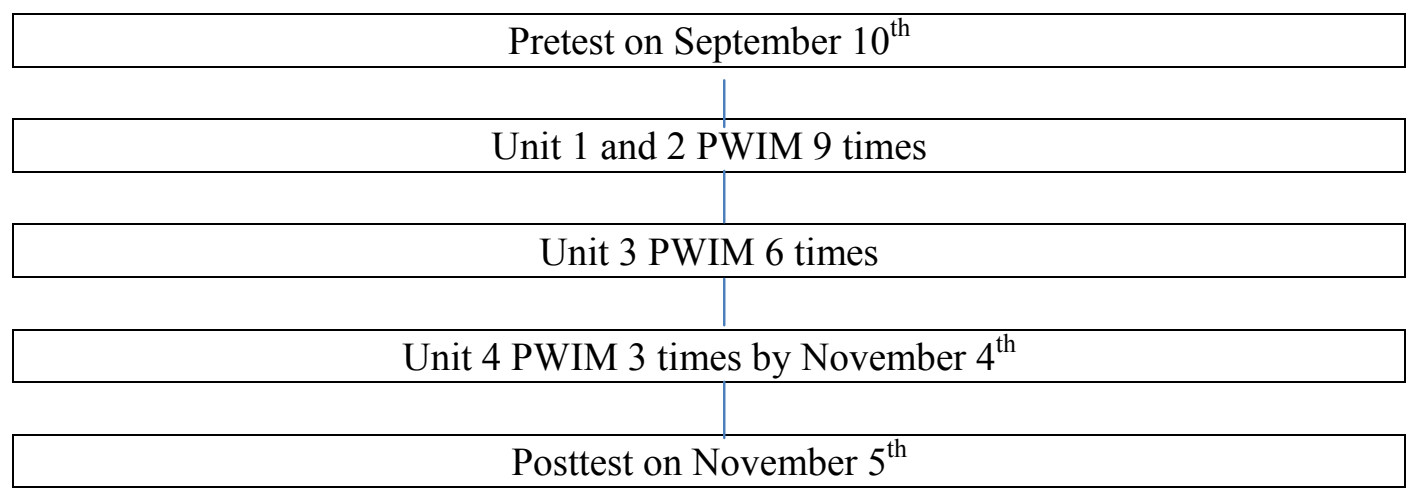

Figure 17. Timetable of implementing PWIM in the middle school

During the implementation, there were changes made based on agreement between the English teacher, Lily and me, different from PWIM implementation in my dissertation proposal.

Table 6

Changes Made from Calhoun's PWIM for the Experimental Group in Grade 7

\begin{tabular}{|l|l|}
\hline Date of change & \multicolumn{1}{|c|}{ Content } \\
\hline September $5^{\text {th }}$ & $\begin{array}{l}\text { Instead of two pictures and two rounds, Lily used three pictures for } \\
\text { PWIM for three rounds. }\end{array}$ \\
\hline September $5^{\text {th }}$ & $\begin{array}{l}\text { Instead of finding a picture to cover all targeted vocabulary, Lily } \\
\text { asked me to put some pictures together to make a collage. I asked } \\
\text { for her approval before printing them out for PWIM. }\end{array}$ \\
\hline September $11^{\text {th }}$ & $\begin{array}{l}\text { Instead of pasting word blocks into sentences, Lily preferred to ask } \\
\text { students to write down sentences directly. }\end{array}$ \\
\hline September 17th & $\begin{array}{l}\text { Instead of using class time to categorize and write using those } \\
\text { words, Lily preferred to have them at least half done after class, to } \\
\text { save class time. ( I prepared a word document as a tool, with word } \\
\text { bank and picture on the paper, seen in Appendices Z, AA \& BB) }\end{array}$ \\
\hline
\end{tabular}

Lily taught both the experimental and the control groups. Lily taught English for 45 minutes of each session, five times a week. But if Lily wanted, she could ask other minor-subject (e.g., music, P.E., computer, history, geography, 
politics, etc.) teachers for more class time for students to focus on English, either teaching, or doing exercises or taking tests. Lily had a textbook, a textbook guide book, an exercise book, an exercise book guide book, textbook CDs, a laptop, and a loudspeaker as her teaching facilities. She had no more than 60 students in a large and bright classroom, where there were a back blackboard, an overhead projector and a front whiteboard, in a brand new building with four floors.

Lily had a strong Chinese accent, but her English was understandable to her Chinese students (revealed from students' in-class reaction and the subseqent interviews). Normally, Lily spoke English first and then translated to Chinese. There were drilling, translations and grammar explanations during class introduction, instruction and consolidation. Moreover, Lily used more than the traditonal way. Lily hinted to encourage students to associate what they were discussing with something related, by directing students with comments such as, "I think we can change another form. Do you think so?" Lily also encouraged students to find more words during PWIM by saying "Can you find some more words?” and by showing her happy facial expressions when students actually did find words. Lily further used encouraging tones to provoke innovations in the stages of categorization and writing. At times, Lily might give a wrong example for students to proofread as a common reminder. As for wrong answers, Lily used direct correction to point out the mistakes, like "my friend name," "she hair," and so on. With respect to feedback to her students seen from my observation, Lily used "good," "very good," "very clever," and so on to praise students, which were expected by the students. Lily also 
used comparison to emphasize the grammatical difference, such as "play basketball" and "play the piano," to give students strategies for acquiring the English expressions by relaying comparison and contrast.

In such an encouraging and welcoming class, students seemed highly motivated. Students raised their hands when Lily asked questions. Students did not appear shy in terms of approaching the whiteboard or standing up to answer the questions. For PWIM outputs, students gave many new words, innovative ways of categorization, and complex sentences. During group discussions, Lily usually walked around, checked students' performance and gave more love and encouragement to both overachievers (who answered questions initiatively and correctly) and underachievers (who were picked on to answer questions and did so with hesitation or errors). Lily also encouraged students to learn from each other within groups and across groups. There were many occasions of teacher-student interactions and interactions among students.

Lily tried her best to follow the PWIM steps. Lily regularly asked all students to read the words and spell them before she moved to new words or new steps. She always took the initative in discussing with me the PWIM steps, how to modify PWIM for her students, and reporting the implementation situation of PWIM when I was not present.

I observed that the PWIM pictures that I chose and Lily agreed to, were closely relevant to and in the same phase of the units students were studying. The PWIM pictures seemed suitable to students' cultural and linguistic background as 
well as to students' interests (i.e., school setting and characters of their age). Thus the pictures could trigger students' previous English word knowledge. Take the third picture (seen Appendix M ) for Unit 4 as an example.

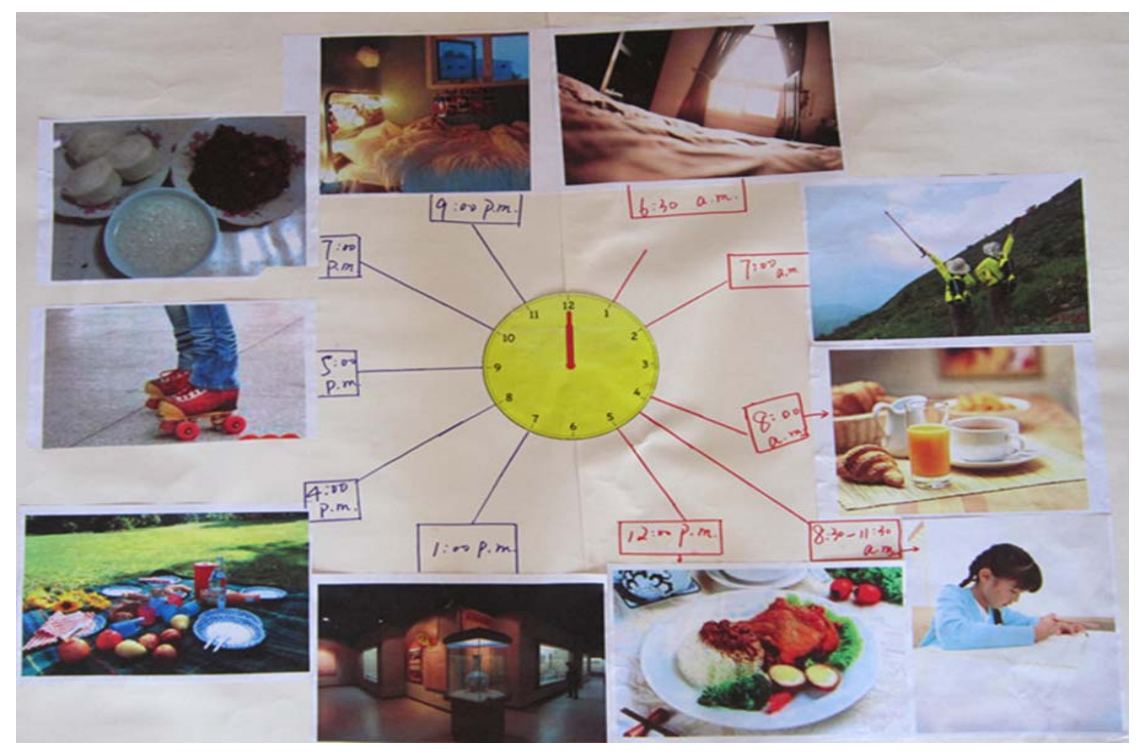

Figure 18. PWIM picture for seventh Graders-Unit 4

Looking at the picture of a person's schedule, students brainstormed the following words: “window, sunshine, hat, go walking in the hills, glass, cup, have breakfast, juice, coffee, bread, do homework, pen, egg, vegetables, meat, rice, light, museum, floor, picture, apple, grass, go on picnics, sunflowers, go roller-skating, ground, building, bowl, night, bedroom, go to bed, and clock" for the first round. These words also revealed that the seventh graders demonstrated more general knowledge and English langauge knowledge; for instance, some students could name "vase" when they saw an antique vase in a museum in the picture. One student even 
said "china" when he saw the vase, although Lily rejected his answer because she thought it was wrong.

\section{After-Class Scienarios}

I was not expected to observe students after class, because I was supposed to observe PWIM implementation only. I happened to do so because I needed to help Ivy and Lily carry their teaching materials, PWIM pictures and modules, and talk with them at time, so I was present after class on some occasions.

After-class observations of the fourth graders. Ivy sometimes left the PWIM pictures in the classroom but folded them and put them in a corner, and students did not take the initative to go to see the pictures. The students did not open the pictures, perhaps maybe because Ivy did not show any approval of doing so, or because the students did not think of doing so or simply did not want to.

The fourth graders (both boys and girls) were often happily playing and chasing each other after class. However, sometimes, when Ivy or other teachers postponed the classes, students continued to sit still, listening to class or doing their assignment, until the teachers announced their disamissal. Student class breaks were often taken, not only because of classes, but also because of classroom management or discipline punishment (i.e., no break as a punishment). Students did not complain or object in public. Similarly, they did not seem to mind me sitting or standing around, although no student ever came to ask me anything. 
After-class observations of the seventh graders. Many boys were playing and chasing after each other after class in their classrooms or out in the hallway, but girls were talking or quietly preparing for the next class. I could see at times that their headmaster or other subject teachers went to the classroom to pull some student(s) out of class to have serious talks with them (and their parents in some severe cases), or to make some annoucement about class discipline, exams, or after-school assignments. The seventh graders seemed used to reduced class breaks because some teachers finished their lessons late. They sat still after the bell rang until the teachers announced their disamissal. They did not ask me anything when I was sitting in class or standing around.

Lily put the PWIM pictures on the back blackboard of the class as frequently as she could, so that students had access to them. I saw students going to the pictures in small groups. They talked about the pictures. Some of the viewers went back to their seats to note down something in their notebook.

\section{Self-learning Class (自习课, zixike) Scenarios}

Self-learning classes were likely to be the last class in the morning or in the afternoon before all students went home during lunch break or after school. Fourth graders had four 40-minute-long classes in the morning and three in the afternoon, with 5- or 10-minute breaks between class sessions. Seventh graders had four 45-minute-long classes in the morning and four in the afternoon, with 10-minute breaks between class sessions. The fourth graders had no official self-learning 
classes; nevertheless, they had so when some teachers experienced an emergency and could not teach for that session. If possible, other teachers or their headmasters showed up and gave students something to do, for instance, free reading or doing handcrafts. The seventh graders had self-learning classes everyday, scheduled in order to assist them in finishing in-school and after-school assignments. Sometimes, teachers made use of the class to teach or explain complete assignments with common mistakes.

I did not stay for students' self-learning classes during the implementation of PWIM. However, I did stay to conduct the survey and interviews, to seek win-win-win opportunities for students, headmasters and me (i.e., self-learning classes are normally least important and loosest, thus extracurricular activity including participation in my research study could happen during such classes). To conduct the questionnaires for the fourth graders, I asked their social science teacher for a class. So after students completed the survey, they automatically treated it as a non-teacher, self-learning class. In other words, I observed that most of them were not able to learn actively or take initiative in learning by themselves. Instead, they looked at me, asked me for ideas, or relied on my guidance. They were not self-discinplined either, occasionally pushing, screaming and shouting in the class.

From my observation while conducting the questionnaire, the seventh graders seemed quite self-disciplined, busy with their homework, unlike the fourth graders. My procedure of conducting the questionnaire was the following: calling one student's name, collecting two consent forms, wiping off the name label on the survey 
and handing out the sheet to the student. When I finished half of the name list, the headmaster stopped me with fury, saying, “Y You should stop. I don't care which principal arranged for you to be here, but you need to stop now." She told me she would arrange for some student to finish this procedure sometime tomorrow, because she thought that I ruined the class discipline and students were distracted from their homework. I explained to her that I had to finish the questionnaire at one time, so I asked her to let me finish after the class was over as I was glad to wait. She finally agreed. There was another teacher in the class ( I guessed she was a math teacher from my overhearing). She scolded students cruelly and mercilessly, for those who did homework poorly or didn't hand it in. She physically pushed and dragged the student, and said, "Look at your poor handwriting. Is it from a human being? It must be from an animal.” My heart raced quickly, and I felt very sorry for the student. The classroom was quiet then, only echoing the teacher's scold-voice and the student's silence, as he cowered in a corner of the room. At that moment, all of my old memories surged up. I was not like the student. Instead, I felt like one of the silent students when some of my teachers similarly chastised my classmates in my elementary, middle and high school.

\section{Students’ Motivation in Participating in Questionnaires and Interviews}

Students told me voluntarily that they were willing to take part in my research study, for one or more of the following reasons: 
1. Their love for the American Cholocate as a reward. They are curious about chocolate abroad, including that from the United States.

2. Following their parents' suggestions (mainly covering the importance of English subject).

3. Misunderstanding of the research study as a PWIM lesson or workshop.

From their voluntary answers, it can be inferred that they had never participated in any research studies before; thus, they had little existing knowledge of what a research study was or what participation might entail.

\section{Survey}

The survey consisted of five questions in the Chinese language (Appendix C), two closed-ended questions and three open-ended questions. Both fourth-grade and seventh-grade students spent approximately 10 minutes to finish the questionnaire. The participants did not ask any questions, seemingly easily and quickly completing the survey in their native language.

\section{Closed-ended Questions in the Survey}

All of the respondents in the seventh grade remembered the PWIM method, as determined from their answers to the first question of the survey (see Appendix C). All of the participants thought PWIM had a positive influence on their new vocabulary acquisition. Twenty out of 30 respondents thought that PWIM had a greatly positive influence on their new vocabulary acquisition. Ten out of 30 
respondents thought that PWIM had a slightly positive influence on their new vocabulary acquisition. No participants thought PWIM had no influence or a negative influence on their new vocabulary acquisition.

All of the fourth grade respondents remembered the PWIM method, as determined from their answers to the first question. Thirteen out of the 18 participants thought that PWIM had a greatly positive influence on their new vocabulary acquisition. Five out of the 18 respondents thought that PWIM had no influence on their new vocabulary acquisition.

\section{Open-ended Questions in the Survey for the Seventh Graders}

With respect to strengths of PWIM, every seventh grader recorded at least one positive attribute about the use of PWIM. In all, there were 15 coded aspects from the 30 respondents: interesting, to study more quickly, to memorize easily, connecting pictures and words, emphasizing how to use these words, acquiring more words, knowing more knowledge, to learn happily, to make the atmosphere lively, to summarize the words by unit, to memorize those words deeply, to build up paragraphs from words, motivating, directly visible, and good for writing. Among those concepts, 13 respondents mentioned "to memorize easily," 10 mentioned "knowing more knowledge" and seven mentioned "connecting pictures and words."

In terms of weaknesses of PWIM, 13 students wrote the following comments: noisy classroom without order, hard to hear clearly, think attentively or write down all of the words, more time for teachers to prepare for the class, time consuming as to the 
reading, spelling and writing down of the upcoming words, extra work and time for teachers, unorganized handwriting on the PWIM sheets, too many words at one time to digest the incoming information, and so on. Among those answers, three students wrote “noisy classroom without order (轰动、吵、乱)," two of them wrote down “more time for teachers to prepare for the class (备课耗时长)," “time consuming as to the reading, spelling and writing down of the upcoming words(用时多),” and one student mentioned that "too many words at one time to digest the incoming information(记不 住)” which is about cognitive overload.

Twenty-nine out of the 30 seventh graders didn't answer that they felt overwhelmed when using PWIM to connect and use English words in the survey. One of them even gave a reason that the words had been learned before (因为以前都 学过). However, the only repondent who answered "yes" wrote, "When I just finished word spelling exercises in class, I may forget some of the words already" (在 刚刚默写过后, 可能有些淡忘).

\section{Open-ended Questions in the Survey for the Fourth Graders}

As to strengths of PWIM, every fourth grader wrote at least one positive attribute of PWIM. In all, there were 11 aspects from the 18 respondents: knowing new words, coonections to sentences, connections to other words, building up more sentences, to memorize words, to memorize words quickly, to memorize words deeply, learning more words, interesting, learning happily, and to consolidate old knowledge of words. Among those concepts, five respondents mentioned "knowing 
new words," and four mentioned "memorizing words." Only one or two students mentioned strenghts other than the two above.

When it comes to weaknesses of PWIM, only two out of the 18 students wrote down their thoughts. One wrote, "too many words were introduced at one time, and those words were too quickly mentioned to hear clearly, thus words can't be remembered." The other wrote "too many words" and "written unclearly." Other than these two students, the rest wrote "no weaknesses."

When it came to the last question, no fourth graders answered that they felt overwhelmed when using PWIM to connect and use English words in the survey. The two close-ended questions of the survey were analyzed quantitatively by determining the frequencies of responses on each of the questions. In addition, the responses on the three open-ended questions were used to construct the interview questions.

\section{Interviews}

I interviewed 18 fourth graders and 30 seventh graders during class breaks, self-learning classes, and minor classes (i.e., geography, history, music, fine arts, and other classes apart from Chinese, math or English). The following is a table of selected interviewees' name codes (used during data collection and analysis) and pseudonyms. Those interviewees' responses will be shown as findings in this section. 
Table 7

Selected Interviewees' Name Codes and Pseudonyms

\begin{tabular}{|c|c|c|c|c|c|}
\hline Grade & Name Code & Pseudonym & Grade & Name Code & Pseudonym \\
\hline 7 & xSm9adsy & Li (李) & 4 & sUhbMeNe & Luo (罗) \\
\hline 7 & C5oeCWy & Wang (王) & 4 & sFzgEx4H & Liang (梁) \\
\hline 7 & 389RpJMD & Zhang (张) & 4 & S7bMxRBQ & Song (宋) \\
\hline 7 & $\mathrm{Ph} 543 \mathrm{Wxj}$ & Liu (刘) & 4 & ywNygwq4 & Zheng (郑) \\
\hline 7 & TYnaxM82 & Chen (陈) & 4 & YHgoRWcU & Xie (谢) \\
\hline 7 & 9v8Zft8R & Yang (杨) & 4 & $\mathrm{CmS703Bu}$ & Han (韩) \\
\hline 7 & pxj7F66M & Zhao (赵) & 4 & $\mathrm{RCx} 35 \mathrm{~N} 7 \mathrm{~A}$ & Tang (唐) \\
\hline 7 & LPPCshoZ & Huang (黄) & 4 & S6rX4djB & Feng (冯) \\
\hline 7 & nyx $4 x V 8 h$ & Zhou (周) & 4 & tpPVUDzx & Yu (于) \\
\hline 7 & scLaHaf3 & Wu (吴) & 4 & ejSD2aaz & Dong (董) \\
\hline 7 & wc2EHnfb & Xu (徐) & 4 & ddskApVG & Xiao (萧) \\
\hline 7 & iEEzcp8D & Sun (孙) & 4 & igSRUfKV & Cheng (程) \\
\hline 7 & vKuRegh2 & $\mathrm{Hu}$ (胡) & 4 & xrmCjkvr & Cao (曹) \\
\hline 7 & $8 \mathrm{cn} 5$ epjD & Zhu (朱) & 4 & 5 efpk5pw & Yuan (袁) \\
\hline 7 & Gsoads6T & Gao (高) & 4 & mxdtsMux & Deng (邓) \\
\hline 7 & rakmkWF6 & Lin (林) & 4 & $\mathrm{~m} 3 \mathrm{HcxhBt}$ & $\mathrm{Xu}$ (许) \\
\hline 7 & mwHrCkkd & He (何) & & & \\
\hline 7 & tgtfvNMH & Guo (郭) & & & \\
\hline
\end{tabular}




\begin{tabular}{|l|l|l|l|l|l|}
\hline 7 & vQmRKjya & $\mathrm{Ma}($ 马 $)$ & & & \\
\hline
\end{tabular}

\section{Interviews with Seventh-Graders}

“... is a miracle method” (Quote from interviewee pseudonym Li).

"It has a greatly positive influence on my vocabulary learning. Compared to

before, I spent 30 minutes to remember two to three words, which would be easily

forgotten; now with this new method, I can remember 30-50 words, which I feel very

happy and satisfied" (Quote from interviewee pseudonym Wang).

\section{Jumping from unknown to acquainted to established word knowledge.}

Armbruster, et al. (2003) distinguished different levels of knowing words, naming the stages as unknown, acquainted, and established (p. 43), defining unknown words as "completely unfamiliar" with unknown meaning, acquainted words as "somewhat familiar" and the established words as "very familiar" which the student can immediately recognize and use correctly. The interviewees discussed their improvement from unknown to acquainted, from acquainted to established, or from unknown to established, directly or indirectly thanks to PWIM, as may be seen in this example from student:

For some words, I just have a general idea about them, without specific knowledge. When my classmates said them from their knowledge, my English teacher Lily would lead us to repeat this word. Then such words helped me a lot...I can't recall what they were then, because they are so familiar to me now; however, they really helped me a lot" (interviewee pseudonym Zhang interviewed on November 21, 2013).

Other interviewees mentioned cloze, reading comprehension in their exercises or tests, as an example to show their jumps from the unknown level to the established level of 
words. One interviewee (pseudonym Liu) said that she benefited most from PWIM in practicing the cloze exercise (filling in words, and similar with writing), because she had a stronger sense of paragraph integrity and continuity. Another interviewee (pseudonym Chen) agreed, mentioning that she improved tremendously in exercises with hints such as cloze and reading comprehension, suggesting that even if she could not spell the newly learned words correctly, she could still recognize those words with hints and contexts, owing to PWIM. Interviewee (pseudonym Yang) also mentioned cloze improvement after the implementation of PWIM because this person thought that cloze is mainly in a lexical form - a key feature of PWIM.

Another interviewee (pseudonym Zhao) talked about her peers' progress in the word knowledge. The girl thought the repetitious words in the three PWIM cycles could help other low-performing or slow-learning students manage those words from unknown or acquainted level to complete correctness in spelling, meaning and use (established level).

Pictures in PWIM. PWIM uses "pictures containing familiar objects and actions" (Calhoun, 1999, p. 21), which was counted as one of its strengths, revealed from the interview answers. One seventh-grade girl (pseudonym Huang) said that "these pictures are more figurative and lively than one picture with one word to say." She preferred PWIM pictures to one-to-one word-picture cards because PWIM pictures (see Appendices K, L, \& M) could prompt more words and connections. Another interviewee (pseudonym Zhou) gave PWIM pictures merits by saying that: [implementing] it enabled my classmates to remember words easily. For one 
thing, it had image to help memorizing in my brain; for the second, the picture-word dictionary at the back blackboard gave students access to check and refer to, if needed.

Moreover, an interviewee (pseudonym $\mathrm{Wu}$ ) compared her way of remembering words without PWIM and with PWIM pictures, by saying "I now have a habit of having a picture when meeting new words, and linking to my life. Before, I just had lexical translation and understanding between Chinese and English.” Another interviewee (pseudonym Chen) gave supportive examples to echo with, "when I see the word "Christmas", I had an image of Christmas tree, the word "Spring Festival" with a picture of fireworks, and the word "mid-autumn Festival" with a picture of the Moon".

It was interesting that when asked to choose pictures of local culture and western culture, the seventh-graders did not mind pictures of western cultures. One student (pseudonym Huang) thought of English as a "carrier," that is as a vehicle to carry foreign cultures, so that she could learn more about English-speaking cultures, knowledge, and the world from pictures of English-speaking countries. Another student (pseudonym $\mathrm{Xu}$ ) told me that as to the word lunch for instance, he welcomed both Chinese lunch (rice, stir fried vegetables and meat) and western lunch (steak and French fries, which he liked). As revealed from the interview, there was little resistance from the seventh-graders to pictures of foreign culture. That is to say, the vocabulary and the PWIM pictures may be not necessarily culturally mapped for those EFL participants.

It was also interesting to hear the interviewees share the differences of pictures 
in PWIM and those elsewhere, for instance in their textbooks. A high-performing student in both the pretest and the posttest (pseudonym Zhao) showed her opinion of the distinctions of the pictures, saying that textbook pictures have less information and fewer words to discover. In textbooks, there is one picture next to one dialogue and sometimes pictures cannot represent dialogues. However, she noted that PWIM pictures are made up of small relevant pictures, more information and details; thus, she could find more words and develop more dialogues.

Another interviewee (pseudonym Sun) echoed a previous girl's comments, saying, " Such pictures (in PWIM) cover more content with more information. For example, an information-intensive picture would be a playground in the unit of sports, which has facilities and people on it to talk about." This interviewee also mentioned the advantages of PWIM pictures by stating, "They are more suitable and relevant pictures, easy to memorize and associate, and connected to my daily life." Similarly, another interviewee (pseudonym Hu) compared the pictures in textbooks and PWIM, by asserting:

Pictures in the textbooks are for students to know the texts or exercises next to them. They provide context or background for the texts. Pictures our English teacher used these days could be connected and made into a story in entirety.

Connections of pictures and words. With pictures, most of the interviewees mentioned that they learned, memorized and retrieved those previouly learned and newly learned words more quickly, easily, conveninently and efficiently, "not one by one, not by rote" ( interviewee pseudonym Xu), possibly due to "connections and imaginations" ( interviewee pseudonym Zhu). They could not tell which jumped out 
of their mind first, pictures or words. Most respondents thought that pictures and words appeared simultaneously. Interviewees also thought that with pictures, the impression of word was much deeper, because words to be considered were associated with the relevant pictures.

Some of the seventh graders developed their own habit or strategy of connecting words in one single picture, after the three cycles of PWIM for three units respectively. One of them (pseudonym Huang) even gave me an example. When she learned tomato, lemon, watermelon, meal, and other fruit in Unit Six, she said that she also automatically developed a picture in her brain, which had a fat boy sitting at the back of a table where there were many fruits and snacks.

Connections to writing in PWIM. Through PWIM, many interviewees were able to build up paragraphs from words. One boy (pseudonym Zhu) thought that words were associated with other words and finally linked into a text; thus, he said that PWIM contributed dramatically to his writing, by just changing the picture to text.

Students could build up paragraphs using individual words. They also learned longer chunks of sentences or phrases from each other during and after writing displays, because " Individual writing is unique, so worthy to learn” (interviewee $\mathrm{Zhu}$ ). Another girl (pseudonym $\mathrm{Wu}$ ) remarked that she could learn from others' writing as to how to write and what to write, by imitating first and then writing better. Moreover, another respondent (pseudonym Chen) remarked that she learned from common mistakes revealed in other's writing which were later on 
pointed out and emphasized by Lily.

More importantly, students had more to write when they saw a writing topic after the implementation of PWIM. One interviewee (pseudonym Zhu) developed a habit of having an image when he saw a writing topic, so he could feel more fluid and flowing during writing, rather than stopping to think and to feel that he had nothing more to write. He said that he was more descriptive and could reach the minimum word requirement easily. The girl (pseudonym $\mathrm{Wu}$ ) showed agreement by giving a concrete example. If she had to write the word "restaurant," with assistance from PWIM, she could describe the word in a short paragraph, even without writing the word down exactly.

\section{Affective enjoyment during PWIM and due to PWIM. All of the} interviewees liked and welcomed PWIM very much. Most of them expected their English teacher to continue using PWIM in the future to consolidate their vocabulary. In addition to the cognitive and linguistic benefits mentioned above, some interviewees discussed affective aspects. One student (pseudonym Xu) said, “I was learning in a happy and easy atmosphere, which reduced my psychological burden and pressure," so he anticipated the next opportunity of his English class with PWIM and would listen to the English teacher attentively. Another inteviewee (pseudonym Wang) talked about happy remembering of words due to PWIM after the in-class implementation cycle of PWIM, and expressed that the importance of happy experiences during PWIM could enhance the possibility of commanding those learned words. In addition, another interviewee (pseudonym Gao) spoke of her peers' 
differences before and after using PWIM, in terms of affective effect, stating, “ This method let us find English funny. I noticed some of my classmates who did not want to memorize words before, started remembering words actively."

One interviewee (pseudonym Chen) compared English classes with PWIM with other classes, as well as English classes with PWIM and without PWIM, by saying, " The class atmosphere was alive, so students liked that class, compared to solo-teacher-teaching without any entertainment, like our history class; the English class without PWIM was dull, with just a few students raising their hands to answer in low spirit." She addressed the importance of being interested in English classes through a comparison. She thought that students may find math interesting later on during problem solving or practice stage, but English needs more techniques or "flavors" in instruction to attract students. This respondent welcomed PWIM in the future, noting that, "Without PWIM this month, I feel lost, less entertained and a little disappointed." The interviewee (pseudonym Lin) expressed the same feeling by saying when Lily taught Unit 5 without PWIM, he, too, felt a little loss.

Nevertheless, there were a few students who were indifferent to whether they would have PWIM in the future or not. Some students (e.g., pseudonym Li) thought they already had the strategy or technique of having an image when meeting new vocabulary or writing topics, so there was no need for teachers to implement PWIM any longer. Another interviewee (pseudonym $\mathrm{He}$ ) remarked that he did not care whether Lily used PWIM any more or not, because it was no longer fresh to him.

In sum, PWIM, indeed for numerous interviewees, made the class alive, 
interesting, engaging and motivating. Students wanted the teacher to write down what they contributed during the word brainstorming and category stages. Students also expected to be picked to read what they had written at the end of each PWIM cycle, that is, the writing stage. PWIM was also welcoming and friendly to those students of unlikely risk-takers or/and with small vocabulary (revealed from the interviews with pseudonym Zhao, Xu, \& Gao above), because they had a lot of easy words to contribute (e.g., breakfast and lunch for Unit 4).

Three PWIM cycles in a huge classroom of over 55 students. Apart from all the merits of PWIM mentioned above, some students talked about practical issues of PWIM, and the remaining respondents found few or no weaknesses of PWIM.

One student (pseudonym Zhou) thought of long physical distance for the near-sighted peers sitting far away from PWIM pictures. In such a large room using PWIM, those neglected groups were more likely to be distracted and even left behind. However, the other interviewees showed disagreement of attributing distraction to PWIM, saying much as one interviewee (pseudonym $\mathrm{Wu}$ ) that "being distracted is an individual phenomenon, not a method weakness." Moreover, even the interviewee (pseudonym Zhou) himself said that he, as well as some of his peers, returned to the picture-word dictionary hanging on the back blackboard after class, either for missing notes or for preparing for the next PWIM session. One might then infer that having access to the PWIM pictures could make up for the long distance for some students, because students were able to see those pictures closely after class.

A few interviewees (e.g., pseudonym Guo) listed noise as one of PWIM's 
weaknesses. However, some interviewees showed disagreement in terms of noise being a disadvantage. "Being noisy is not the weakness," said one interviewee (pseudonym Huang), “It's students' personality weakness.” Another interviewee (pseudonym Zhang) said that "being noisy can be counted as one small weakness; however, if Lily can manage the class well and my classmates are more disciplined, then the class has better order and students have more chances and time available to answer the questions."

For the three PWIM cycles, there were many repeated words (words of body parts, color, background—sky, cloud, etc.) brainstormed. A couple of the interviewees grouped such repetition as a weakness, much in the vein of the Redundancy Effect (causing cognitive overload). One interviewee (pseudonym Zhang) said that too many repetitous words slightly kept her from thinking of more words from PWIM pictures, and from easily finding newly learned words in the word bank on her category and writing module papers. She also mentioned that if Lily could break the table of word bank (see Appendices Z, AA \& BB) into two parts, one with high frequency words and one with newly met words, then such a problem would be solved. Moreover, one of the interviewees (pseudonym Ma) complained by saying, "Many words (tree, world, sky, eyes, leg) are repeated in the three cycles, which were repetitious and meaningless. Don't repeat the common words again and again. Say more typical and unique words." What the students mentioned was exactly the Redundancy Effect, which causes Cognitive Overload. However, one of the interviewees (pseudonym Zhao) considered repeated words as a merit. The girl 
talked about the same repetitious words, but showed a different attitude. She already had known these words, but thought these repetitious words could help other low-performing or slow-learning students consolidate their vocabulary. The girl's persumption was contradicted by that of the other two interviewees, in terms of repetitious words being redundant or necessary.

\section{Interviews with Fourth-Graders}

“...Four-skill-required words short and easily pronounced words, with tapes and voice-recordings. Three-skill-required words do not have specific listening materials, but some of them may appear in the unit text with tape-recordings...”(interviewee pseudonym Luo interviewed on November 29, 2013)

Four-skill-required words and PWIM. Many fourth graders mentioned the term “ four-skill-required words”(四会单词) in the interviews. Such words differed from other words in that students need to manage four skills (listening, speaking, reading and writing) for them, but need to manage fewer skills (e.g., listening, speaking and reading) for the rest. In other words, those four-skill-required, three-skill-required, and two-skill-required words were in different levels of word establishment according to their syllabus. The students reported that the four-skill-required words were more important in every unit (only four to five for a unit told by interviewee pseudonym Liang) with the words garnering higher possiblity to be examined in the fourth graders' tests. Accordingly, fourth-grader interviewees 
paid more attention to these words, particularly their spellings. As interviewee (pseudonym Song) said, she could only spell four-skill-required words out, such as tiger, happy, bird, and bag. "Those words were short, easy to read, reasy to memorize,” told by one interviewee (pseudonym Song), “ My English teacher (Ivy) told us to check or underline them from our textbooks, and we need to manage how to spell them correctly."

Such differential levels of managing words was linked to the three levels of word knowledge-- unknown, acquainted, and established levels (Armbruster et al., 2003, p. 43). Four-skill-required words were more likely to be in the established level, and the other words stayed in the acquainted level since fourth graders could not spell those words out or write them down. Different from the seventh graders, fourth graders still failed to spell words out, including the words that had been taught but not been required to spell (such as three-skill-required and two-skill-required words). Some interviewees used such differences to rationalize their level of word knowledge before, during and after PWIM. Such an existing mindset may influence how many and how deep they would like to know newly-learned and previously-learned-and-recently-mentioned words in the three PWIM cycles. Other interviewees (e.g., pseudonym Zheng) said that they would love to manage both the four-skill-required word and the others, because her parents expected her to and she agreed to know all the words for the future, including both in-curricular and extracurricular English words.

\section{The vital importance of the Chinese language to the English language}


learning. Fourth graders'native language played a vital role in their English language learning. They did not develop phonetic awareness yet, nor any linguistic, cognitive or metacognitive strategies in learning English from my observation. That is to say, the Chinese language was the only existing previous knowledge they could rely on in terms of vocabulary learning. Similar to other interviewees, one student (pseudonym Xie) could think of unknown words in Chinese language first in the brainstorming stage of PWIM and then memorize the English version told by other students and Ivy. In other words, he thought that the Chinese language was important at his stage of learning English. But sometimes he said he found that his first language (L1) had negative transfer to his second language (L2). For instance, he mismatched the Chinese and English meanings of chicken and cloud. Again, this may be due to his solo reliance on his L1 and such a case may be different if the fourth graders had phonetic awareness or cognitive strategies in learning the English language.

Rather than the brainstorming stage of PWIM, the interviewee (pseudonym Han) said that he/she categorized those old and new words, based on their Chinese meaning. The fourth graders also expected to have the word bank (for categorization and writing, see Appendices W, X \& Y) in both English and Chinese. The interviewee (pseudonym Tang) said, "My English teacher (Ivy) should have put the Chinese meanings next to those English words." The words this interviwee referred to were both old and newly learned words generated in the brainstorming stage.

In the writing stage, the interviwee (pseudonym Feng) said that she sometimes 
thought about new words in Chinese when making stories based on pictures, wrote them down in Chinese and then asked Ivy for the English corresponding words. The student thought that it was a good way to learn new words embedded in contexts.

After Ivy and students introduced new words in the PWIM, some of the interviewees (e.g., pseudonym Yu, Zheng, \& Dong ) reported that they could only remember those words in Chinese. In addtion to the words per se, some strategies using the students' L1 were emerging after the introduction and implementation of PWIM. One interviewee (pseudonym Liang), for instance, developed a new habit. She stated that she started to take initiative in writing Chinese meanings next to English expressions when she previewed a new unit. Such emergent use of L1 to L2 learning showed her developing self-learning autonomy and higher awareness of using L1 as scaffolding. She also said that after Ivy used PWIM in her class, a picture may arise in her thinking of new English word and Chinese words. For those Chinese words, she may then ask her peers for the English translations at times.

No influence of PWIM on their vocabulary learning? Some of the fourth-grade interviewees chose the answer "no influence," when they were asked about the influence of PWIM on their vocabulary learning in the survey, which I would love to seek answers and rationales from the subsequent interviews.

I asked the no-influence-choosing interviewees to confirm or disapprove my preliminary assumption. A student (pseudonym Song) said, “I chose no influence because I actually had no idea about this option, nor did I know whether this new method had influence or not, since it was a new method. But I feel that the method 
helped me remember words and with other processes in my brain."

After I interviewed the student above, I developed a new way to ask other interviewees with the same choice for the question. For instance, when I interviewed another student (pseudonym Feng) with the same answer, I explained to the interviewee that no influence means no interface/ interaction/ action/counteraction with words from textbooks, positive influence means this method helped vocabulary learning, and negative influence means this method hindered vocabulary learning. After I explained all the five choices in the second question, she chose greatly positive influence rather than no influence.

Except for the salient differences mentioned above, the younger interviewees had opinions in common with the seventh graders. The following sections will show the similarities as to the PWIM perceptions.

\section{Jumping from unknown to acquainted to established word knowledge.}

The interviewee (pseudonym Dong) confessed that he only remembered Chinese meaning of the newly learned words. This interviewee was not able to spell or read the new words, but could recognize them when see them pictures in PWIM. Such confession was an evidence of jumping from the unknown to acquainted word knowledge. Similarly, another interviewee (pseudonym Xiao) said that she could only remember the exact Chinese expressions and blurry English expressions; however, once she saw the words the subsequent time, she still had some memory about them.

After I heard these two interviewees' responses, I wrote down the English 
translations for the following interviewees (e.g., pseudonym Cheng, \& Cao) to see if they told me the Chinese expressions of those newly learned words. Then the interviewees could identify them immediately and tell me the Chinese meanings, but they could not read them out without my assitance nor spell them correctly without seeing the words.

Strengths of PWIM. As one of the salient strengths of PWIM, categorization in PWIM was useful thus heartily welcomed by the fourth-grade interviewees. Because these fourth graders had categorization questions in their tests at times, they (e.g., pseudonym Dong, Zheng, \& Xiao) found that categorization in PWIM (see Appendices W, X \& Y) was similar to and closely related to what they had in their tests. For instance, Exercise Two in their pretest and posttest (seen in Appendix N) is a categorization exercise, in which they need to choose the one that does not belong to the other two words. Therefore they would love to practice categorizing during PWIM.

In addtion to preparing for tests, some other students spoke highly of categorization and writing in PWIM, when it comes to memorizing words. Take an interviewee (pseudonym Xie), for instance, who said,

Before this new method [PWIM], I can not think of categorization to memorize words. I used to memorize words according to the alphebetic order and by rote. Now I can memorize words according to categories, which deepen my impresson of old words. Now when I think of a word, I can think of a string of words related (smile). I like the new method. I would love to use categorization method to memorize word in the future, which is more efficient and effective...(interview on November 29, 2013) Other interviewees showed similar responses, when asked which picture and which 
words they could still remember from previous implementation of PWIM. The interviwee (pseudonym Luo), for instance, thought that categorization was necessary and helpful, because it was a string of related words, not word by word in isolation. With categorization, this interviewee could output more words and more correctly spelled words.

Another salient strength of PWIM was the use of pictures. "Pictures were very interesting thus impressive," one interviewee (pseudonym Feng) said. Another interviewee (pseudonym Yuan) talked about pictures in PWIM with more details, stating that pictures in the new method are "interesting and funny." The characters and stories in the pictures were suitable to her age, so she could easily associate with them. She continued to compare pictures in her textbooks with pictures in PWIM, saying that "Pictures in textbook are a little interesting, and boring with the same style; the new method [PWIM] has extra-curriculum pictures which are greatly interesting and totally fresh to me.” Some interviewees ( e.g., pseudonym Zheng) compare word-picture cards they had in their previous English learning with PWIM pictures, and said that " The word-picture cards are used for learning the specific words per se; but PWIM pictures can be used for learning more extra-curricular words and knowing more words in general, which is good (for my English learning)." Similarly to what the interviewee (pseudonym Zheng) said, another interviewee (pseudonym Tang) compared PWIM pictures and pictures in other English-learning materials, by saying that many words can be found in one PWIM picture versus only one word to be found in one picture (i.e., word cards), and a paragraph or story can be developed from one 
PWIM picture versus a word in one picture (i.e., word cards). Seen from both, PWIM pictures are more informative, connective with words and inductive as a source.

Closely related to the use of pictures, the connection of pictures and words was also a key concept revealed from the interviews. Many interviewees mentioned this with excited and happy facial expressions. Some of them compared memorizing words with such a connection and without. An interviewee (pseudonym Cao) said, "With pictures, memorization became lively and interesting to me; Without pictures, I feel it boring and dull..." This interviewee went on to talk about connections of pictures and writing, "I have pictures when I write. With pictures, I can make sentences; Without pictures, I can not write sometimes." The connections of pictures and words was also true in another interviewee (pseudonym Han)'s case. She said that she had pictures in her head during her writing. Another interviewee (pseudonym Cheng) also talked about memorizing words with and without connections of pictures and words, by saying that she had to do rote (reading many times) after class without PWIM, compared to easily memorization of words with PWIM and pictures in mind.

In addition to linguistic and cognitive benefits mentioned above, some students had strategic development and personality maturity. The interviewee (pseudonym Zheng) developed a new habit, that is, associating pictures with words, after the implementation of PWIM. This respondent said that once she saw a word, she would think of a picture and vice versa, which had not happened to her before. 
Through this process, she said that abstract words became concrete, which she felt happy about. The interviewee (pseudonym Liang) remarked that during PWIM, she found that she had less vocabulary, compared to other students who gleaned more words out of textbooks. As a result, she planned to have some time at night to learn some new words by herself. This can be an indirect strength of PWIM, that is, peer pressure during PWIM implementation could motivate students. Similarly, another interviewee (pseudonym Feng) stated that this new method (PWIM) let her be more initiative, automatic and independent. She sought pictures on line and discovered words after the implementation of PWIM by herself, to contribute in the following PWIM classes. In the same vein, the interviewees (pseudonyms Cheng \& Deng with shy smiles) were glad and happy during the word brainstorming stage, stating that when they contributed a new word in class, they felt self-satisfied and fulfilled. Similarly, the interviewee (pseudonym Cheng) added that if others said some words in class and she was also happy, because she could learn from her peers.

\section{Affective enjoyment from PWIM and other in-class activities. Affective}

enjoyment is one of the strengths of PWIM, but I put it here seperately because I think such a benefit was so precious and rare in a teacher-centered big classroom, mainly under IRE- operating classes.

The interviewee (pseudonym Feng) contended that she liked enjoyable learning or learning with fun and games. In her opinion, an English class with PWIM became more lively and interesting, compared to other methods (which she found boring and dull). 
In addition to PWIM, there were other happy moments for the fourth-graders. The interviewee (pseudonym Feng) shared her happy moments (other than from PWIM) as: 85 to 90 percents of the moments were cartoon time and story time, with 10 to 15 percents belonging to reading texts in chorus. The interviewee (pseudonym Cheng) said that Ivy's class was interesting, when there was student involvement intertwined with cartoon time and role play, but less so during solo-teacher-instruction, which she did not like. Echoing Cheng's comments was the fourth-grader (pseudonym Dong), who said that she was happy in Ivy's class, when it was time for games or extrinsic rewards; for example, she won a picture drawn by Ivy. The interviewee (pseudonym Xu) said he preferred PWIM to cartoon time, even though he liked both, but still emphasizing that upcoming new words are good to know and learn through PWIM.

\section{Novice teacher using PWIM in a crowded classroom over 55 students.}

Given the fact that a novice English teacher, Ivy, who started to teach in this elementary school two years ago, was inexperienced with PWIM, and implemented the PWIM cycles in the 7-week-long period allows the interviewees' responses about the weaknesses of PWIM to be analyzed more deeply. Fourth graders' renderings of PWIM weaknesses were similar to those of seventh-graders, such as disorganized word notes on the pictures mismatching words and pictures (from pseudonym $\mathrm{Xu}$ ), and noise. However, the interviewee (pseudonym Yuan) argued that being noisy was not a PWIM weakness because the students were actively discussing and trying to answer questions. 
Other reported weaknesses of PWIM, however, were unique to the fourth graders. For instance, the interviewee (pseudonym Tang) noted that there were too many examples in the writing stage to make their own sentences, and students just copied what Ivy just said or wrote. My observation also confirmed this. I noticed Ivy giving so many examples, either as a scaffolding or for the sake of saving time that I had to wonder if doing so was actually counter-effective. Such seemed to be a possible case of the redundancy effect.

Cognitive overload and students' acknowledgement. Closely linked to the weaknesses mentioned above, some interviewees disclosed that they felt cognitive overload at some time during the PWIM implementation. The girl in fourth grade (pseudonym $\mathrm{Yu}$ ) described intrinsic and extraneous cognitive load:

There are a lot of moments when I can not note down new words. All of my classmates raised their hands to say, very noisily, so I could not memorize so many new words, nor could I write down them all. I could only note down a few of them. Luckily, my English teacher [Ivy] wrote them down afterwards. At that time, there were so many strange words, which did not have Chinese meanings next to them, so I had to ask my English teacher during categorization and writing (see Appendices W, X, \& Y). My concern is if I memorize those new extra-curricular words, and forget the new words for tests in my syllabus, what should I do? (有很多生词记不住的时候, 全举手那么多 人说...七嘴八舌...那么多我不会的单词, 脑子也记不下来、也写不下来。 幸好老师后来写下来了，因为当时我只能记住一两个。而且当时陌生单词 太多了, 分类和写作时问老师, 不知道中文意思记不住。要是我把那些新 单词记住了, 把那些考试要考到的单词忘记了, 怎么办啊? (Interview on November 26, 2013). 
In summation, the issues raised by fourth graders regarding PWIM included the following: too many words are intrinsic cognitive overload, noisy classrooms, lack of Chinese meanings, time constraints during PWIM, and concern about conflict between PWIM words and any word pool established for tests as extraneous cognivie cognitive overload.

Another interviewee (pseudonym Xiao) also talked about intrinsic cognive load, but did not consider such load as cognitive overload, saying “ There are some moments when I can not remember new words which are long with irregular pronunications, but I will try my best to command them." Similarly, the interviewee (pseudonym $\mathrm{Xu}$ ) said that he was at a loss when too many words surged up at one time, especially when the writings of those new words were not well organized and not easily pinpointed; however, this person said he would try his best to digest them later.

\section{Answers to Research Question : In what instances do participants feel cognitively overloaded when they practice using PWIM?}

Only one seventh grader out of 30 answered that he felt overwhelmed when using PWIM to connect English words in the survey, stating "When I just finished word spelling exercises in class, I may forget some of the words already(在刚刚默写 过后，可能有些淡忘).” The others, however, said they did not feel overwhelmed. As an example, one respondent noted that the words had been learned before. 
In fact, the opposite of overwhelmed was largely described, one interviewee (pseudonym Ma) complaining that some students gave the same words again and again in the three pictures, thus, such words were "repetitious and meaningless." The interviewee thought that such words did not help students learn at all. What the student mentioned was exactly the Redundancy Effect, as one effect of extraneous Cognitive Overload.

Contradicting Ma's comments, another girl participant (pseudonym Zhao) talked about the same repetitous words, but showed a different attitude. She already had known these words, but thought these repetitious words could help other low-performing or slow-learning students consolidate their vocabulary.

The fourth graders did not mention the counter-effect of repeated words, from both questionnaries and interviews. They mentioned too many new words at one time, many words written out of place, no Chinese meaning scaffolding their knowledge of new English words, and noisy classrooms, if any.

As a conclusion, just a few seventh graders and fourth graders realized or admitted cogntive overload during PWIM. Any reported cogntive overload was mainly intrinsic or extraneous cogntive load (e.g., noisy classroom, displaced writing of new words, \& mismatches between words and pictures). None of interviewees mentioned the use of pictures as a source of cogntive overload. The two groups both mentioned redundancy effect (too many writing examples in the fourth grade and repititious words during the three PWIM cycles in the Grade 7). The seventh graders did not mention that they had intrinsic cognitive overload. The fourth 
graders felt intrinsic cogntive overload when they met many new words at one time, or new words without Chinese meaning during the stage of use, that is categorization and writing.

Table 8

Cognitive Overload Circumstances for Fourth and Seventh Graders

\begin{tabular}{|l|l|l|l|}
\hline $\begin{array}{l}\text { Cognitive } \\
\text { Overload }\end{array}$ & Source & $\begin{array}{l}\text { Grade } \\
\mathbf{4}\end{array}$ & $\begin{array}{l}\text { Grade } \\
\mathbf{7}\end{array}$ \\
\hline Intrinsic & too many new words at one time & $\checkmark$ & $\checkmark$ \\
\hline Extraneous & noisy classrooms & $\checkmark$ & $\checkmark$ \\
\hline Extraneous & many words written out of place/ unclearly & $\checkmark$ & $\checkmark$ \\
\hline Extraneous & mismatches between words and pictures & $\checkmark$ & $\checkmark$ \\
\hline Extraneous & time constraints during PWIM & $\checkmark$ & \\
\hline Extraneous & $\begin{array}{l}\text { no Chinese meaning scaffolding their knowledge } \\
\text { of new English words }\end{array}$ & $\checkmark$ & \\
\hline Extraneous & conflict between PWIM words and words for tests & $\checkmark$ & \\
\hline $\begin{array}{l}\text { Extraneous } \\
\text { (Redundancy) }\end{array}$ & too many writing examples to follow & $\checkmark$ & \\
\hline $\begin{array}{l}\text { Extraneous } \\
\text { (Redundancy) }\end{array}$ & repetitious and meaningless words & & $\checkmark$ \\
\hline Extraneous & long distance to PWIM pictures & & $\checkmark$ \\
\hline
\end{tabular}

\section{Answers to Research Question : What are student participants’ perceptions of}

\section{PWIM as to its strengths and weaknesses?}

In reference to the question asked of the seventh graders about the strengths of PWIM, there were 15 reported concepts from the survey and interview responses: interesting, to study more quickly, to memorize easily, connecting pictures and words, emphasizing how to use these words, acquiring more words, knowing more knowledge, to learn happily, to make the atmosphere lively, to summarize the words 
by unit, to memorize those words deeply, to build up paragraphs from words, motivating, directly visible, good for writing, and peer learning. The 15 concepts were further categorized into five themes: linguistic acquisition, knowledge acquisition, cognitive development/advancement, emotional/psychological enjoyment, and peer learning.

The figure 19 below shows the 15 concepts and five themes in five different colors. Because the 15 concepts were equally important without any vertical or hierachical order, I clustered them together based on each theme and used five highlight colors to distinguish them.

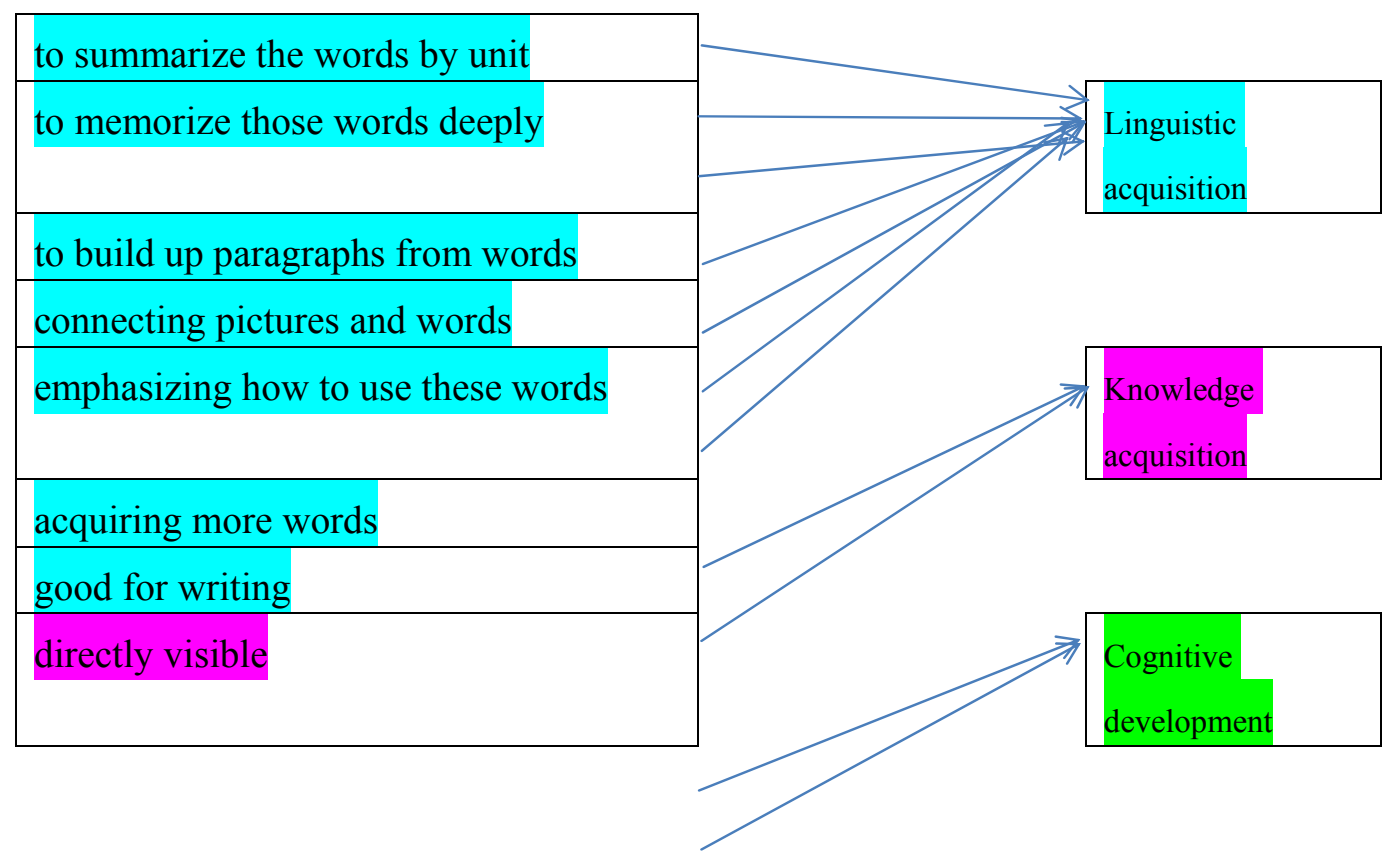




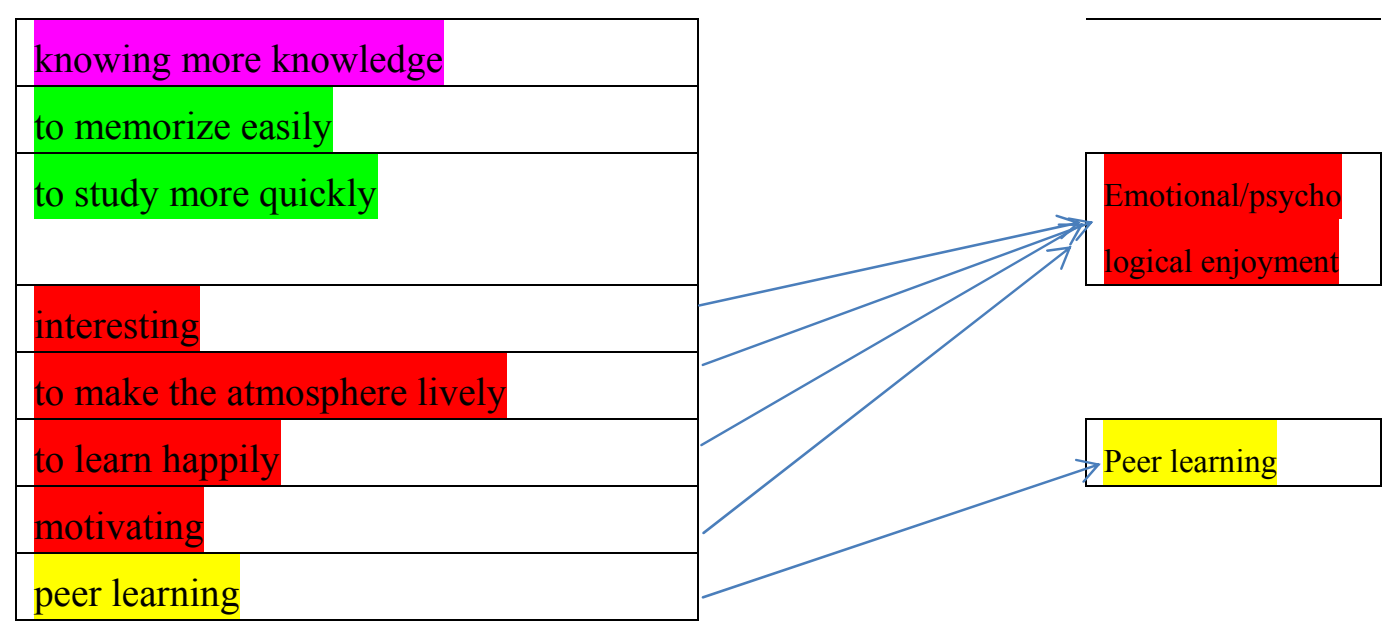

Figure 19. Strength of PWIM reported by the seventh graders

Similarly to the seventh graders, the fourth-graders spoke highly of PWIM because of the interesting pictures, strong connections of pictures and words as an efficient way to manage new words, linkage to their tests, affective enjoyments and strategic development.

When it comes to weaknesses of PWIM, a few of the seventh graders wrote in their questionnaires: noisy classroom without order, hard to hear clearly, think attentively or write down all of the words, more time for teachers to prepare for the class, time consuming as to the reading, spelling and writing down of the upcoming words, extra work for teachers, unorganized handwriting on the PWIM sheets, etc. However, during the interview when asked these weaknesses, student participants stated they would prefer to keep using PWIM by avoiding or improving these weaknesses, as opposed to not using PWIM at all. The fourth graders gave a shorter list of PWIM weaknesses: noisy classroom, too many new words at one time, too many writing examples to think of their owns, and so on, which have been mentioned 
in the section of cognive overload.

The respondents interviewed confessed that they experienced some difficulty in learning and with cognive overload, but they felt they would overcome it. They thought that they can process the information and manage them subsequently, which is seen as normal process learning to them.

All of the interviewees greatly welcomed PWIM and would use PWIM as English learners and English teachers if possible. Some of them mentioned that they had a habit of connecting pictures and words automatically after experiencing PWIM. Some seventh graders even developed a mind-set to seek a picture to consolidate their unit vocabulary autonomously, but they would love to receive some kind of scaffolding or guidance of using pictures from their English teacher.

\title{
Answers to Research Question : Do participants feel PWIM is affecting their
}

\section{English learning? If so, do they consider this a positive effect or negative effect?}

\begin{abstract}
And why?
All seventh grade respondents remembered the PWIM method, as can be seen from their answers to the first question in the survey (see Appendix C \& D). All of the seventh grade participants thought that PWIM had positive influence on their new vocabulary acquisition. Twenty out of 30 respondents thought that PWIM had a greatly positive influence on their new vocabulary acquisition. One interviewee
\end{abstract}


(Wang) compared learning English vocabulary both with PWIM and without, saying, "I used to spend 30 minutes to remember two to three words, which would be easily forgotten; now with PWIM, I can remember 30 to 50 words, which I feel satisfied with". Ten out of 30 respondents thought that PWIM had a slightly positive influence on their new vocabulary acquisition. Many interviewees expressed the idea that there was a positive effect of PWIM on their vocabulary learning, and tests (e.g., cloze and writing). No participants thought PWIM had no influence or negative influence on their new vocabulary acquisition.

All of the respondents in fourth graders remembered the PWIM method. Thirteen out of the 18 participants thought that PWIM had a greatly positive influence on their new vocabulary acquisition. During interviews, they expressed the idea that there was a positive effect of PWIM on their vocabulary learning, categorization exercises and writing, in the interviews. The other five out of 18 respondents thought that PWIM had no influence on their new vocabulary acquisition. However, when I asked the five respondents why they chose no influence, they said that they did not know what influence exactly meant, so they chose no influece as a moderate and neutral answer. After I paraprased "positive influence on their new vocabulary learning as "help them learn new words", all of the five said they would change their answer to "positive influence". 


\section{CHAPTER VI}

\section{INTEGRATED INFERENCE}

In this chapter, I will explain how "the qualitative-quantitative methods inform each other" (Newman et al., p. 192). This chapter is a "conclusion generated through an integration of the inferences" (Tashakkori et al., 2010, p. 45) from the results of both quantitative and qualitative studies. In my research study, the results came from the quasi-experimental study, observations, questionnaires, interviews and my research journals. PWIM was not found to be more effective than the traditional method (以教师为中心、以教科书分析为 基础的语法翻译法), in the 7-week-long quasi-experimental research study in both the fourth grade and seventh grade (what it is). The reasons for such findings may be delineated as follows (why it is so), from the qualitative data.

\section{Time Constraints on PWIM Implementation}

The teachers did not follow the agreement of implementing PWIM for 10 minutes for each class. As mentioned before in Chapter 5, I observed the experimental group in the Grade 411 times during the 13 sessions of PWIM implementation. Ivy should have implemented PWIM for 22 class sessions in the 7-week-long intervention, even with no PWIM in the Unit 3 and school closed because of public holidays (reasons seen Appendix CC). For one observation of the 
class on October 31, there was no PWIM that day, even though I was present to observe. Ivy explained to me after class that she did not have time to use PWIM for the class session. Even when I was present to observe, Ivy could not grant 10 minutes for each PWIM session. PWIM seemed to be the last one in her to-do list, from my consecutive observations. In fact, Ivy used more than 10 minutes once, as detailed in my journal:

Ivy complained about how difficult and stressful it was to implement PWIM in such a short time. For real, Ivy did not use 10 minutes for PWIM twice, and she only spent the last 5 or 6 minutes. Ivy said that each 10 minutes is not enough for students to categorize, summarize or write, so she suggested that she use one whole class session for PWIM as a consolidation or revision class at the end of a unit. I agreed with what she said because it was at her discretion as to whether or not to use PWIM and how to use it. (an excerpt from my dairy, September $16^{\text {th }}, 2013$ )

I observed the experimental group of the seventh graders12 times during the 18 sessions of PWIM implementation. Lily should have implemented PWIM for 33 class sessions in the 7-week-long intervention, even with school closed because of public holidays (reasons seen in Appendix DD). Lily implemented PWIM either at the beginning or at the end of her class for approximately 10 minutes. Lily used more than 10 minutes twice, based on my observational notes.

Neither teacher followed our pre-set schedule, mainly because they did not have enough time. They needed to review for tests, have class sessions for tests, explain tests afterwards, prepare for different level of educational adminstrators to supervise their classes and students' homework. Thus, such directives seemingly explain that why both Ivy and Lily never had time to check the students' outputs of PWIM and give further feedback, why Ivy had some words in advance for the 
brainstorming stage of PWIM, why Ivy gave too many examples in the writing stage, why the interviewees in Ivy's class felt cognitive overload when meeting too many new words at one time, why teachers' handwritings were written in such a hurry that they were out of place and not clear to recognized, and why Lily assigned categorization and writing as after-school homework.

Even when PWIM categorizations and writings were set as after-school

homework, students still did not have time to finish them.

Since some students did not finish the writing part of the PWIM, Lily had to ask them to do in class. Lily came to me and explained that because the mid-term was approaching, and many subject teachers assigned hours of homework, students were less likely to finish time-consuming and optional tasks, such as the PWIM categorization and writing. (field note, October 23, 2013)

\section{Teachers' Resistance}

Closely related to time constraints mentioned above, both Ivy and Lily showed resistance during the PWIM implementation. To be specific, they did not resist PWIM per se, but resisted new methods, risks, and extra work in general. Such resistance mainly stems in their educational experiences before their teaching career. They both were born in the 1980s in Mainland China and they still experienced "teacher-centered textbook-analysis-based Grammar-Translation Method" of English teaching for all of their public school life (Yang, 2000, p. 19; 以教师为中心、以教科 书分析为基础的语法翻译法). Ivy and Lily did not have further education in country and abroad, nor did they have any professional development with respect to 
pedagogical methodologies following their graduation from normal(teachers') universities in China. In other words, the teaching style they received and learned, mostly a teacher-centered style, was the one they were most comfortable using with their English students. The teacher-centered teaching style starts with teacher demonstrations (i.e., reading out a paragraph from a textbook, writing down new word and phrases on a blackboard, and explaining the form and meaning of those new words), followed by student practice (i.e., following the teacher to pronounce those words, taking notes from the blackboard and trying to read the paragraph in chorus) and memorization of the spelling after class (Yang, 2000). This style was still predominant in the two classes I observed.

Such resistance was also related to their prinicipals' attitude and mindset. Ivy and Lily were assigned by their vice-principals at the very beginning of the semester. They had to accept the mission, not only because they were greatly interested in PWIM and expected to gain experiences in this new method for their students, but also because they worked in a top-down hierarchy system. In other words, they did it for their principals, not for their students, or me, or even themselves. Both vice-principals were female. The elementary one was indifferent to this new method. She expected me to be a substitute English teacher because of the English teacher shortage, instead of a researcher and PWIM introducer. The middle school vice-principal was welcoming toward this new method and interested in promoting PWIM in the future. She once met me on campus, then recognized me as a researcher and asked the follow-ups of the PWIM implementation. 
The two teachers reacted the same way as their vice-principals. The elementary teacher Ivy was not open and confident enough to implement PWIM in her classroom. The middle school teacher Lily was a self-starter. She took initiative in preparing for, reflecting on, and discussing PWIM. However, they both asked me many times whether this method was effective or not, and whether the set-aside 10 minutes for PWIM would make the experimental groups fall behind, in terms of teaching content and test scores.

Moreover, there were so many tests in the two schools, such as unit tests, simulated tests, middle-term tests, unified district tests, unified city tests, and unified regional tests, that the two teachers appeared to be "tested out" and they have no recourse for trying out new things. They seemed unlikely to use PWIM in their future teaching, unless on the occasions of teaching observations or public demonstrations. They thought that though it was effective and motivating, but preparing PWIM in class as an extra work load was time consuming, more knowledgeably challenging, and with higher level of class and time management. Such resistance resulting from the factors mentioned above can effectively stagnate the teachers' practitional progression and their profession's onward run into better teaching. 


\section{It is More about How to Use it, not Just What to Use}

As "products" of the same system of English education, Ivy and Lily fell into two different schools. From my observation, Ivy was in the old school, although she was younger and had more recent English learning experiences; Lily was moving to the new school, advocating student-centered style and interactive communications in her class. Such difference was also true in the PWIM implementation, even they both had the identical PWIM workshop training from me.

I wrote about Ivy's class in my research journal:

Ivy actually handed out the module sheets [see Appendices W, X, \& Y ] with words given already during the brainstorming stage, which appeared cheating... I suddenly felt that my PWIM [categorization and writing] was made as another burden to these students, without too much fun. I honestly believed that it is not only what to use, but how to use it. (an excerpt from my research journal on November 4, 2013)

One might then infer from the quotes above that Ivy turned PWIM, a student-centered new-school way, into her own teacher-centered old-school way, because of her mindset. Moreover, from my observations, Ivy criticized students very frequently, in an explicit or implicit way, and the fourth graders were not as excited as the seventh graders during PWIM. Such a class atmosphere could have changed the essential nature of PWIM and even its effectiveness. I can also presume that Ivy would use the same style of teaching in the control group.

On the contrary, Lily was easy-going and active in her English teaching classes, with extrinsic personality,. Lily used explicit encouragement and praises very frequently. She had strategies to draw students' attention and to create a 
competitive but friendly class climate. For sure, Lily practiced an old-school way of teaching, because of the teaching content and test pressures, but Lily had more than that, from my observations and discussions with her. She communicated with students interactively and gave encouraging feedback to those brave respondents. I can also presume that Lily would treat the students in the control group the same as those in the experimental group.

It can be concluded that merely implementing PWIM itself would not make a change in students' English test performances, instead, how to use PWIM and other methods to teach might do so.

\section{PWIM Implemented in a Classroom of Over 55 Students}

I can imagine that Calhoun never considered implementing PWIM in such a crowded classroom with such a large number of students $(n=55-60)$. I had not expected such a big number, either. When I was an elementary school pupil in the same district in 1980s, I had approximately 45 classmates. When I was a middle school student in the same district in 1990s, I had around 50 classmates. I was told by the two English teachers and other teachers in the schools that more students attended urban public schools, because of the mass urbanization in China nowadays, and more resources and higher quality of public schools in downtown area, compared to outskirts, surburban and rural places. 
From my observations and the following interviews, I noticed that students sitting far back away from the pictures could not see the pictures and words clearly. The seventh graders could go to see them after class because the pictures were put on the back blackboard, but the fourth graders did not have acess after class. Moreover, noise from peers kept students from hearing clearly. Even with classroom management, neither teacher was able to grant quiet moments for one specific respondent to make him/herself heard. Thus, students were more likely to be distracted and lost. This factor can be a rationale to any unsuccessful implementation of teaching methods, but it plays a more important role in student-centered activites, such as PWIM. With a PWIM format, a teacher can arrange any individual activity, as well as small-group and large-group activities (Calhoun, 1999). However, her concept of large groups may not be as large as a group of over 55 students.

\section{More Contextual Factors Playing their Roles - Review of the Literature Review}

When I reviewed the chapters one to three to write up the dissertation, I had some reflections about the text and citation as well as quotes. I spontaneously commented on my own draft, to refresh my memory about the first three chapters and to show my personal thumbs-up or thumbs-down. Those comments were mainly on the contextual factors which played an important role in this research study. The 
following Table 9 and 10 show a summary of the reviewed literature and my reactions,

with respect to contextual factors and the use of PWIM.

Table 9

What Literature Says and What I Found/Felt-- Context

\begin{tabular}{|c|c|}
\hline $\begin{array}{l}\text { According to the official rhetoric, } \\
\text { elementary pupils receive two or three } \\
40 \text {-minute English classes per week. } \\
\text { Students in secondary and high schools } \\
\text { have five or six } 45 \text {-minute English lessons } \\
\text { every week (Nunan, 2003, p. } 595 \text { ). }\end{array}$ & $\begin{array}{l}\text { In this research study, the fourth graders received } 4 \\
\text { 40-minute English classes per week and the seventh } \\
\text { graders received } 5 \text { 45-minute English lessons every week. } \\
\text { The English teachers and other major-subject (i.e., } \\
\text { Chinese, math, English) teachers (i.e., Chinese, math, } \\
\text { English) can swap minor-subject (i.e., geography, } \\
\text { physical exercises, etc.) classes for their classes. So the } \\
\text { real English classes are more than outlined in their class } \\
\text { tables. }\end{array}$ \\
\hline $\begin{array}{l}\text { School principals and teachers may feel } \\
\text { uncomfortable and unsafe when they are } \\
\text { informed of change. This feeling occurs } \\
\text { when "change... upsets the pattern" people } \\
\text { are accustomed to, thereby thrusting people } \\
\text { into new perceptions and challenging } \\
\text { people's way of dealing with life (Evans, } \\
\text { 1996, p. 27). }\end{array}$ & $\begin{array}{l}\text { Both vice-principals involved in the study were female. } \\
\text { The elementary one was indifferent to PWIM. The middle } \\
\text { school vice-principal welcomed this new method, with } \\
\text { interest in promoting PWIM in the future. The two } \\
\text { teachers reacted the same way as their vice-principals. } \\
\text { The elementary teacher was not open and confident } \\
\text { enough to implement PWIM in her classroom. She did so } \\
\text { because her vice-principal assigned her. The middle } \\
\text { school teacher took initiative in preparing for, reflecting } \\
\text { on and discussing about PWIM with me. }\end{array}$ \\
\hline $\begin{array}{l}\text { "Docility, passivity, and conformity" are } \\
\text { what education demanded of its students in } \\
\text { this Confucian heritage culture (Yen, 1987, } \\
\text { p. 52). }\end{array}$ & $\begin{array}{l}\text { PWIM was salient to students in the Confucian culture, } \\
\text { because they had a chance to say freely and express their } \\
\text { thoughts and knowledge. }\end{array}$ \\
\hline $\begin{array}{l}\text { The requirement to recruit foreign teachers } \\
\text { in China is increasing. }\end{array}$ & $\begin{array}{l}\text { There were no foreign teachers in the two public schools } \\
\text { in Lianyungang, China, during the research study. }\end{array}$ \\
\hline $\begin{array}{l}\text { One may infer that the "teacher-centered } \\
\text { textbook-analysis-based } \\
\text { Grammar-Translation Method" (Yang, } \\
\text { 2000, p. 19) was still predominant in } \\
\text { English learning in China. One may also } \\
\text { conclude that English instruction has yet } \\
\text { not changed with respect to using the new } \\
\text { textbooks effectively. }\end{array}$ & $\begin{array}{l}\text { This is true in the research study. The ELT was still } \\
\text { predominant with traditional methods, regardless of } \\
\text { updated textbooks. Such is a case of using new bottle with } \\
\text { old wine. }\end{array}$ \\
\hline $\begin{array}{l}\text { There are few training programs with } \\
\text { regard to pedagogical methodologies. Nor } \\
\text { are there experts to resort to. }\end{array}$ & $\begin{array}{l}\text { For my stay of the four months, English teachers did not } \\
\text { have any academic or pedagogical workshops to have } \\
\text { access to new student-centered teaching approaches. They } \\
\text { had peer contests or demonstrations, but could not get } \\
\text { constructive feedback from those competitions. }\end{array}$ \\
\hline
\end{tabular}


Table 10

What Literature Says and What I Found/Felt-Use of PWIM

\begin{tabular}{|c|c|}
\hline $\begin{array}{l}\text { The teacher puts these words on large } \\
\text { vocabulary cards and gives each student a } \\
\text { set of smaller cards with the same words } \\
\text { on them (Joyce et al., 2009) }\end{array}$ & $\begin{array}{l}\text { In the research study, two English } \\
\text { teachers disagreed with what the authors } \\
\text { suggest here. The two Chinese English } \\
\text { teachers thought that giving cards to } \\
\text { students may result in garbage in } \\
\text { classrooms and disorder in terms of class } \\
\text { discipline, so they wanted students to } \\
\text { write on given papers with modules. }\end{array}$ \\
\hline $\begin{array}{l}\text { The teacher writes each identified word } \\
\text { on chart paper outside the picture and } \\
\text { draws a line from the word to the item in } \\
\text { the picture, essentially creating a } \\
\text { picture-word dictionary which the } \\
\text { students can employ to connect words } \\
\text { with corresponding pictures. Joyce and } \\
\text { Weil claim this kind of connection as } \\
\text { contributing to developing new ideas and } \\
\text { learning vocabulary. }\end{array}$ & $\begin{array}{l}\text { It is true in Xuan's research study, from } \\
\text { Xuan's observations and student } \\
\text { interviews. }\end{array}$ \\
\hline $\begin{array}{l}\text { In other words, pictures are used for } \\
\text { simple matching or labeling. Pictures, at } \\
\text { least seen from the textbooks as an } \\
\text { example, serve as merely background. } \\
\text { There is no induction or scaffolding for } \\
\text { writing in those tasks. }\end{array}$ & $\begin{array}{l}\text { This was true from students' answers in } \\
\text { interviews. They seldom paid attention to } \\
\text { the textbook pictures when they were } \\
\text { taught. They occasionally noticed } \\
\text { pictures in their reading exercises, which } \\
\text { may serve as a context or background. }\end{array}$ \\
\hline $\begin{array}{l}\text { Someone may argue that making stories } \\
\text { is beyond the capability of fourth } \\
\text { graders ... However, such may not be } \\
\text { true of the seventh graders ... }\end{array}$ & $\begin{array}{l}\text { NO story-telling in the research study. } \\
\text { Because English teachers and some } \\
\text { English learners just believed that telling } \\
\text { stories was loosely relevant to English } \\
\text { learning, and wasted their in-class time. }\end{array}$ \\
\hline $\begin{array}{l}\text { One of CLT contributions is to inform } \\
\text { English teachers how to calibrate an } \\
\text { appropriate amount of new information } \\
\text { which they may give to English learners } \\
\text { at one time, due to the limited capacity of } \\
\text { students' WM. }\end{array}$ & $\begin{array}{l}\text { Comparing the fourth grade English } \\
\text { teaching and the seventh grade English } \\
\text { teaching, I inferred that one PWIM cycle } \\
\text { in less available time for fourth graders } \\
\text { was more likely to exert cognitive } \\
\text { overload to English learners. }\end{array}$ \\
\hline $\begin{array}{l}\text {...the extra images (in PWIM) may be } \\
\text { redundant to English language learners. }\end{array}$ & $\begin{array}{l}\text { In reality, the redundancy effect took } \\
\text { place because of repeated words and too } \\
\text { many writing examples. }\end{array}$ \\
\hline
\end{tabular}


In a conclusion, this chapter used qualitative findings to explain the result of the quantitative data, from four aspects: time constraints on PWIM implementation, teachers' resistance, how to use PWIM and PWIM implemented in a classroom over 55 students. Such contextual factors should be accounted for the results that there were no significant differences of the effects of the PWIM between the experimental and control groups in both grade levels, and there were no differential effects of PWIM on vocabulary acqusition, based on grade levels. 


\section{CHAPTER VII}

\section{SUMMARY AND CONCLUSION}

This concluding chapter will start with summaries of this mixed methods study, then move to its limitations and afterwards share some thoughts for future research studies.

\section{Summary of the Research Study}

I used the framework of CLT in this study to evaluate the effectiveness of using PWIM to teach fourth-graders and seventh-graders English vocabulary. Specifically, this research involved the investigation of the following research questions:

(a) What are the effects of the PWIM on vocabulary acquisition? Are there differential effects of PWIM on vocabulary acquisition based on grade level?

(b) In what instances do participants feel cognitively overloaded when they are in the practice stage using PWIM?

(c) What are student participants' perceptions of PWIM as to its strengths and weaknesses?

(d) Do participants feel PWIM is affecting their English learning? If so, do they consider this a positive effect or negative effect? And why? 
For the first research question, this research study did not show varying degrees of effectiveness regarding implementation of PWIM in terms of grade level. Thus, quantitative pre- and posttest data did not provide evidence of PWIM being more effective than traditional methods.

With respect to the second research question, several participants reported cognitive overload (e.g., too many words at one time-intrinsic cognitive overload, displaced writing of novel words - extraneous cognitive overload) and the redundancy effect (e.g., words mentioned many times during the three cycles of implementing PWIM) occurred during the implementation of PWIM, both of which impeded their meaningful learning to some extent. However, more participants believed that it was a normal learning process with cognitive overload and redundancies, so they did not admit such as overwhelming moments. As a Chinese speaker, born and raised in Mainland China for decades, I realized that admitting cognive overload has negative associations or connections in Chinese culture. For one thing, admitting failure to do something is losing face, not saving face; for another thing, admitting cognive overload refers to cognitive incompetence and less intelligence.

In terms of strengths and weaknesses of PWIM, participants listed many PWIM strengths (e.g., interesting, motivating, connecting words with pictures, memorizing those words deeply and easily, building up paragraphs from words, etc. ) and a few PWIM weaknesses (e.g., noise, too many word at one time, unclear 
handwriting, mismatches between words and pictures, etc.). Its strengths greatly outnumbered its weaknesses.

All of the participants considered PWIM to have a positive effect on their English learning, because they found the positive change with PWIM in their English language learning (e.g., writing, cloze, vocabulary). Moreover, PWIM was greatly welcomed and liked by the fourth and seventh graders in the experimental group. It could draw students' attention and interest and engage students, connect to their old knowledge and boost peer learning. PWIM was salient to students, because they had a chance to speak freely and express their thoughts and knowledge. There was a climate of competition from peers, based on the complexity of their known words and phrases, as well as their writing. Peer learning happened among both fourth and seventh graders, but more among seventh graders. Such findings are connected to the fact that many of the seventh graders in that middle school have years of after-school English training experiences. Thus there was a vocabulary gap among them. With extra-curricular and beyond-textbook vocabulary, those competent students would grasp PWIM as their show time (i.e., chance to demonstrate their competence and larger vocabulary). The other students would love to learn from them to enrich their vocabulary. Moreover, they were more likely to be autonomous in learning new words actively by looking up dictionaries, using online translation software, or asking peers or their English teachers after class. Hence, the findings of the qualitative data may contribute to the perceptions of PWIM in this particular EFL context. 
Seen from the four answers above, the discrepancy existed between qualitative and quantitative data. Quantitatively, PWIM was no more effective than traditional English teaching methods; however, qualitatively, PWIM was greatly welcomed, had many more strengths than weakness, and exerted a positive effect on the students' vocabulary learning. That is to say, what I discovered is not only "what it is", but that the degree to which PWIM seemed to work and that the application of PWIM has the potential to be evaluated on its own, notwithstanding teacher implementation. It should be also noted from the participants' responses that the circumstances when they had cognitive overload could partly explain the quantitative result.

In terms of theoretical contributions, this research study may add some thoughts to Cowan's (2001) word amount to be processed at one time in the working memory, from EFL learners' perspectives rather than native English speakers'. This study also added more examples of cognitive overload, in particular extraneous cognitive overload in the field of English language learning, to the existing CLT literature.

As a bonus, using PWIM also transformed the two English teachers from being close towards being more open to new teaching method, from my observation field notes. They were more ready to transform their ways of teaching along the continuum from old school to new school. They also had a deeper concept of participating in educational research studies. 


\section{Limitations}

Aside from findings of this research study, there are listed but not limited five main limitations which need to take into consideration.

Firstly, there are no reliability or validity coefficients for the the pretests and posttests. They were not specially designed tests; instead, they were simulated mid-term tests chosen by the two English teachers at the beginning of the semester, from their available exercise book (see Appendices $\mathrm{N} \& \mathrm{O}$ ). I did not have the right to choose or design tests based on incoming words from the PWIM intervention in both grade levels, which followed Torcasic and Sweller's (2010) design. In other words, the pre- and post-assessments may not be effective in testing the differences of having PWIM or not, thus with high possibility of losing content validity. I did not have a chance to have a postponed posttest to see the differences between the immediate posttest and prolonged posttest, either, because the immediate posttests were arranged sharply before their mid-term exam, and students may have been over-anxious about or careless about the posttests.

Secondly, the time for PWIM implementation was not as long as I expected and compromised with the two teachers. It should have been 10 minutes for each class session. There should have been three PWIM cycles of 22 sessions for the fourth-graders and three PWIM cycles of 33 sessions for the seventh graders (see Appendices CC \& DD). However, the fourth graders only had 13 sessions and the seventh graders had 22 PWIM sessions. Even for the PWIM sessions, the time 
period did not last for 10 minutes. At the end of this quasi-experimental study, when it was approaching the mid-term exam, two teachers had less time to use PWIM in class, so they presented the material so intensively that many students could not catch up. In other words, the two English teachers did not implement PWIM regularly and even for each unit and each class session.

Additionally, there was no protocol for PWIM for students in secondary schools. Calhoun (1999), as PWIM founder, suggested that PWIM with modification can be used for older language beginners, though she didn't state how. In the current study, I trained two English teachers (one from an elementary school and one from a secondary school), and gave them the 10 steps of PWIM practice in a classroom (Calhoun, 1999, p.43), videos of PWIM demonstrations copied from YouTube and an implementation log (Calhoun, 1999, p.23) instead of the protocol. Fourthly, based on the educational, cultural and practitional context in the two schools, there were some modifications of PWIM implementations from Calhoun's original version of PWIM (see Tables 5 and 6 in Chapter 5). The question here is whether the modified PWIM was effective or not. Moreover, PWIM was used in a crowded classroom with over 55 students, not individually or in small groups. The class size in this research study was larger than many those of previous research, so the effectiveness of using PWIM to teach Chinese students English vocabulary may be reflected in the findings. The classes were so large that the experimental intervention PWIM may not have had an effect. Those contextual factors may influence the effectiveness of PWIM, which is yet unknown. 
Fifthly, I should have some fourth-graders and seventh-graders answer the questionnaire before I gave the survey to all of my participants, in order to determine whether the written language was comprehensible to them or not. I had done translation and back-translation with a Chinese English adult learner with advanced proficiency in both languages. However, I should have repeated this procedure with some students in the population. Five fourth-graders chose the option "no influence" in the survey, because they did not understand the meaning of "influence." As a Chinese speaker, I came to realize that the reason they chose no influence lay in the negative connotation of "influence" in the Chinese language. For instance, in China, a teacher may ask a middle school student who was found to date someone, " Do you think that such a premature date will influence your study?" In this context, “influence" means "interfere, hinder, or debilitate." Another case may be in a quiet zone as a library, where A has to answer a call but after A ends the call, he/she would ask someone sitting next to him/her, “ Did I influence you or not?” Thus it can be seen that the word influence has negative connotations in Chinese language. If I had changed the options into "greatly help...", "slightly help...", " nothing to do with...", "slightly hold back...", and "greatly hold back...", such use of words would have given the fourth-grade respondents an easier time. 


\section{Thoughts for Future Research}

This research study spanned a 3-month period, so the data only reflected such a time period. The quasi-experimental aspect of the study was conducted through a pretest- intervention-posttest process; thus, the experimental group had PWIM all the time and the control group did not have any PWIM at all in their English classes. Future research may let both groups have a period of PWIM and no PWIM, so in the questionnaires students can show their preferences to (not) having PWIM in their English language learning (see Figure 20).

\begin{tabular}{|c|l|}
\hline Grade $4(\mathrm{E})$ & PWIM \\
\hline Grade $4(\mathrm{C})$ & Traditional \\
\hline Grade 7 (E) & PWIM \\
\hline Grade 7 (C) & Traditional \\
\hline
\end{tabular}

\begin{tabular}{|l|l|l|}
\hline Grade X (1) & PWIM & Traditional \\
\hline Grade X (2) & Traditional & PWIM \\
\hline Grade Y (1) & PWIM & Traditional \\
\hline Grade Y (2) & Traditional & PWIM \\
\hline
\end{tabular}

Figure20. Recent groups distribution and future groups distribution. $\mathrm{E}=$ Experiment group; $\mathrm{C}=$ Control group; $\mathrm{X}, \mathrm{Y}=$ different grade levels.

For the current study, I only observed the experimental group who had PWIM. Even for the two experimental groups in Grade 4 and 7, I did not observe all of the PWIM sessions, because of the schedule conflict. For the further research study, it would be better to observe both the experimental and control groups, to see whether the classes have the same instructional conditions, the teachers have the same teaching style and the students in two groups play the similar roles in 
teacher-student interactive communications. In that way, it may be further inferred which matters more, using the intervention or how to use the intervention?

In the current study, I interviewed students only instead of involved classroom teachers, in order to meet students' needs and know students' opinions about PWIM. For the future research studies about PWIM, both students and teachers should be interviewed, for the sake of the information from the other side in the two-way classroom interactions. As well, data from interviews with teachers, who are educational practitioners facing students every day, may reveal teachers' professional openness and personal dispositions toward new instructional methods, both of which might influence the effectiveness of the intervention. Teachers' voice from bottom up would be noticed and considered by educational policy makers.

As to the theoretical framework, only CLT was used in the current study. For future research, other relevant theories or concepts (e.g., dual coding theory) may be chosen and used to examine PWIM.

Because of the contextual constraints and time restraints, the quantitative data did not support my research hypothesis that the effectiveness of PWIM varies according to different grade levels. In the future, I would require a longer time for the intervention, tests proven with strong validity and reliablity estimates of the intervention, and regular intervention sessions to test the hypothesis. In addition, the collected quantitative data was to confirm or falsify my research hypothesis, so I did not use the three levels of word knowledge (Armbruster et al., 2003, p. 43) to 
examine the students' advancement from unknown to acquainted levels, from unknow to established levels, or from acquainted to established levels. In the future study or future research manuscript, I would analyze quantitative date to study the signficant differences of these advancements my participants made.

In the current study, qualitative data were collected from 18 fourth graders and 30 seventh graders, to answer the three research questions. The 18 fourth graders did not give much information as the 30 seventh grader did in all. Each of them did not give as much information as the seventh graders, either. One of the reasons might lie in the developmental differences between the age of nine and 12 , specifically, the ability of judging, evaluating and critiquing. The other reason was the fourth graders were pulled out to be interviewed as a cluster of three to five, based on the headteacher's request, thus they were easily distracted by their peers at the time of interviews, and the seventh graders were pulled out and interviewed individually.

My last concluding thought is for researchers planning to do educational research studies in Mainland China. They need to be aware of the hierarchical system in public schools (principals at the top and students at the bottom), teachers' discretions (dos and don'ts) and dispositions to new instructional methods and research studies, numerous tests of every subject matter, class schedules subject to be changed frequently, and more importantly, participants' misunderstanding or lack of understanding of educational research studies. I am a native Chinese speaker and was born and raised in that city, but I still needed to adjust to fit in the local school 
culture. Even this thought can not be generalized to all parts of China, but it is still worthy of considering for future researchers. 


\section{REFERENCES}

Armbruster, B.B., Lehr, F., \& Osborn, J. (2003). Put reading first: The research building blocks for teaching children to read kindergarten through grade 3. Jessup, MD: National Institute for Literacy.

Astorga, M. C. (1999). The text-image interaction and second language learning. The Australian Journal of Language and Literacy, 22(3), 212-233.

Atkinson, R. C., \& Shiffrin, R. M. (1968). Human memory: A proposed system. In K. W. Spence \& J. T. Spence (Eds.), The psychology of learning and motivation: Advances in research and theory, (Vol. 2, pp. 89-195). New York: Academic Press.

Bazeley, P. (2004). Issues in mixing qualitative and quantitative approaches to research. In R. Buber, J. Gadner \& L. Richards (Eds.), Applying qualitative methods to marketing management research (pp. 141-156). UK: Palgrave Macmillan.

Beckmann, J. F. (2010). Taming a beast of burden--on some issues with the conceptualization and operationalization of cognitive load. Learning and Instruction, 20(3), 250-64.

Brunken, R., Seufert, T., \& Paas, F. (2010). Measuring cognitive load In J. L. Plass, R. Moreno, \& R. Brunken (Eds.), Cognitive load theory (pp. 181-202). New York, NY: Cambridge University Press.

Calhoun, E. (1999). Teaching beginning reading and writing with the picture word inductive model. Alexandria, VA: Association for Supervision and Curriculum Development.

Chandler, P., \& Sweller, J. (1991). Cognitive load theory and the format of instruction. Cognition and Instruction, 8, 293-332.

Chandler, P., \& Sweller, J. (1996). Cognitive load while learning to use a computer program. Applied Cognitive Psychology, 10, 151-170.

Chinese Ministry of Education. (2001). National curriculum English standards for nine year compulsory education and senior high schools. Beijing, China: Beijing Normal University Press.

City feature: Lianyungang, Jiangsu province. (n.d.). Retrieved from http://www.iesingapore.gov.sg/wps/portal/WCMPreview?WCM_GLOBAL_C ONTEXT=/wps/wcm/connect/ie/My Portal/Market Guide/Market Information/North Asia/China/News/City Feature Lianyungang Jiangsu province 
Clay, M. M. (2001). Change over time in children's literacy development. Auckland, New Zealand: Heinemann Education.

Collins, K. M. T., Onwuegbuzie, A. J., \& Jiao, Q. G. (2007). A mixed methods investigation of mixed methods sampling designs in social and health science research. Journal of Mixed Methods Research, 1, 267-294.

Cowan, N. (2001). The magical number 4 in short-term memory: A reconsideration of mental storage capacity. Behavioral and Brain Sciences, 24(1), 87-185

Craig, S., Gholson, B., \& Driscoll, D. (2002). Animated pedagogical agents in multimedia educational environments: effects of agent properties, picture features, and redundancy. Journal of Educational Psychology, 94, 428-434.

Crystal, D. (2008). Two thousand million? English Today,24(1), 3-6. doi: http://dx.doi.org/10.1017/S0266078408000023

Dawson, C . (2001). English 7A. (2 ed.). Nanjing, China: Writing group of English, Oxford University Press (China) limited.

de Jong, T. (2010). Cognitive load theory, educational research, and instructional design: some food for thought. Instructional Science, 38(2), 105-34.

Denzin, N. K., \& Lincoln, Y. S. (2000). The discipline and practice of qualitative research. In N. K. Denzin \& Y. S. Lincoln (Eds.), Handbook of qualitative research (2nd ed., pp. 1-28). Thousand Oaks, CA: Sage.

Diao, Y., Chandler, P., \& Sweller, J. (2007). The effect of written text on comprehension of spoken English as a foreign language. American Journal of Psychology, 120, 237-261.

Diao, Y., \& Sweller, J. (2007). Redundancy in foreign language reading comprehension instruction: Concurrent written and spoken presentations. Learning and Instruction, 17, 78-88.

Evans, R. (1996). The human side of school change: Reform, resistance, and the real-life problems of innovation. San Francisco, CA: Jossey-Bass.

Feldon, D. F. (2010). Why magic bullets don't work. Change, 42(2), 15-21.

Feng, C. (2011). The cooperative classroom: Scaffolding EFL elementary learners' English literacies through the picture word inductive model - the journey of three teachers in Taiwan (Doctoral dissertation). Retrieved from https://tspace.library.utoronto.ca/handle/1807/27578

Flyvbjerg, B. (2001). Case study. In N. Denzin \& Y. Lincoln (Eds.), The sage handbook of qualitative research (4 ed., pp. 301-316). Thousand Oaks, CA: Sage. 
Fredericks, T., Choi, S., Hart, J., Butt, S., \& Mital, A. (2005). An investigation of myocardial aerobic capacity as a measure of both physical and cognitive workloads. International Journal of Industrial Ergonomics, 35(12), 1097-1107.

Galbraith, J. K., \& Lu, J. (2000). Sustainable development and the Open-Door policy in China. Paper prepared for the Council on Foreign Relations, May 5, 2000.

Gao, L. (2012). Examining argumentative coherence in essays by undergraduate students of English as a foreign language in Mainland China and their English speaking peers in the United States (Doctoral dissertation). Retrieved from http://digitalcommons.fiu.edu/dissertations/AAI3517010

Hanson, W. E., Creswell, J. W., Plano Clark, V. L., Petska, K. S., \& Creswell, J. D. (2005). Mixed methods research designs in counseling psychology. Journal of counseling psychology, 52, 224-235.

He, D., \& Zhang, Q. (2010). Native speaker norms and china English: from the perspective of learners and teachers in china. TESOL Quarterly, 44(4), 769-789. Retrieved from http://onlinelibrary.wiley.com/doi/10.5054/tq.2010.235995/pdf

Hitchcock, J. H., \& Newman, I. (2013). Applying an interactive quantitative-qualitative framework: How identifying common intent can enhance inquiry. Human Resource Development Review, 12(1), 36-52. doi:http://dx.doi.org/10.1177/1534484312462127

Hu, G. (2002). Potential cultural resistance to pedagogical imports: The case of communicative language teaching in China, Language, Culture and Curriculum, 15(2), 93-105.

Janssen, J., Kirshner, F., Erkens, G., Kirschner, P. A., \& Paas, F. (2010). Making the black box of collaborative learning transparent: combining process-oriented and cognitive load theory. Education Psychological Review, 22, 139-154.

Jiang, X. (2011). Challenges for college-level learners of academic English writing in China. In M. S. Plakhotnik, S. M. Nielsen, \& D. M. Pane (Eds.), Proceedings of the Tenth Annual College of Education \& GSN Research Conference (pp. 95-100). Miami: Florida International University. http://coeweb.fiu.edu/research_conference/

Jiangsu top 8 make great performances. (2011, April 4). Retrieved from http://mykomec.blogspot.com/2011/04/jiangsu-top-8-make-great-performances $\underline{. h t m l}$

Johnson, R. B., \& Onwuegbuzie, A. J. (2004). Mixed methods research: A research paradigm whose time has come. Educational Researchers, 33(7), 14-26. 
Joyce, B., Calhoun, E., \& Hopkins, D. (2002). Models of learning: Tools for teaching (2nd ed.). Philadelphia, PA: Open University Press.

Joyce, B., \& Showers, B. (2002). Student achievement through staff development. Alexandria, VA: Association for Supervision and Curriculum Development.

Joyce, B., \& Weil, M. (2004). The picture-word inductive model: Developing literacy across the curriculum. In B. Joyce \& M. Weil (Eds.), Models of teaching $\left(7^{\text {th }}\right.$ ed.). Boston, MA: Pearson Education.

Joyce, B., Weil, M., \& Calhoun, E. (2004). Models of teaching ( $7^{\text {th }}$ ed.). Boston, MA: Allyn \& Bacon.

Joyce, B., Weil, M., \& Calhoun, E. (2009). Models of teaching ( $8^{\text {th }}$ ed.). Boston, MA: Pearson Education.

Kalyuga, S., Chandler, P., \& Sweller, J. (1999). Managing split-attention and redundancy in multimedia instruction. Applied Cognitive Psychology, 13, 351-371.

Maley, A. (1990). "Xanada - a miracle of rare device": The teaching of English in China. In Y. F. Dzau (Ed.), English in China (pp. 95-105). Hong Kong, China: API Press.

Mayer, R., Bove, W., Bryman, A., Mars, R., \& Tapangco, L. (1996). When less is more: meaningful learning from visual and verbal summaries of science textbook lessons. Journal of Educational Psychology, 88, 64-73.

Mayer, R., Heiser, H., \& Lonn, S. (2001). Cognitive constraints on multimedia learning: when presenting more material results in less understanding. Journal of Educational Psychology, 93, 187-198.

Mayer, R., \& Moreno, R. (2010). Techniques that reduce extraneous cognitive load and manage intrinsic cognitive load during multimedia learning. In J. L. Plass, R. Moreno, \& R. Brunken (Eds.), Cognitive load theory (pp. 131-152). New York, NY: Cambridge University Press.

Merriam, S. B. (1998). Qualitative research and case study applications in education. San Francisco, CA: Jossey-Bass.

Merriam, S. B. (2009). Qualitative research: A guide to design and implementation. San Francisco, CA: Jossey-Bass.

Miller, G. A. (1956). The magical number seven, plus or minus two: Some limits on our capacity for processing information. The Psychological Review, 63, 81-97.

Morgan, K. (2013, January 9). Why designing experiments is so hard for students \& what we can do to help!. Retrieved from http://kellymorganscience.com/why-designing-experiments-is-so-hard-for-stud 
ents-what-we-can-do-to-help/

Newbridge man's English teaching adventure in China. (2010, August 6). Retrieved from

http://www.kildare.ie/community/notices/community/newbridge mans_englis h teachin.asp

Newman, I., \& Hitchcock, J. H. (2011). Underlying agreements between quantitative and qualitative research: The short and tall of it all. Human Resource Development Review, 10(4), 381-398. doi:http://dx.doi.org/10.1177/1534484311413867

Newman, I., Newman, D., \& Newman, C. (2011). Writing research articles using mixed methods: Methodological considerations to help you get published. In T. S. Rocco \& T. Hatcher (Eds.), The handbook of scholarly writing and publishing (pp. 191-208). San Francisco, CA: Jossey-Bass.

Niu-Cooper, R. (2012). Unexpected Realities: Lessons from China's new English textbook implementation. International Journal of Education Policy and Leadership, 7(2). Retrieved from www.ijepl.org.

NSTES. (2001). The national standards for teaching English subject. Issued by the National Academy of Education in China. Printed by Beijing Normal University Press.

Nunan, D. (2003). The impact of English as a global language on educational policies and practices in the Asia-Pacific region. TESOL Quarterly, 37(4), 589-613. Retrieved from www.greenstone.org/greenstone3/sites/nzdl/collect/literatu/.../doc.pdf

Onwuegbuzie, A. J., Johnson, R. B., \& Collins, K. M. T. (2010). A framework for assessing legitimation in mixed research: Implications for the field of stress and coping In K. Collins, A. Onwuegbuzie \& Q. Jiao (Eds.), Toward a broader understanding of stress and coping: Mixed methods approaches (pp. 3-30). Charlotte, NC: Information Age.

Paas, F., Renkl, A., \& Sweller, J. (2003). Cognitive load theory and instructional design: Recent developments. Education Psychologist, 38(1), 1-4. Retrieved from http://cis.msjc.edu/evoc/637/References/Pass-CognitiveLoadTheoryAndID.pd $\underline{f}$

Paas, F., \& van Merrienboer, J. (1993). The efficiency of instructional conditions: an approach to combine mental-effort and performance measures. Human Factors, 35(4), 737-743.

Peterson, L., \& Peterson, M. (1959). Short-term retention of individual verbal items. Journal of Experimental Psychology, 58, 193-198. 
Plass, J., Chun, D., Mayer, R., \& Leutner, D. (2003). Cognitive load in reading a foreign language text with multimedia aids and the influence of verbal and spatial abilities. Computers in Human Behavior, 19, 221-243.

Qi, X., \& He, F. (2004). Fun with English 4A. (2nd ed.). Nanjing, China: Writing group of English and Oxford University Press.

Scollon, S. (1999). Not to waste words or students: Confucian and Socratic discourse in the tertiary classroom. In E. Hinkel (Ed.), Culture in second language teaching and learning (pp. 13-27). Cambridge, U.K.: Cambridge University Press.

Shor, I., \& Freire, P. (1987). A pedagogy for liberation: Dialogues on transforming education. South Hadley, MA: Bergin \& Garvey.

Skinner, B. F. (1968). The technology of teaching. New York, NY: Appleton Century-Crofts.

Stake, R. E. (2005). Qualitative case studies. In N. Denzin \& Y. Lincoln (Eds.), The Sage handbook of qualitative research (3rd ed., pp. 443-466). Thousand Oaks, CA: Sage

Swartzendruber, K. (2007). The picture word inductive model and vocabulary acquisition. Proceedings of the 3rd Annual GRASP Symposium (pp. 177-178). Wichita, KS: Wichita State University. Retrieved from http://soar.wichita.edu/dspace/bitstream/handle/10057/850/grasp\%20178.pdf ?sequence $=1$

Sweller, J. (1988). Cognitive load during problem solving: Effects on learning. Cognitive Science, 12, 257-285.

Sweller, J. (2004). Instructional design consequences of an analogy between evolution by natural selection and human cognitive architecture. Instructional Science: An International Journal of Learning and Cognition, 32(1-2), 9-31.

Sweller, J. (2005). The redundancy principle in multimedia learning. In R.E. Mayer (Ed.), Cambridge handbook of multimedia learning (pp. 159-167). Cambridge, UK: Cambridge University Press.

Sweller, J. (2010). Cognitive load theory: recent theoretical advances. In J. L. Plass, R. Moreno, \& R. Brunken (Eds.), Cognitive load theory (pp. 29-47). New York, NY: Cambridge University Press.

Sweller, J., \& Chandler, P. (1994). Why some material is difficult to learn. Cognition and Instruction, 12(3), 185-233.

Tang, P. C.L. (1997). On the special logic thesis in Chinese philosophy. Metaphilosophy, 28, 371-384. doi: 10.1111/1467-9973.00066 
Tashakkori, A., Brown, L. M., \& Borghese, P. (2010). Integrated methods for studying a systemic conceptualization of stress and coping. In K. Collins, A. Onwuegbuzie \& Q. Jiao (Eds.), Toward a broader understanding of stress and coping mixed methods approaches (pp. 31-58). Charlotte, NC:

Information Age.

Tashakkori, A., \& Teddlie, C. (2008). Quality of inferences in mixed methods research. In M. Bergman (Ed.), Advances in mixed methods research (pp. 101-119). London: Sage.

The Gale Group. (2013). Information processing theory. Retrieved from http://www.education.com/reference/article/information-processing-theory/

The world factbook. (n.d.). Retrieved from https://www.cia.gov/library/publications/the-world-factbook/geos/ch.htm

Tonette S. R., \& Hatcher, T. (Ed.). (2011). The handbook of scholarly writing and publishing. San Francisco, CA: Jossey Bass.

Top 10 things to do during Chinese spring festival. (n.d.). Retrieved from http://traditions.cultural-china.com/en/14Traditions11819.html

Torcasio, S., \& Sweller, J. (2010). The use of illustration when learning to read: a cognitive load theory approach. Applied cognitive psychology, 24, 659-672.

von Glasersfeld, E. (1987). Learning as constructive activity. In C. Janvier (Ed.), Problems of representation in the teaching and learning of mathematics (pp. 3-17). Hillsdale, NJ: Lawrence Erlbaum.

Wang, J., Lin, E., \& Spalding, E. (2008). Learning effective instructional strategies in a workshop context: lessons about conceptual change from Chinese English teachers. International Journal of Teacher Leadership, 1(1), 1-22. Retrieved from http://www.csupomona.edu/ijtl

Wang, P. (1998). Shilun yingxiang dangqian daxue yingyu jiaoxue de feizhengchang qingxiang [On the abnormal tendencies in influencing the current college English teaching]. Waiyu Yu Waiyu Jiaoxue [Foreign Language and Foreign Language Teaching], (5), 29-30.

Wang, Y. J., \& Robertson, M. (2004). The influence of china's entry into the WTO on foreign language education in china. Australian Association for Research in Education Conference 2004, Melbourne, Australia. Retrieved from http://publications.aare.edu.au/04pap/rob04729.pdf

Wong, A. C. (2009). The influence of picture word inductive model on kindergarten students'development of literacy skills (Unpublished master's thesis). Ontario Institute for Studies in Education of the University of Toronto, Toronto, Canada. 
Yang, Y. (2000). History of English education in china (1919-1998). Retrieved from http://www.eric.ed.gov/PDFS/ED441347.pdf

Yen, R. T. (1987). Foreign language teaching in China: Problems and perspectives. Canadian and International Education. 6(1), 48-61

Yu, M. C. (2008). Teaching and learning sociolinguistics skills in University EFL classes in Taiwan. TESOL Quarterly, 42, 31-52.

Zhang, X. Q., \& Daun, H. (2010). The reform of Chinese college English teaching (CCET) in the context of globalization. In J. Zajda \& M. Geo-JaJa (Eds.), The politics of education reforms (pp. 165-181). New York, NY: Springer. 


\title{
APPENDICES
}

\author{
Appendix A
}

Table Cognitive load effects

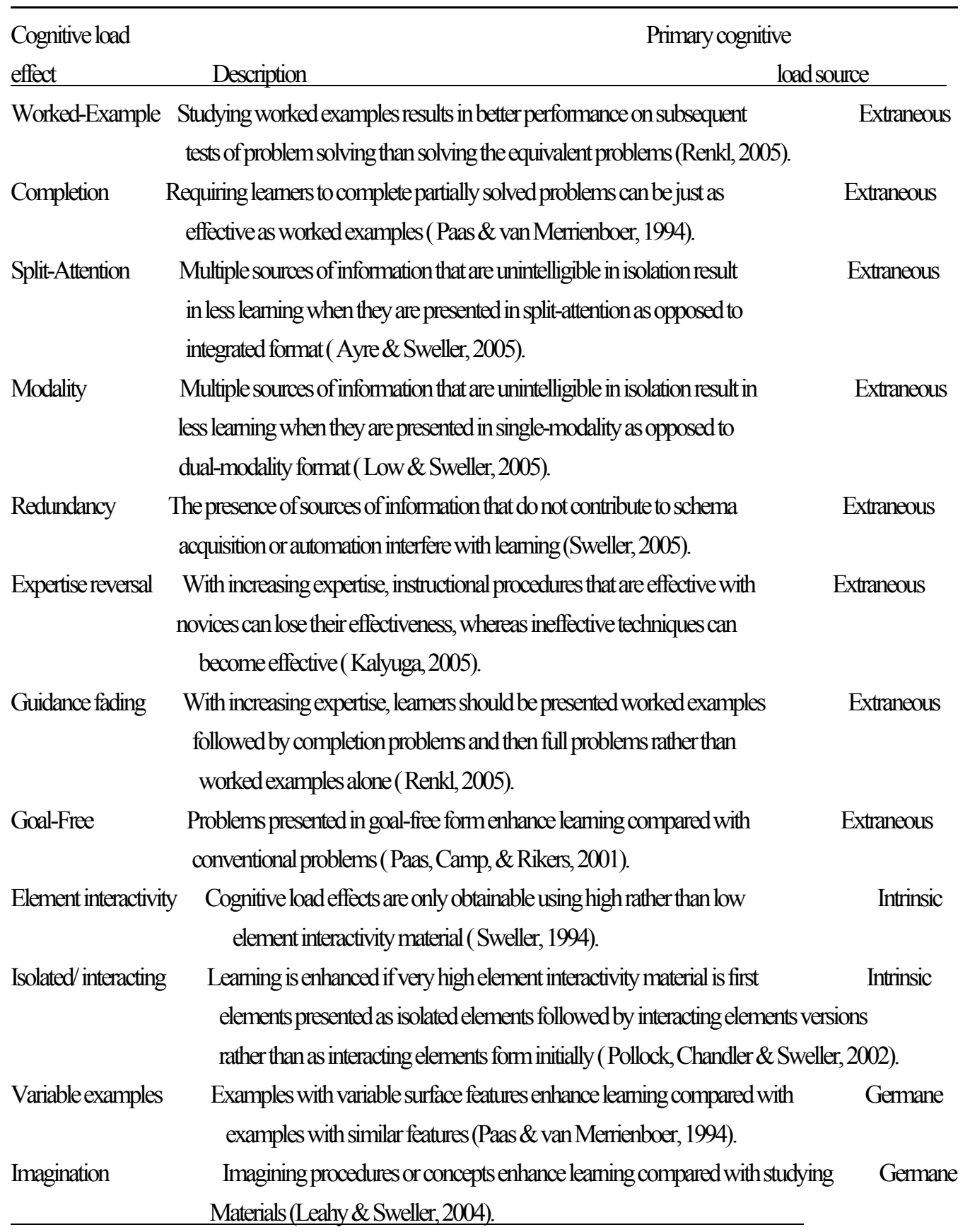

From “Cognitive load theory: recent theoretical advances" by Sweller, 2010, p. 30. In J. L. Plass, R. Moreno, \& R. Brunken(Eds.), Cognitive load theory (pp. 29-47). Copyright 2010 Cambridge University Press. 
Appendix B

Table Classification of cognitive load measures

\begin{tabular}{|c|c|c|c|}
\hline loadmeasure & Measure & Main research question & Research example \\
\hline \multirow[t]{2}{*}{ Subjective } & Subjective rating & Leamer's subjective assessment & Paas \& van Memienboer, \\
\hline & Scales & oftask demands & 1993 \\
\hline \multirow[t]{17}{*}{ Objective } & Leaming outcomes & Relation between instructional & Mayer,2005; Mayer \& \\
\hline & & design andknowledgeacquisition & Moreno, 1998 \\
\hline & Time-on-task & Leamer'sinvestment in the & Tabbersetal.,2004 \\
\hline & & leaming process & \\
\hline & Navigation behavior, & Leamer's information need & Moller \& Muller-Kalthoff, \\
\hline & & help-seeking behavior & 2000 \\
\hline & Task complexity & Relation among affordances, & Seufertetal., 2007 \\
\hline & & instructional design, and & \\
\hline & & knowledgeacquisition & \\
\hline & Behavioral data & Global or specific physiological & Van Gerven etal.,2004 \\
\hline & (heartrate,pupil & reactions of the organism & \\
\hline & dilation) & involved in a leaming process & \\
\hline & Secondary task & Mental load induced by the & Bunkenetal., 2002 \\
\hline & analysis & (primary) learning task & \\
\hline & Eye-tracking & Basic behavioral aspects of & Folkeretal., 2005 \\
\hline & analysis & information processing and & \\
\hline & & their relation to leaming outcomes & \\
\hline \multirow[t]{3}{*}{ Combined } & Efficiency measures & Optimizing instructional design & Paasetal., 2003 \\
\hline & & decisions by calculating the relation & \\
\hline & & of invested effort and leaming outco & \\
\hline
\end{tabular}

From “Measuring cognitive load” by Brunken, Seufert, \& Paas, 2010, p. 193. In J.L. Plass, R. Moreno, \& R. Brunken

(Eds.), Cognitive load theory (pp. 181-202). Copyright 2010 Cambridge University Press. 
Appendix C

Questionnaires (in Chinese language)

年级

班级

代码（粘贴）

请在相应的信息后面的括号里打勾来表示你的选择。

1. 你还记得你的英语老师用一副图来帮助你们联想和使用单词吗? (如果是, 请继续回答如下问题；如果否，请将这张纸交还给英语老师）
是 $(\quad)$
否 ( )

2. 你觉得老师用图来帮助你们联想和使用单词的这种方法对你记新单词有什么

影响呢? ( 单选题)

非常积极的影响（）

有点积极的影响（）

没有影响（）

有点消极的影响（）

非常消极的影响（）

3. 你觉得老师用图来帮助你们联想和使用单词的这种方法有什么优点?

4. 你觉得老师用图来帮助你们联想和使用单词的这种方法有什么缺点? 
5. 你会不会觉得老师用图来帮助你们联想和使用单词的这种方法信息量太大?

脑子承受不了?

是（）何时？

否 
Appendix D

Questionnaires (in English language)

Grade Class Code (paste)

Please click in the blanket after the option to show your choice.

1. Do you still remember that your English teacher once used a picture to help you connect and use English words? (If yes, please continue to answer the following questions; if no, please give this paper back to your English teacher).

Yes ( ) No( )

2. What kind of influence do you think the method which your English teacher used to help you connect and use English words would have on your new vocabulary acquisition? (You can only choose one from the below).

a lot positive influence ( )

a little positive influence ( )

no influence ( )

a little negative influence $(\quad$ )

a lot negative influence ( )

3. What are the strengths of the method which your English teacher used to help you connect and use English words?

4. What are the weaknesses of the method which your English teacher used to help you connect and use English words?

5. When your English teacher used a picture to help you connect and use English words, have you felt too much information at one time that exceeds your brain 
processing capacity?

Yes ( ) when?_ no ( ) 
Appendix E

Ten PWIM Steps (in Chinese)

图文归纳模式十步骤

1. 选图。

2. 请学生说出他们在图中所看到的。

3. 标出学生认出的部分 (从认出的物体或区域画线, 说出那个单词、写 下来, 请学生大声拼写出那个单词、然后读出来 )。

4. 复习这张图文表并大声朗读。

5. 请学生朗读 (如果需要的话使用图表上的画线) , 将单词归类。用一些 常规的概念 (如首字母辅音、押韵的词) 在整个班级强调这种分类。

6. 复习这张图文表并大声朗读（说出那个单词、拼写然后再说一遍）。

7. 如果愿意, 可以在图文表上添加词汇, 并加入词汇库。

8. 引导学生给图文表加标题。请学生考虑表里的信息及他们如何描述这 张表。9. 请学生就图文表造一个句子、多个句子、写个段落。请学生将 句子分类。示范如何将句子拼成一个好的段落。

10. 复习并朗读句群和段落(Calhoun, 1999, p. 23). 
Appendix F

PWIM Implementation Log

图文归纳模式教学日志

District/School（校名）:

Name（教师姓名）：

Grade Level/ Position（年级、职务）：

Beginning Date of PWIM Cycle（图文归纳模式本轮开始日期 ):

Description of Class (grade level, number of students, special needs): 班级描述（年

级、学生人数、需求 )

A. Describe your picture. 描述这幅图。

B. List of words shaken out of the picture: 列出从图中引出的单词

Words added to the picture word chart and word sets after the first round: 在第一轮

之后加入图文表格或者单词库中的单词 
C. Examples of categories of words or phrases generated by students:举例学生说出 的单词或词组归类

D. Examples of categories or concepts selected by you for instructional emphasis:举 例你出于教学重点考虑选择的类别或者概念

Phonetic Analysis Categories or Concepts --- 音标类分析类别或者概念

Structural Analysis Categories or Concepts - 结构类分析类别或者概念

Other - 其他

E. Examples of titles generated by students: 举例学生想出的标题

From the Picture- 从图中

From the Picture Word Chart - 从图文表格中 
From Sentence Groups or Categories- 从句群中或类别中

F. Examples of sentences generated by students: 举例学生想出的句子

G. One of the informative paragraphs composed by you from student ideas: 学生构 思由你写出的段落。

Comments and Reflections: 意见及感想 :

Questions: 问题 :

Number of lessons/days in PWIM Cycle ( 本轮图文归纳模式第几节课或第几天 ):

Ending date of PWIM Cycle (本轮图文归纳模式结束日期 ): 
Number of times you planned with Xuan in this PWIM Cycle ( 本轮图文归纳模式 中与江璇备课的次数 ) :

Number of times you demonstrated in front of Xuan in this PWIM Cycle ( 本轮图文 归纳模式中在江璇面前展示的次数 ) : 
Appendix G

Calendar for Self-Check Using PWIM or not

\section{September}

October

\section{November}

Dates: weekends or holidays

\begin{tabular}{|c|c|c|c|c|c|c|}
\hline- & $=$ & $\equiv$ & 四 & 五 & 六 & 日 \\
\hline 9 & 10 & 11 & 12 & 13 & 14 & 15 \\
\hline 16 & 17 & 18 & 19 & 20 & 21 & 22 \\
\hline 23 & 24 & 25 & 26 & 27 & 28 & 29 \\
\hline 30 & 4 & $z$ & 3 & 4 & 5 & $\theta$ \\
\hline 7 & 8 & 9 & 10 & 11 & 12 & 13 \\
\hline 14 & 15 & 16 & 17 & 18 & 19 & 20 \\
\hline 21 & 22 & 23 & 24 & 25 & 26 & 27 \\
\hline 28 & 29 & 30 & 31 & 1 & $z$ & 3 \\
\hline 4 & 5 & 6 & 7 & 8 & 9 & 10 \\
\hline
\end{tabular}


Appendix $\mathrm{H}$

PWIM Picture for Fourth Graders-Unit 1

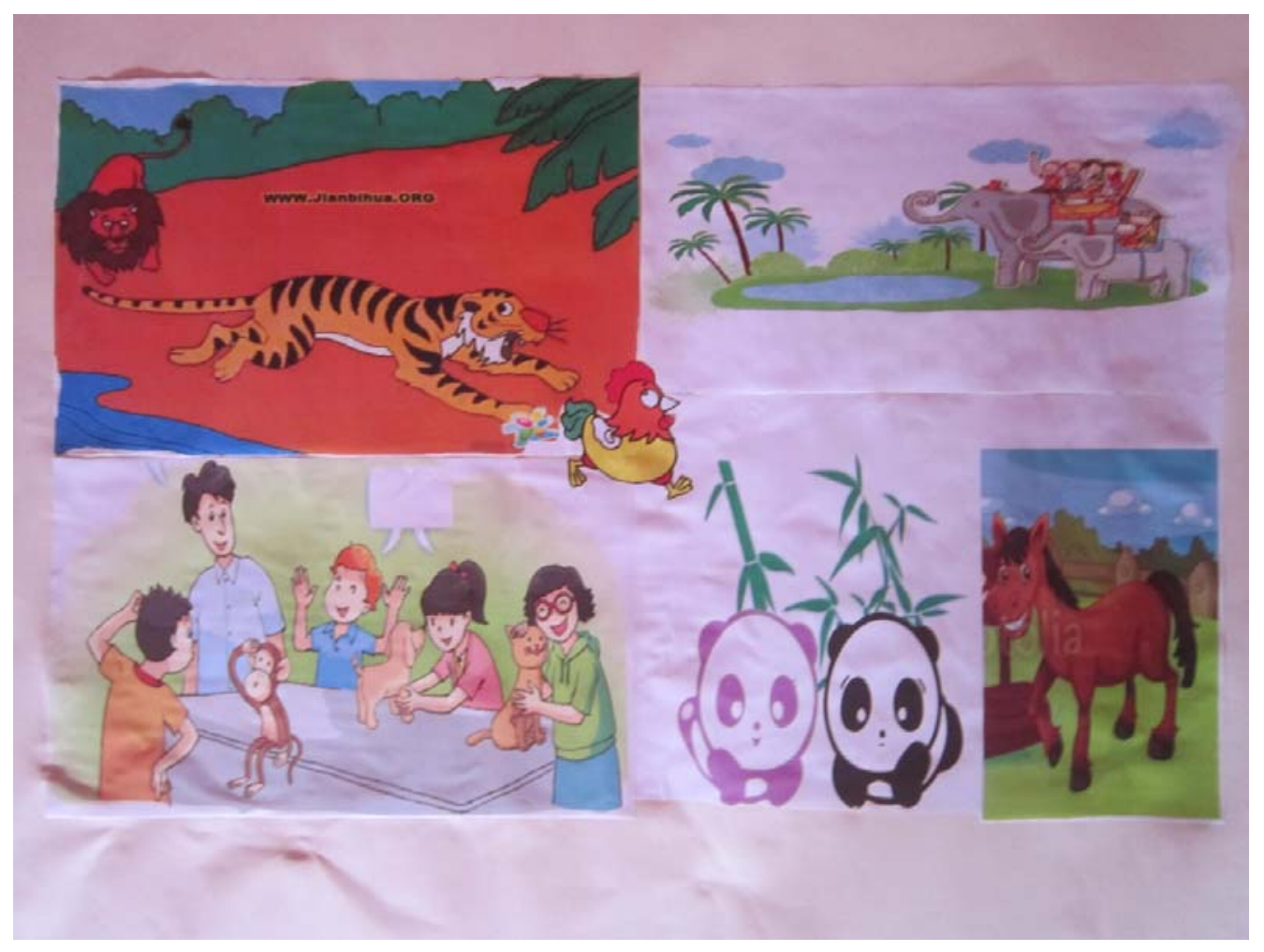


Appendix I

PWIM Picture for Fourth Graders-Unit 2

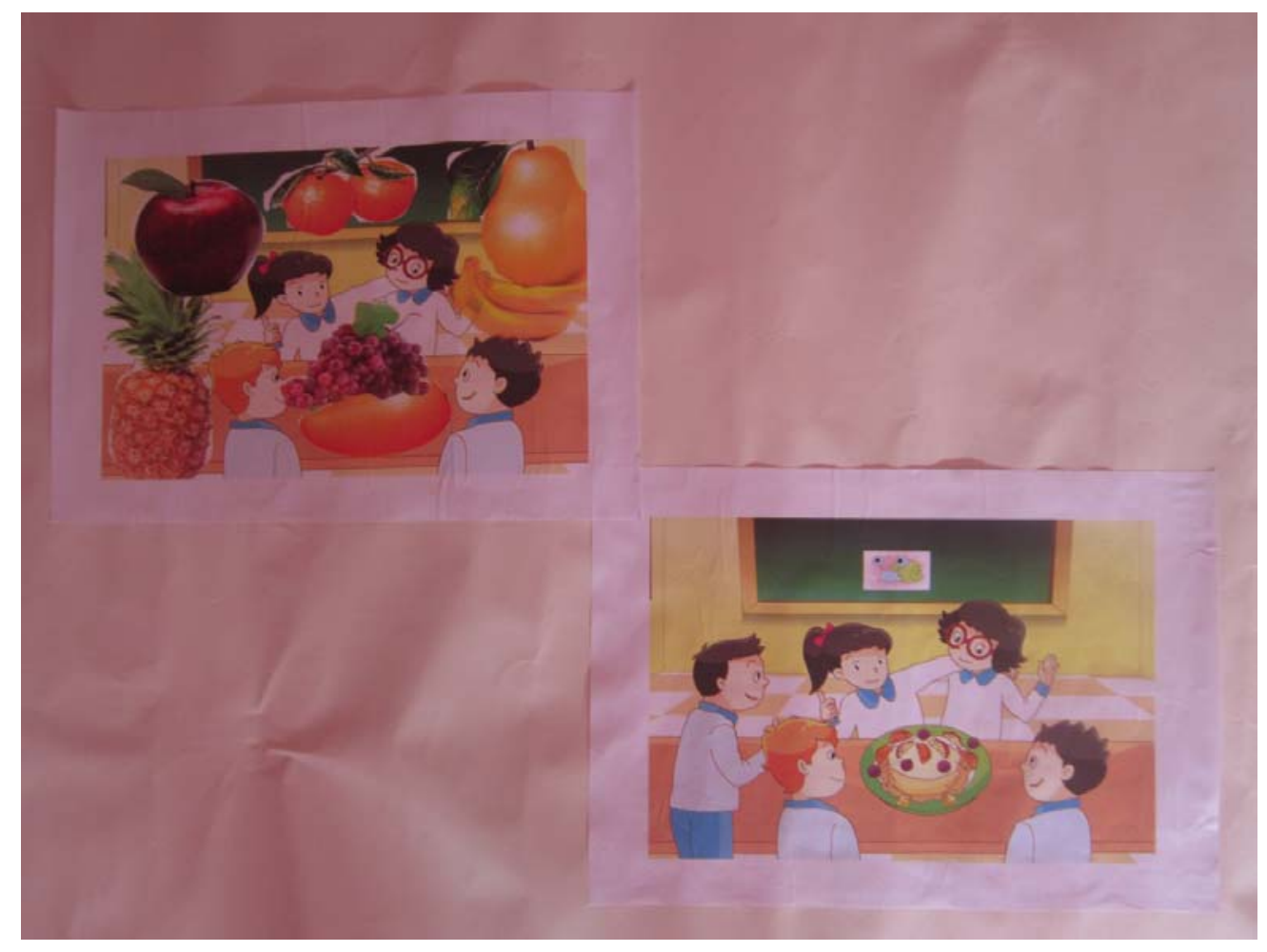


Appendix $\mathrm{J}$

PWIM Picture for Fourth Graders-Unit 4

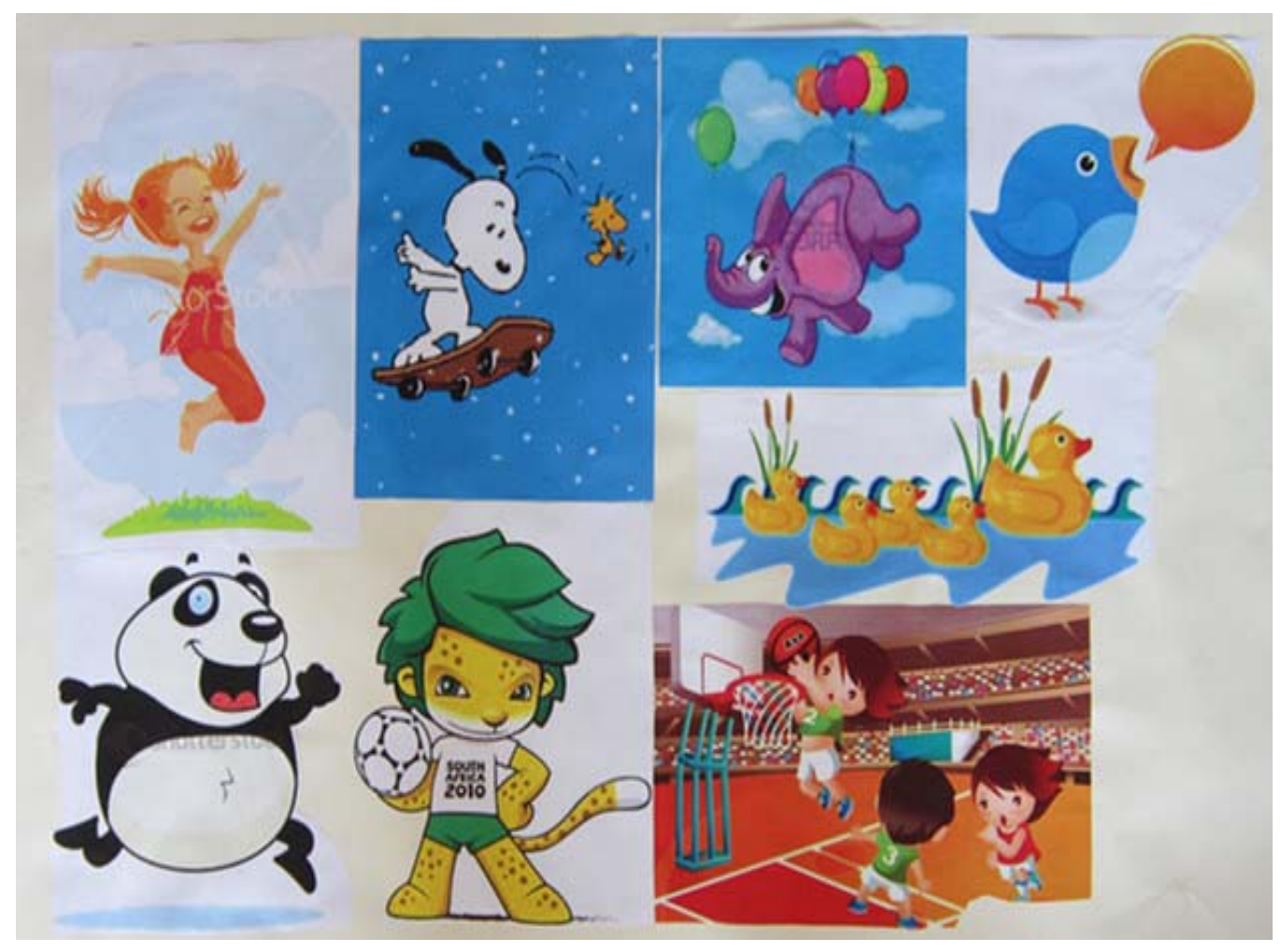


Appendix K

PWIM Picture for Seventh Graders-Unit 1 and 2

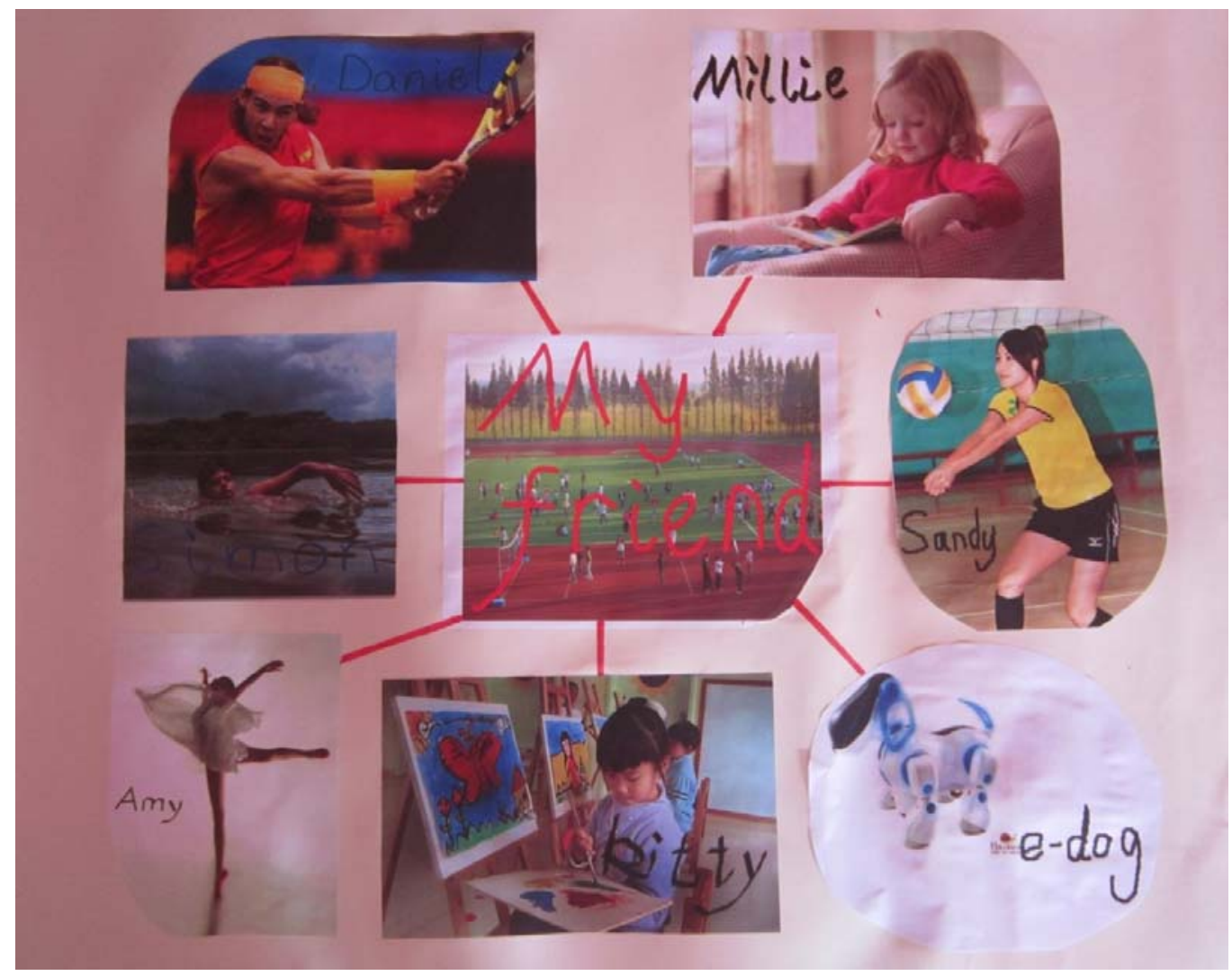


Appendix L

PWIM Picture for Seventh Graders-Unit 3

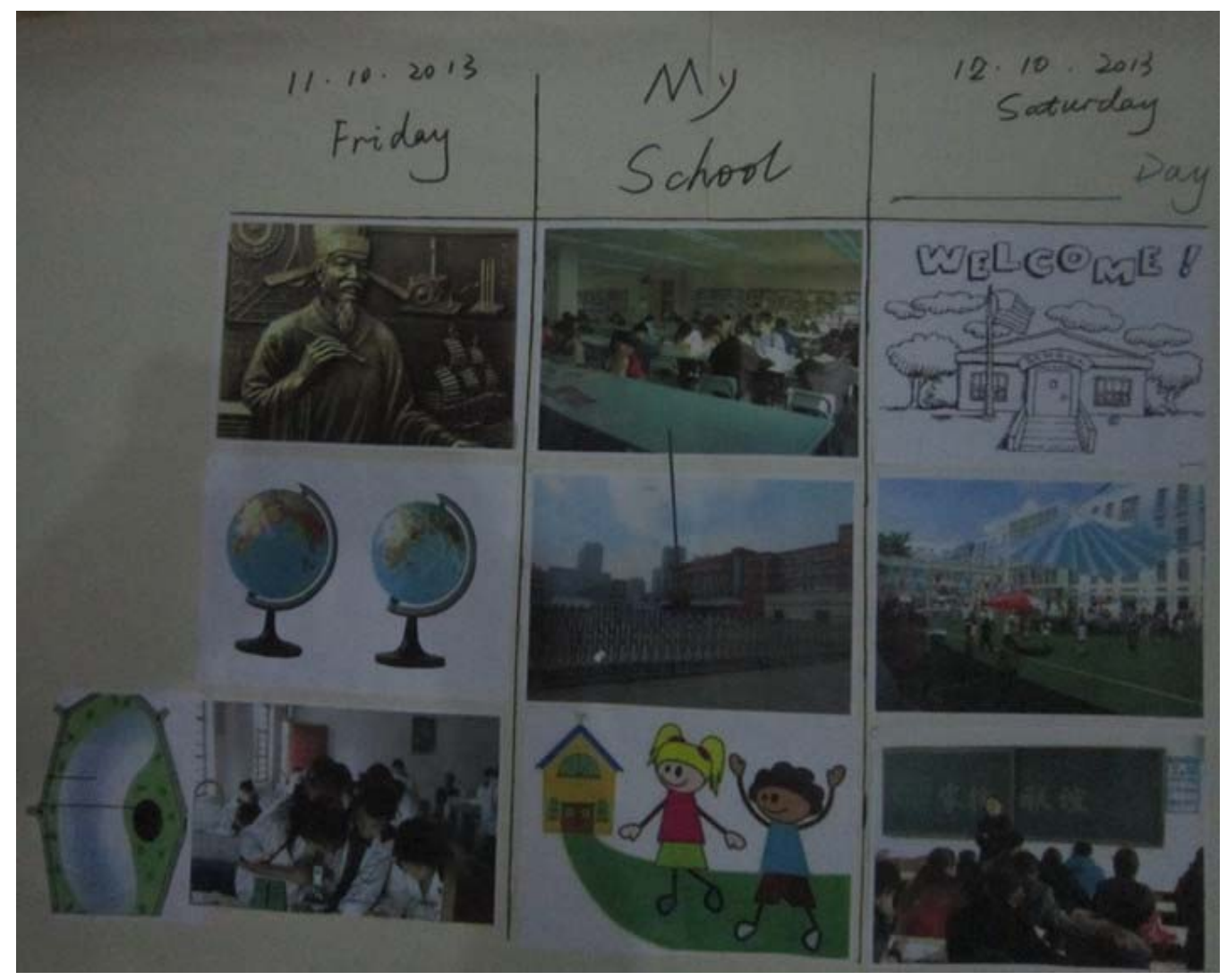


Appendix M

PWIM Picture for Seventh Graders-Unit 4

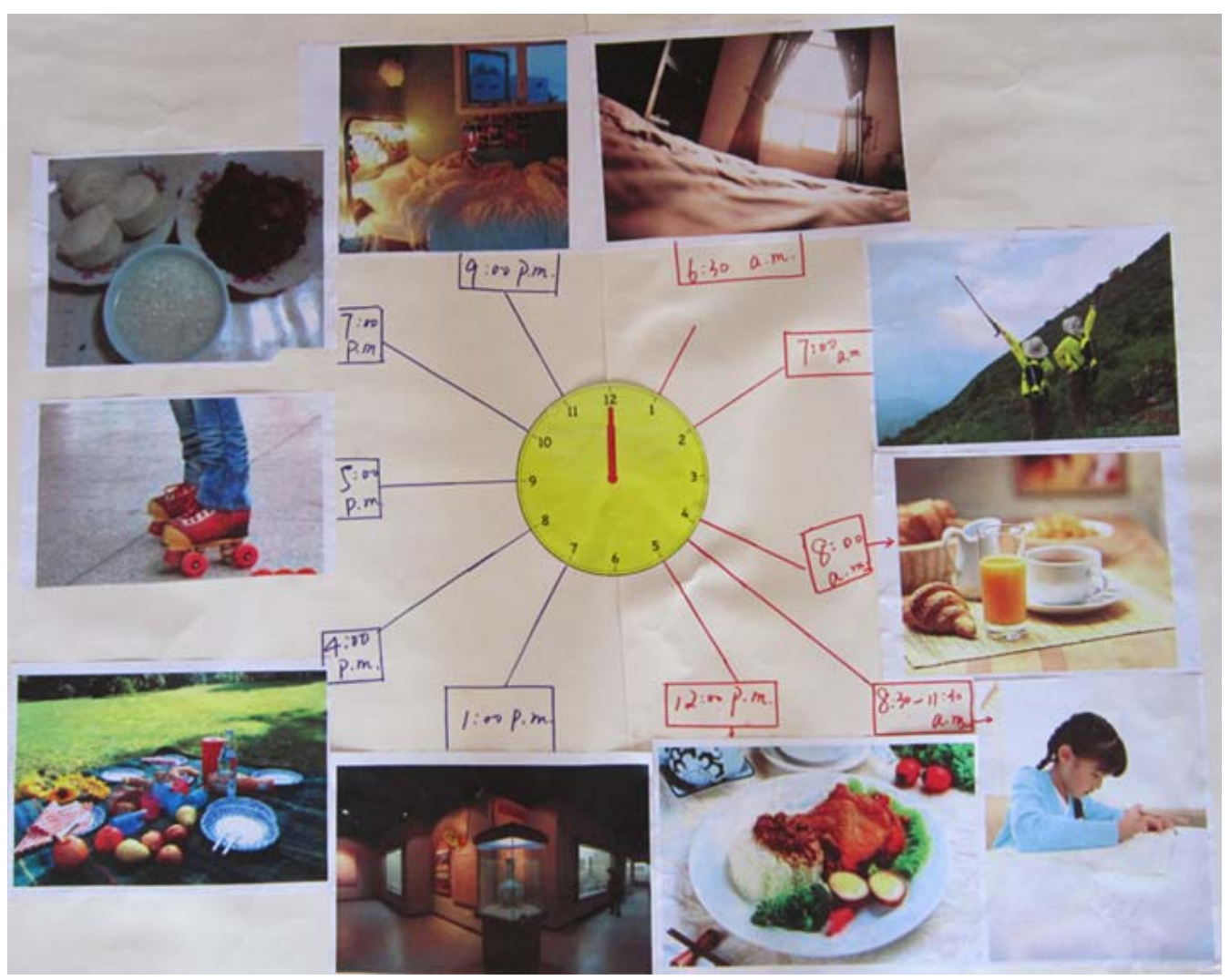




\section{Appendix N}

Pre- and Posttest for Fourth Grader

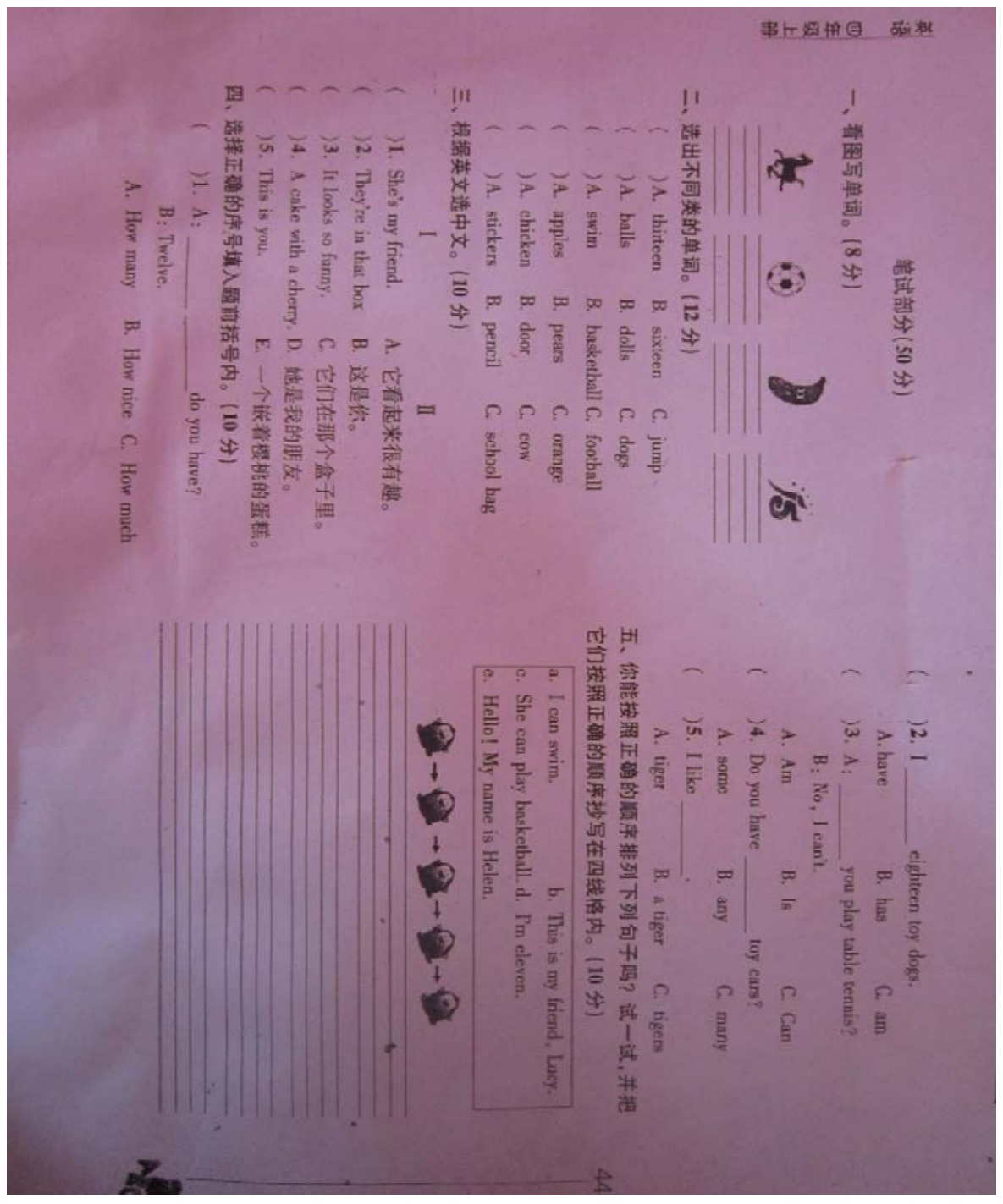


Appendix $\mathrm{O}$

Pre- and Posttests for $7^{\text {th }}$ Graders

五、填空 (共 10 分, 每小题 1 分)

A ) 根据括号中所给汉语写出单词, 使句子意思完整。

61. My daughter looks small and (可爱)。

62. Come to my birthday party if you are ( 空闲) this evening.

63. At ( 周末 ), I always have a good rest.

64. There is a ( 现代的 ) car there. Let's go and have a look.

65. We enjoyed our colourful ( 生活)。

B ) 根据句子意思, 用括号中所给单词的适当形式填空。

66. ---- what do you want to buy?

---- I'd like (buy) some books.

67. Many young people enjoy (chat) with others on the Internet.

68. Do you know all you classmates

69. There are some (good)?

70. These books help us (library) in the city. (learn) more about animals.

六、句型转换 (共 5 分, 每空 0.5 分)

71. Does Amy do well in sports? (改为同义句) Amy sports?

72. They come from Shanghai. (改为同义句) They Shanghai.

73. The boy takes a bus to school. (改为同义句) The boy goes to school

74. My father runs for an hour every day. (对画线部分提问 ) does your father run every day?

75. The man on the bike is my father. (对画线部分提问 ) 
man is your father?

七、根据汉语意思完成句子 ( 共 10 分，每题 2 分 )

76 . 卡尔经常和家人去野餐。

Carl often his family.

77. 基蒂每个星期四去上舞蹈课。

Kitty goes to her lessons every

78. 吃太多对你没好处。

Eating is you.

79. 音乐总能使我开心。

Music can

80. 我希望你可以来和我一起看足球比赛。

I hope you come and the football match with me.

\section{九、短文缺词填空 (写出完整的单词 )(共 10 分，每小题 1 分 )}

English is an important language (语言). Many people around the $\mathrm{w} \_$91 are learning English. Some of them are Some people learn English at $\mathrm{s}$ , and others are young people.

Why do so many people want to learn English? English is one of the most useful languages in the world. Children learn English at school because it is one of their s_ 94 . Some people learn English because they have to s_ 95 or w_ 96 in English when they work. Some learn English because they like watching English $\mathrm{f} \_\underline{97}$ or even because they like playing computer $\mathrm{g} \_\underline{98}$. Others learn English because they want to learn $\mathrm{m} \_\underline{99}$ about the world by r_1 100 English newspapers (报纸) or magazines(杂志).

(91)

(96)

\section{十、书面表达 (满分 15 分)}

根据下面表格内容, 以 My friend 为题, 写一篇 70 词左右的短文。

要求: 语言通顺, 语法正确。可适当发挥。 


\begin{tabular}{|l|l|l|l|}
\hline Name & Angel & Age & 14 \\
\hline Birthplace & Nanjing & Living place & Shanghai \\
\hline Class & Class 5, Grade 7 & Looks & slim \\
\hline Hobbies & Music... & Be good at & $\ldots$ \\
\hline
\end{tabular}

My Friend 


\section{Appendix P}

Three Levels of Knowing Words

\begin{tabular}{|c|l|l|l|}
\hline & Unknown & Acquainted & Established \\
\hline Pretest & & & \\
\hline Posttest & & & \\
\hline
\end{tabular}




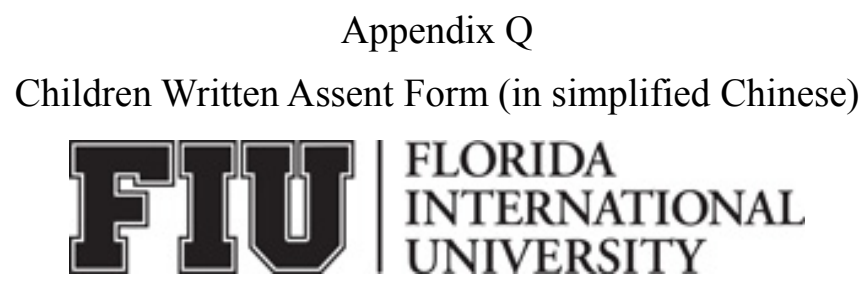

\section{儿童同意参加此研究的决定书}

对中国少儿英语学习者使用图文归纳模式采用混合方法研究其认知负荷和词汇学习

\section{1. 为何你在做这个研究?}

我希望你加入我正在做的研究。研究是了解某种事物的方法。我想发现图文归纳 模式在中国的有效性。

\section{2. 还有多少人参与这个研究?}

如果你同意参加这个研究, 你将是 20 个儿童中的一个。

\section{3. 这项研究持续多久?}

你最多需要参与 30 分钟。

\section{4. 这研究中会发生什么?}

如果你同意参加此研究, 我们会要求你做如下事情：

1. 你将要完成一份调查问卷 (最多 20 分钟)

2. 你将要接受一次最多 10 分钟的采访，采访中的谈话将会被录音。

\section{5. 会对我有什么伤害吗?}

没有任何已知的伤害。 


\section{6. 会带给我有什么好处吗?}

没有好处。

\section{7. 我还有别的选择吗?}

你还可以选择不参加这个研究。

\section{8. 会有人知道我参加这个研究吗?}

研究的所有数据将由江璇保管并予以保护。

\section{9. 我参加这个研究能得到什么东西吗?}

你将会得到一块美国巧克力。

\section{0. 如果我不想参加这个研究了呢?}

如果你不想参加, 你就可以不参加随时退出。如果你不喜欢某个问题, 你不必回 答。如果你要求, 你的回答不会被用于此项研究。如果你不想参加, 没有人会生 你的气的。

\section{1. 我能跟谁谈一谈这个研究呢?}

如果你对这个研究有任何问题,你可以联系江璇。她的手机号码是 $* * * * * * * * * * *$, 邮箱是 xjiang@fiu.edu。如果你想找某人谈谈你作为参与者的权利，你可以联 系佛罗里达国际大学研究诚信办公室。他们的联系电话是 1-305-348-2494，邮 箱是 ori@fiu.edu.

\section{参与者同意：}

已经有人将这个研究解释给我听, 我同意参与此研究。 
儿童参与者名字 (打印字体)

持有儿童同意书的人签字

日期 
Appendix R

Children Written Assent Form (in English language)

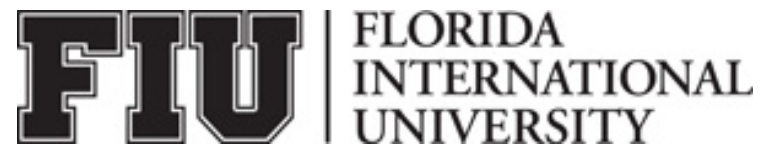

\author{
CHILD ASSENT TO PARTICIPATE IN A RESEARCH STUDY \\ A MIXED METHODS EXAMINATION OF COGNITIVE LOAD AND \\ VOCABULARY LEARNING THROUGH USE OF THE PICTURE-WORD \\ INDUCTIVE MODEL FOR YOUNG ENGLISH LEARNERS IN CHINA
}

\title{
WHY ARE YOU DOING THIS STUDY?
}

I would like for you to be in a research study I am doing. A research study is a way to learn information about something. I would like to find out more about the effectiveness of using PWIM to teach Chinese students English vocabulary in China..

\section{HOW MANY OTHERS WILL BE IN THIS STUDY?}

If you agree to participate in this study, you will be one of 20 children in this research study.

HOW LONG WILL THE STUDY LAST?

Your participation will require 30 minutes maximum.

WHAT WILL HAPPEN IN THIS STUDY?

If you participate in this study, we will ask you to do the following things:

1. You will answer questions in a questionnaire for 20 minutes maximum.

2. You will be audio taping in an interview for 10 minutes maximum.

\section{CAN ANYTHING BAD HAPPEN TO ME?}

There are no known risks.

\section{CAN ANYTHING GOOD HAPPEN TO ME?}

There are no benefits.

\section{DO I HAVE OTHER CHOICES?}

There are no known alternatives available to you other than not taking part in this study.

\section{WILL ANYONE KNOW I AM IN THE STUDY?}

The records of this study will be kept private and will be protected by the researchers.

\section{WILL I BE GIVEN ANYTHING FOR PARTICIPATING?}

You will receive a chocolate bought in the United States for your participation. 


\section{WHAT IF I DO NOT WANT TO DO THIS?}

You do not have to be in this study if you don't want to and you can quit the study at any time. If you don't like a question, you don't have to answer it and, if you ask, your answers will not be used in the study. No one will get mad at you if you decide you don't want to participate.

\section{WHO CAN I TALK TO ABOUT THE STUDY?}

If you have any questions about the research study you may contact Xuan Jiang at [phone number], xjiang@fiu.edu. If you would like to talk with someone about your rights of being a participant in this research study, you may contact the FIU Office of Research Integrity by phone at 305-348-2494 or by email at ori@fiu.edu.

\section{PARTICIPANT AGREEMENT}

This research study has been explained to me and I agree to be in this study.

Signature of Child Participant

Printed Name of Child Participant

Signature of Person Obtaining Consent
Date

Date 
Appendix S

Parental Written Consent Form (in simplified Chinese)

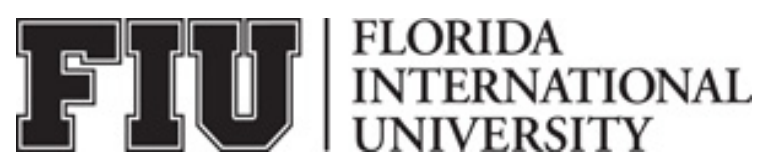

家长同意参加此研究的决定书

对中国少儿英语学习者使用图文归纳模式采用混合方法研究其认知负荷和词汇学习

\section{1. 此研究的目的}

请您同意您的孩子参加此研究。此研究的目的是发现图文归纳模式 (一种英 语教学方法 ) 在中国的有效性。

\section{2. 参与这个研究的人数}

如果您同意您的孩子参加这个研究，他/她将是 20 个人中的一个.

\section{3. 这项研究持续时间}

您的孩子最多需要参与 30 分钟.

\section{4. 过程}

如果您的孩子参与此研究, 他/她会被要求做如下事情:

1. 您的孩子将会完成一份调查问卷 (最多 20 分钟)

2. 您的孩子将会接受一次最多 10 分钟的采访，采访中的谈话将会被录音。

\section{5. 风险和 (或) 不适}

没有已知的风险。 
6. 好处

没有好处。

\section{7. 别的选择}

您的孩子还可以选择不参加这个研究。

\section{8. 保密性}

研究的所有数据将按法律规定进行全方位的保密和保护。在有可能出版的任何文 书中, 都不会包含任何信息以识别出您的孩子作为参与者。研究数据将会被安全 保存, 研究者江璇是唯一可以接触到数据的人。

\section{9. 补偿}

您的孩子将会得到一块美国巧克力作为参与的奖励。

\section{0. 拒绝或退出的权利}

您的孩子参加此研究是自愿的。您的孩子可以自由参与此研究或者在此研究过程 中随时退出。您孩子的退出或者不参与不会给您的孩子的任何权益带来影响。如 果研究人员觉得您的孩子退出最好, 她保留这项权利且无需您的同意。

\section{研究人员联系信息}

如果你对此研究的目的、过程或者其它方面有任何问题，你可以联系江璇。她的 手机号码是 $* * * * * * * * * * *$, 邮箱是 xjiang@fiu.edu.

\section{机构审查委员会联系信息}


如果您想找某人谈谈您的孩子作为参与者的权利、或者此项研究的伦理道德问题， 您可以联系佛罗里达国际大学研究诚信办公室。他们的联系电话是 1-305-348-2494，邮箱是 ori@fiu.edu.

\section{参与者同意：}

本人已经看完此同意书上的信息，并同意我的孩子参与此项研究。我有机会问关 于此项研究的任何问题，也已有人回答了我的问题。我知道在同意书阅读和签 字之后，我有权保留一份。

父母或监护人签字

日期

父母或监护人的名字 ( 打印字体 )

儿童参与者名字 ( 打印字体 )

持有该同意书的人签字

日期 
Appendix T

Parental Written Consent Form (in English)

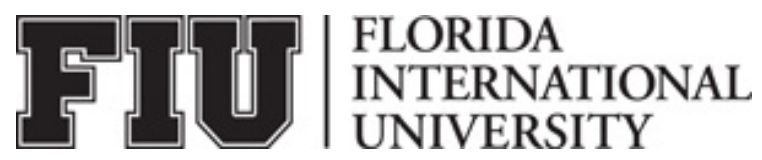

\author{
PARENTAL CONSENT TO PARTICIPATE IN A RESEARCH STUDY \\ A MIXED METHODS EXAMINATION OF COGNITIVE LOAD AND \\ VOCABULARY LEARNING THROUGH USE OF THE PICTURE-WORD \\ INDUCTIVE MODEL FOR YOUNG ENGLISH LEARNERS IN CHINA
}

\title{
PURPOSE OF THE STUDY
}

You are being asked to give your permission for your child to be in a research study. The purpose of this study is to find out more about the effectiveness of using PWIM to teach Chinese students English vocabulary in China.

\section{NUMBER OF STUDY PARTICIPANTS}

If you agree to allow your child to participate in this study, he/she will be one of 20 people in this research study.

\section{DURATION OF THE STUDY}

Your child's participation will require 30 minutes maximum.

\section{PROCEDURES}

If your child participates in this study, we will ask your child to do the following things:

1. Your child will answer questions in a questionnaire for 20 minutes maximum.

2. Your child will be audio taping in an interview for 10 minutes maximum.

\section{RISKS AND/OR DISCOMFORTS}

There are no known risks.

\section{BENEFITS}

There are no benefits.

\section{ALTERNATIVES}

There are no known alternatives available to your child other than not taking part in this study. 


\section{CONFIDENTIALITY}

The records of this study will be kept private and will be protected to the fullest extent provided by law. In any sort of report I might publish, I will not include any information that will make it possible to identify your child as a subject. Research records will be stored securely and only the researcher will have access to the records.

\section{COMPENSATION \& COSTS}

Your child will receive a chocolate bought in the United States for your participation.

\section{RIGHT TO DECLINE OR WITHDRAW}

Your child's participation in this study is voluntary. Your child is free to participate in the study or withdraw his/her consent at any time during the study. Your child's withdrawal or lack of participation will not affect any benefits to which he/she is otherwise entitled. The investigator reserves the right to remove your child from the study without your consent at such time that they feel it is in the best interest.

\section{RESEARCHER CONTACT INFORMATION}

If you have any questions about the purpose, procedures, or any other issues relating to this research study you may contact Xuan Jiang at xjiang@fiu.edu.

\section{IRB CONTACT INFORMATION}

If you would like to talk with someone about your child's rights of being a subject in this research study or about ethical issues with this research study, you may contact the FIU Office of Research Integrity by phone at 305-348-2494 or by email at ori@fiu.edu.

\section{PARTICIPANT AGREEMENT}

I have read the information in this consent form and agree to allow my child to participate in this study. I have had a chance to ask any questions I have about this study, and they have been answered for me. I understand that I am entitled to a copy of this form after it has been read and signed.

Signature of Parent/Guardian

Date

Printed Name of Parent/ Guardian

Printed Name of Child Participant

Signature of Person Obtaining Consent Date 


\section{Appendix U}

Xuan Jiang's Research Study Proposal (in brief in Chinese language)

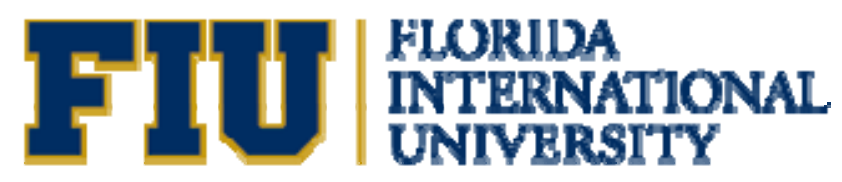

敬爱的家长:

您好！

首先, 我先自我介绍一下。我叫江璇, 现为佛罗里达国际大学教育学院四年级的在读博 士生, 我的专业为课程与教学领域里的对外英语教学(Teachers of English to Speakers of Other Languages, TESOL) 。

其次, 我介绍一下我的博士论文。这个研究课题将检测图文归纳模式 (Picture Word Inductive Model ) 作为一个新兴教学方法是否对中国的英语学习者的词汇量有效及是对哪种 学生群体有效 (若有效的情况下)。我将在连云港的一所初中和小学进行为期六周的实验 ( 2013 年秋季 )。在测试之后, 我会发一份调查问卷。根据问卷的回答，我会采访实验班的 一些学生。采访中提问的问题不涉及他们的词汇量, 是关于他们对图文归纳模式教学方法的 看法和感受。

再次, 考虑到实验中的各种因素, 本人也做了相应的准备。本人经过社会科学研究的培 训并取得了所需要的证书, 在各个环节的设计方面也是考虑到隐私安全。整篇论文不会出现 在哪个学校、哪个老师的班级、对哪个学生进行研究的字眼。

您的配合对本人论文成败事关重大。基于此, 既请您同意并签字以允许你的孩子接受我 的采访。本人将非常感谢您的配合。您若有疑问请与我联系（xjiang@fiu.edu， 011-86-*********** 或 Xuan Jiang 11200 SW 8th Street, ZEB 215,Miami, FL 33199 \%。 
此致

敬礼

\section{江璇}

2013 年 3 月 19 日 


\section{Appendix V}

Xuan Jiang's Research Study Proposal (in brief in English language)

\section{FIU}

Dear Parents,

Greetings!

First of all, let me introduce myself. I am Xuan Jiang, a fourth-year Ph.D. student in the College of Education at Florida International University. I am in the program of Curriculum and Instruction with specialty in Teachers of English to Speakers of Other Languages (TESOL).

Secondly, let me introduce my dissertation research study. This study will investigate whether Picture Word Inductive Model (PWIM) as a new English teaching method to China is effective or not and if it is effective, it is so to which grade level students. I will conduct a six-week-long experiment in the Fall 2013. After the posttest at the end of the six weeks, I will give a questionnaire to students in the experiment group. Based on the answers to the questions on the survey, I will interview some students in the two experiment classes. The interview questions will cover their ideas and feeling about PWIM, rather than assessing their vocabulary.

Thirdly, I have already prepared for being qualified for conducting social science studies after taking IRB training courses and obtaining certificates. I also have considered carefully about privacy issues and identification safety during my research design, to make sure that no school, class or student can be identified through my dissertation.

Your cooperation is vital to my research study. Therefore, please sign your name to approve that your child will be interviewed. Thank you very much for your cooperation. If you have any questions, please feel free to contact me at xjiang@,fiu.edu , or Xuan Jiang 11200 SW 8th Street, ZEB 215, Miami, FL 33199. Sincerely, Xuan Jiang 


\section{Appendix W}

Module for Categorization and Writing for Fourth Graders-Unit 1

第一单元根据图所总结出的单词

\begin{tabular}{|l|l|l|l|l|l|}
\hline tiger & lion & river (河) & tree & yellow & black \\
\hline white & green & brown & blue & eyes (眼睛) & ears (耳 朵) \\
\hline legs (腿) & nose (鼻子) & tooth (牙齿) & tail (尾巴) & run & cloud (云) \\
\hline elephants & girl & boy & man & woman & old man \\
\hline old woman & water (水) & sky (天空) & grey (灰色) & hat (帽子) & red \\
\hline family & chicken & walk (走路) & monkey & dog & cat \\
\hline toy & hair (头发) & T-shirt & desk & pandas & picture \\
\hline $\begin{array}{l}\text { happy } \\
\text { (高兴) }\end{array}$ & $\begin{array}{l}\text { smile } \\
\text { (微笑) }\end{array}$ & $\begin{array}{l}\text { wood } \\
\text { (木头) }\end{array}$ & grass (草) & $\begin{array}{l}\text { bamboo } \\
\text { (竹子) }\end{array}$ & $\begin{array}{l}\text { children } \\
\text { (儿童) }\end{array}$ \\
\hline land (地面) & think (想) & horse & on the farm & & \\
\hline
\end{tabular}




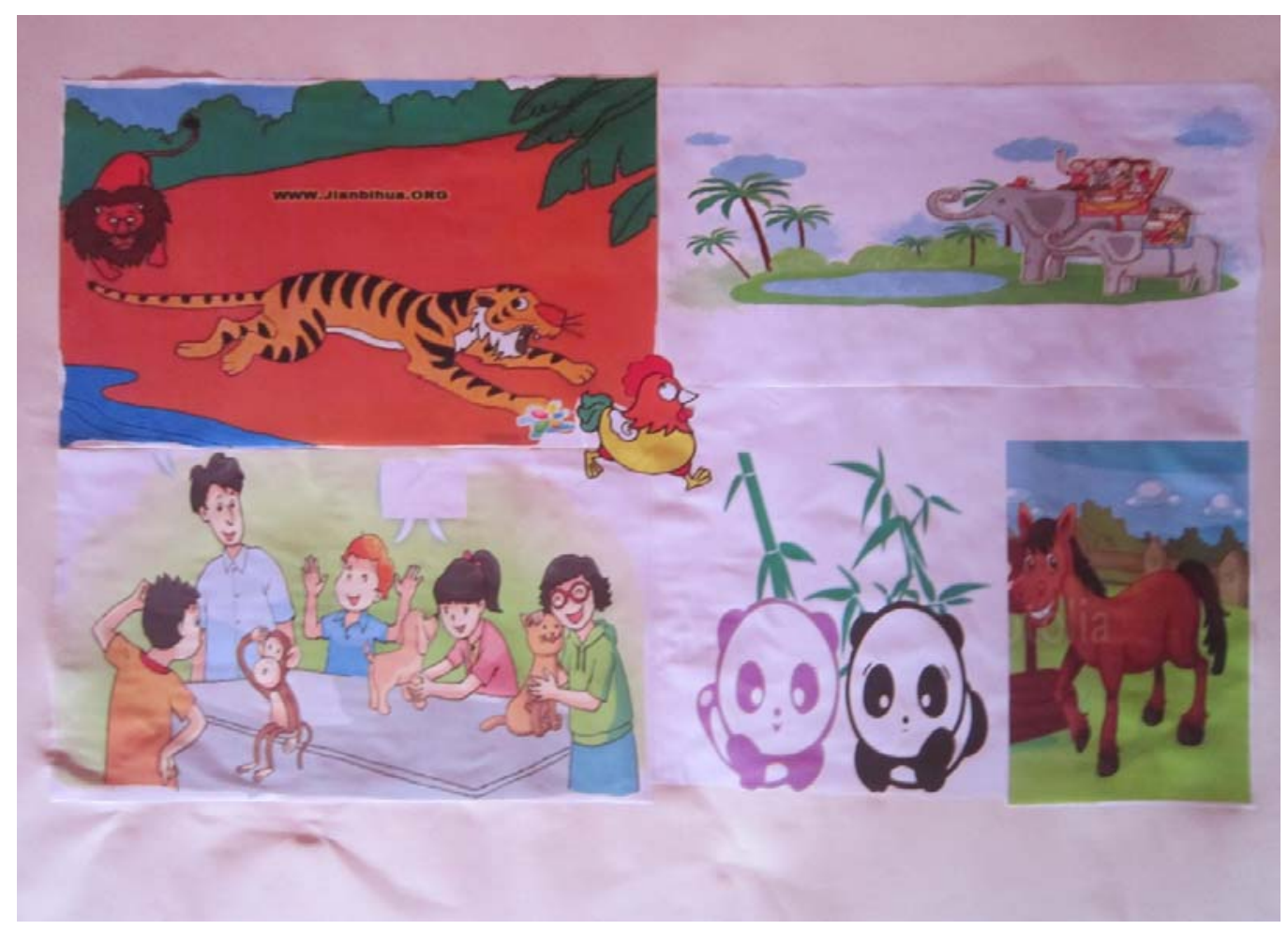

Appendix X

Module for Categorization and Writing for Fourth Graders-Unit 2

第二单元根据两幅图所总结出的单词

\begin{tabular}{|l|l|l|l|l|l|}
\hline apple & pineapple & mango & pear & banana(s) & orange(s) \\
\hline grape(s) & boy(s) & blackboard & desk & fruit & salad \\
\hline picture & floor & girl(s) & wall & fruit salad & \\
\hline
\end{tabular}




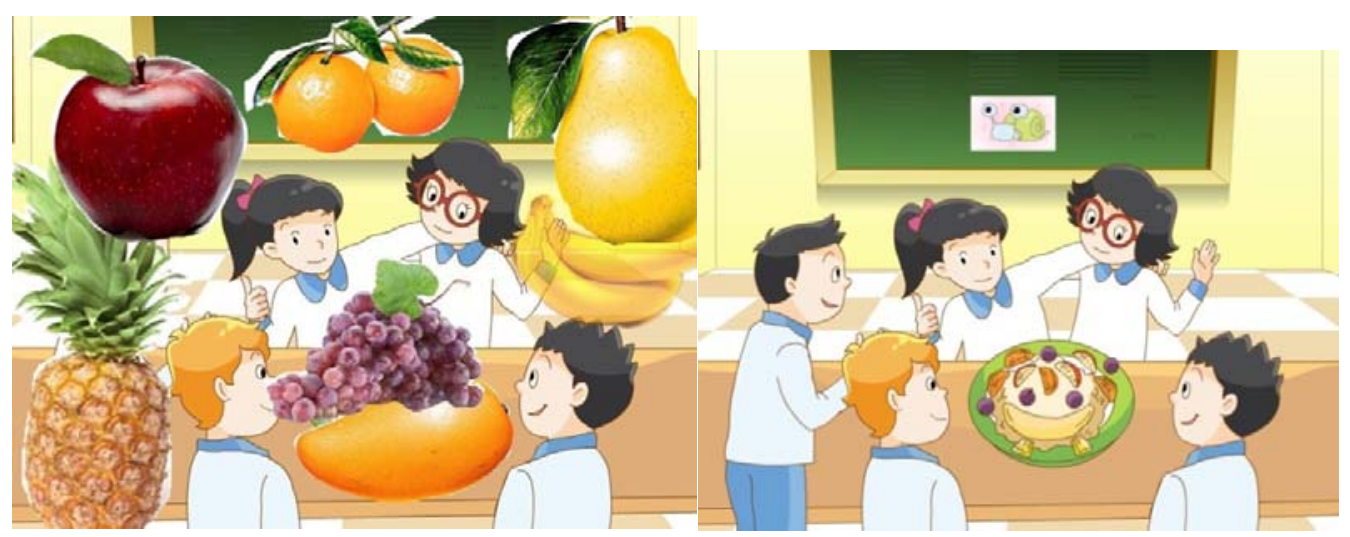

Appendix Y

Module for Categorization and Writing for $4^{\text {th }}$ Graders - Unit 4

第四单元根据图所总结出的单词

\begin{tabular}{|l|l|l|l|l|l|}
\hline dog & girl & duck(s) & panda & bird & elephant \\
\hline cute and fat & lion & jump & boys & blue & run \\
\hline fly & purple & skate & swim & white & balloon \\
\hline $\begin{array}{l}\text { black and } \\
\text { white }\end{array}$ & $\begin{array}{l}\text { play } \\
\text { basketball }\end{array}$ & $\begin{array}{l}\text { play } \\
\text { football }\end{array}$ & & & \\
\hline
\end{tabular}




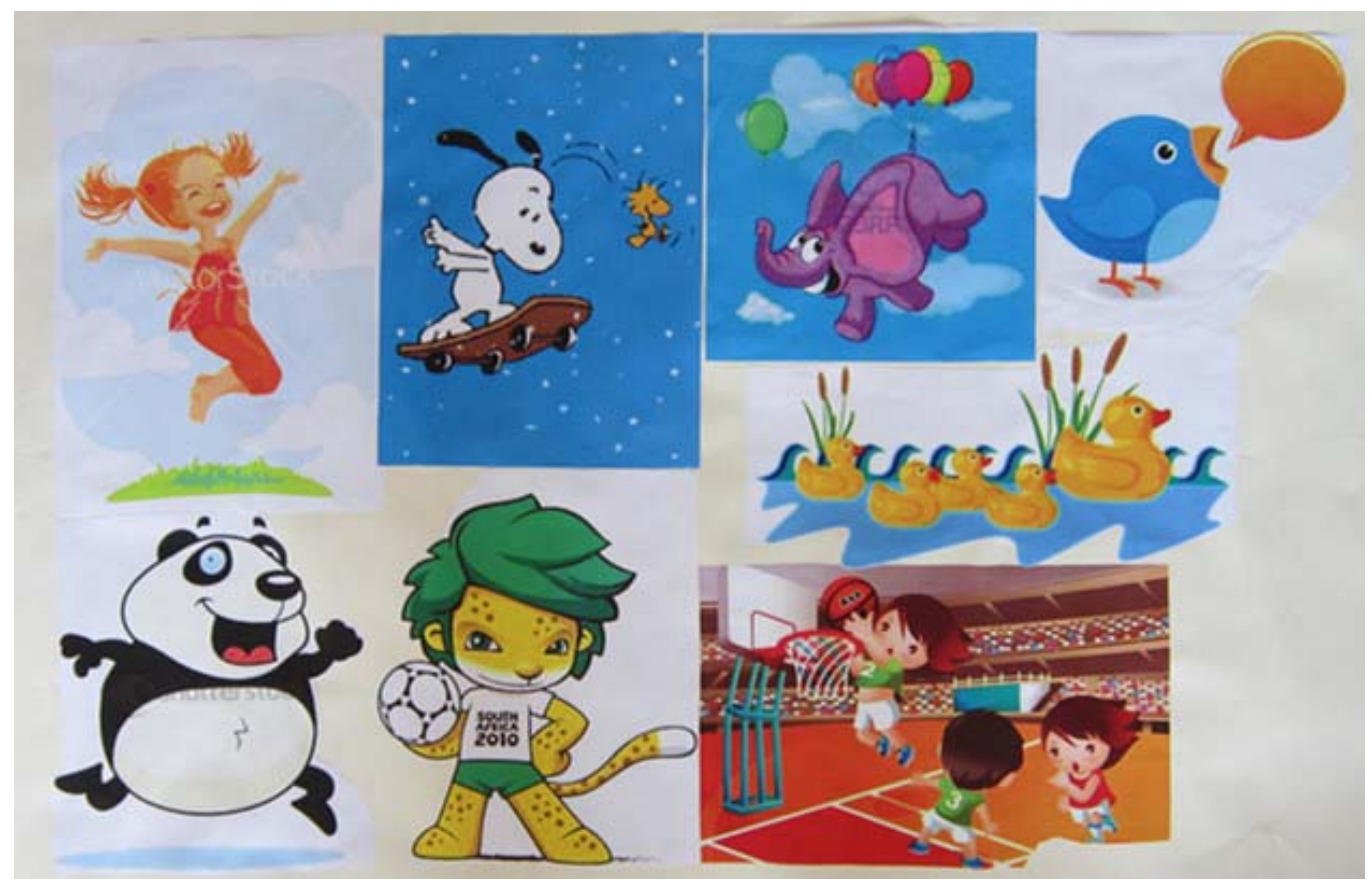

Appendix Z

Module for Categorization and Writing for $7^{\text {th }}$ Graders-Unit 1 and 2

\begin{tabular}{|l|l|l|l|l|l|l|}
\hline e-dog & girl & volleyball & reading & tennis & drawing & Playground \\
\hline swimming & dancing & lake & trees & picture & player & Sofa \\
\hline window & book & hill & water & pen & chair & Sweater \\
\hline sky & floor & dress & T-shirt & butterfly & cloud & Light \\
\hline swimmer & hair & head & ears & sunflower & house & Grass \\
\hline child(ren) & colour & earth & paper & people & sunny & Photos \\
\hline hands & running & walking & ground & foot & leg & Face \\
\hline boy & wood & $\begin{array}{l}\text { English } \\
\text { words }\end{array}$ & basketball & clothes & shoes & Flowers \\
\hline tail & shorts & sock & net & forest & yellow & Black \\
\hline red & & & & & & \\
\hline
\end{tabular}




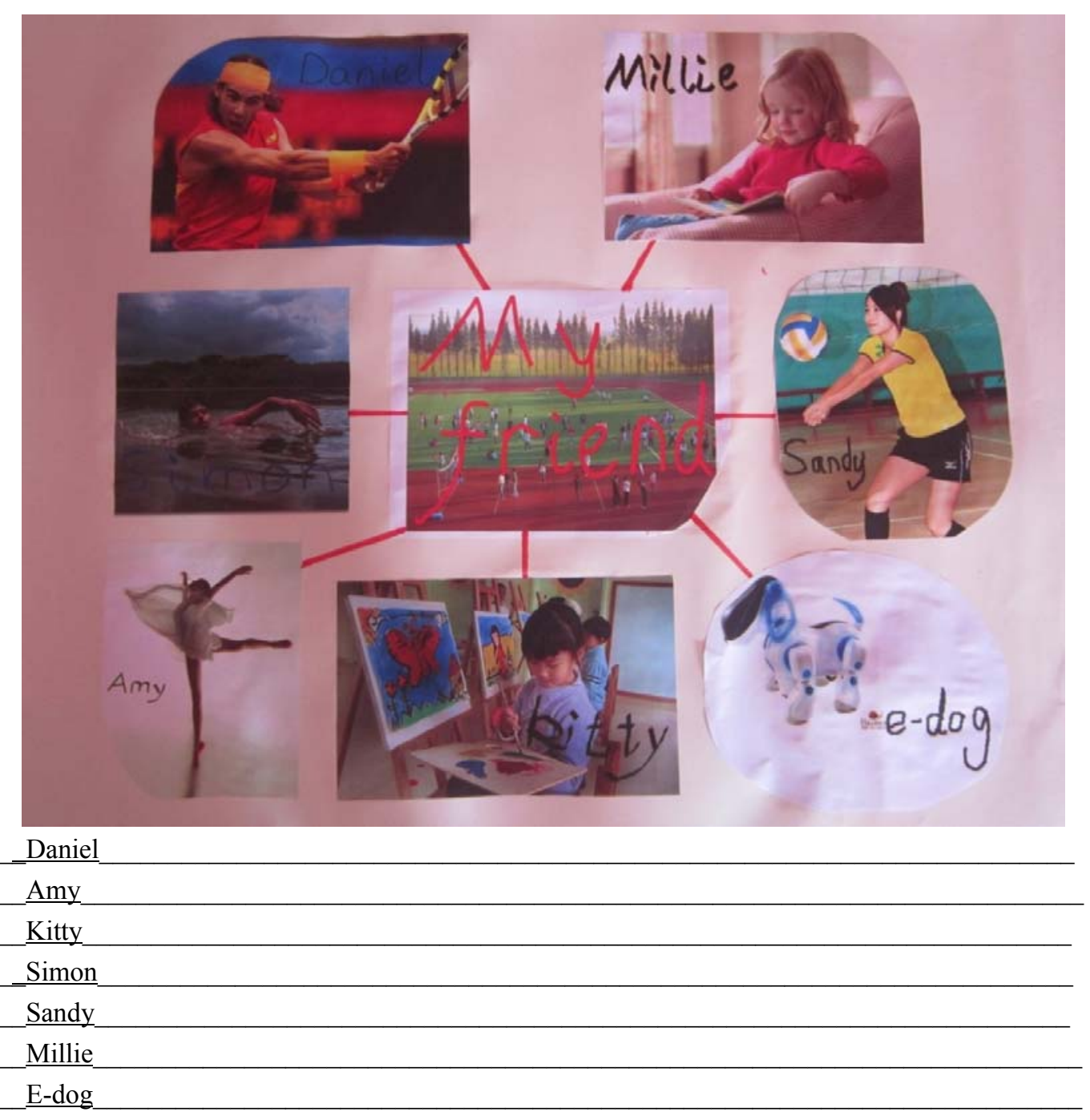

Appendix AA

Module for Categorization and Writing for $7^{\text {th }}$ Graders-Unit 3

\begin{tabular}{|l|l|l|l|l|l|}
\hline classroom & house & blackboard & students & playground & teacher \\
\hline $\begin{array}{l}\text { parents' } \\
\text { meeting }\end{array}$ & $\begin{array}{l}\text { boys and } \\
\text { girls }\end{array}$ & school & book & library & $\begin{array}{l}\text { school } \\
\text { gate }\end{array}$ \\
\hline model & geography & history & trees & window & wall \\
\hline biology & building & & & & \\
\hline & & & & & \\
\hline & & & & & \\
\hline & & & & & \\
\hline
\end{tabular}



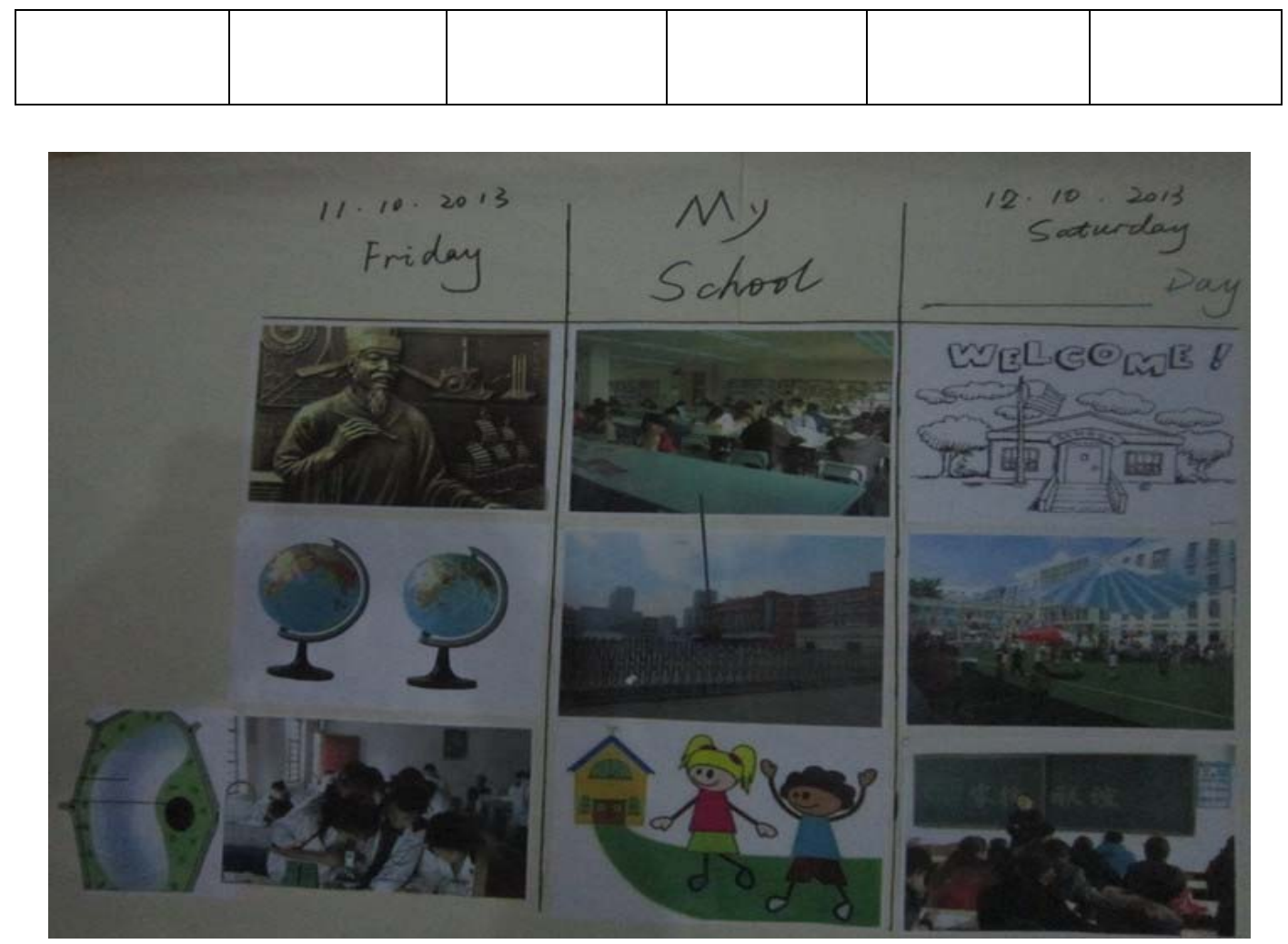

Appendix BB

Module for Categorization and Writing for $7^{\text {th }}$ Graders-Unit 4

\begin{tabular}{|l|l|l|l|l|l|}
\hline window & sunshine & hat & $\begin{array}{l}\text { go } \\
\text { walking in } \\
\text { the hills }\end{array}$ & glass & cup \\
\hline $\begin{array}{l}\text { have } \\
\text { breakfast }\end{array}$ & juice & coffee & bread & $\begin{array}{l}\text { do } \\
\text { homework }\end{array}$ & pen \\
\hline egg & vegetables & meat & rice & light & museum \\
\hline floor & picture & apple & grass & $\begin{array}{l}\text { go on } \\
\text { picnics }\end{array}$ & sunflowers \\
\hline $\begin{array}{l}\text { go } \\
\text { roller-skating }\end{array}$ & ground & building & bowl & night & bedroom \\
\hline go to bed & clock & tomato(es) & photo(s) & wall & have dinner \\
\hline cloud & have lunch & bed & vase & fruit & trousers \\
\hline hill & sky & milk & plate & table & bag(s) \\
\hline
\end{tabular}




\begin{tabular}{|l|l|l|l|l|l|}
\hline old things & trees & yellow & red & blue & morning \\
\hline numbers & & & & & \\
\hline
\end{tabular}

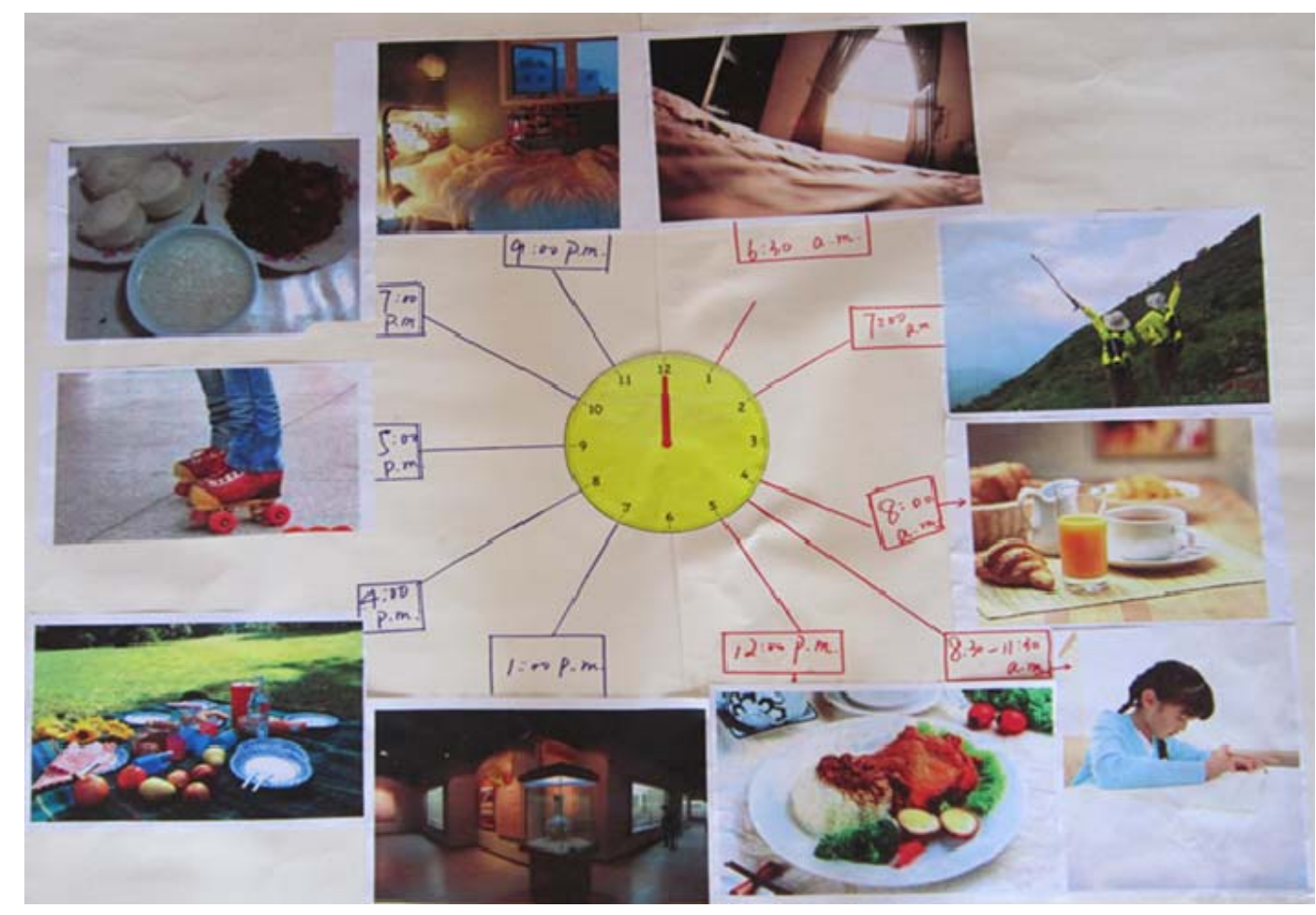

Appendix CC

Implementation Dates of PWIM for the $4^{\text {th }}$ Graders

\begin{tabular}{|c|c|c|c|c|c|c|}
\hline M & $\mathrm{T}$ & W & $\operatorname{Tr}$ & $\mathrm{F}$ & $\mathrm{Sa}$ & $\mathrm{Su}$ \\
\hline 2 & 3 & $\begin{array}{l}4 \text { (meet } \\
\text { vice-principal } \\
\text { Wen and teacher } \\
\text { Ivy \& train PWIM } \\
\text { for the } 1^{\text {st }} \text { time) }\end{array}$ & 5 & 6 & 7 & $\begin{array}{l}8 \text { (PWIM } \\
\text { training } \\
\text { with Ivy } \\
\& \quad \text { Lily } \\
\text { for the } \\
2^{\text {nd }} \text { time) }\end{array}$ \\
\hline 9 & $\begin{array}{lr}10 \quad \text { (pretest } \\
\text { for } \quad \text { both } \\
\text { classes) }\end{array}$ & $\begin{array}{l}11 \text { (PWIM 1st pic } \\
1^{\text {st }} \text { time) }\end{array}$ & $\begin{array}{l}12 \text { (PWIM } \\
2^{\text {nd }} \text { pic } 1^{\text {st }} \\
\text { time visit) }\end{array}$ & 13 & 14 & 15 \\
\hline $\begin{array}{l}16 \text { (PWIM } \\
2^{\text {nd }} \text { pic } 2^{\text {nd }} \\
\text { time visit) }\end{array}$ & $\begin{array}{l}17 \text { (no PIWM } \\
\text { because of } \\
\text { class change) }\end{array}$ & $\begin{array}{l}18 \text { (no PWIM } \\
\text { because Ivy was } \\
\text { not at school) }\end{array}$ & 19 & 20 & 21 & $\begin{array}{l}22 \quad \text { (no } \\
\text { PWIM } \\
\text { because }\end{array}$ \\
\hline
\end{tabular}




\begin{tabular}{|c|c|c|c|c|c|c|}
\hline & & & & & & $\begin{array}{l}\text { there was } \\
\text { no class } \\
\text { on Fri) } \\
\text { Fri }\end{array}$ \\
\hline $\begin{array}{l}23 \text { (PWIM } \\
2^{\text {nd }} \text { pic } 3^{\text {rd }} \\
\text { time visit) }\end{array}$ & $\begin{array}{l}24 \text { (no PWIM } \\
\text { because of } \\
\text { Unit 3) }\end{array}$ & $\begin{array}{l}25 \text { (no PWIM } \\
\text { because of Unit 3) }\end{array}$ & $\begin{array}{l}26 \quad \text { (no } \\
\text { PWIM } \\
\text { because of } \\
\text { Unit 3) }\end{array}$ & 27 & 28 & $\begin{array}{l}29 \quad \text { (no } \\
\text { PWIM } \\
\text { because } \\
\text { of Unit 3) }\end{array}$ \\
\hline $\begin{array}{l}30 \quad \text { (no } \\
\text { PWIM } \\
\text { because of } \\
\text { Unit 3) } \\
\end{array}$ & 4 & $z$ & 3 & 4 & 5 & $\theta$ \\
\hline 7 & $\begin{array}{l}\text { 8(no PWIM } \\
\text { because of } \\
\text { Unit 3) }\end{array}$ & $\begin{array}{l}\text { 9(no PWIM } \\
\text { because of Unit 3) }\end{array}$ & $\begin{array}{l}\text { 10(no } \\
\text { PWIM } \\
\text { because of } \\
\text { Unit 3) }\end{array}$ & 11 & $\begin{array}{l}\text { 12(no } \\
\text { PWIM } \\
\text { because } \\
\text { of Unit } \\
\text { 3) }\end{array}$ & 13 \\
\hline $\begin{array}{l}\text { 14(PWIM3 } \\
1^{\text {st }} \text { time) }\end{array}$ & $\begin{array}{l}15 \text { (PWIM3 } \\
2^{\text {nd }} \text { time) }\end{array}$ & $\begin{array}{ll}16(\text { PWIM3 } & 3^{\text {rd }} \\
\text { time }) & \end{array}$ & $\begin{array}{r}17 \text { (PWIM3 } \\
4^{\text {th }} \text { time) } \\
\end{array}$ & $\begin{array}{l}\text { 18(PWIM3 } \\
5^{\text {th }} \text { time) }\end{array}$ & 19 & 20 \\
\hline $\begin{array}{l}21 \text { (no } \\
\text { PWIM } \\
\text { because of } \\
\text { unit test) }\end{array}$ & $\begin{array}{l}\text { 22(no PWIM } \\
\text { because of } \\
\text { homework } \\
\text { supervision) }\end{array}$ & $\begin{array}{l}23 \text { (no PWIM } \\
\text { because } \\
\text { homework } \\
\text { supervision from } \\
\text { superintendent) }\end{array}$ & $\begin{array}{c}\text { 24(PWIM3 } \\
6^{\text {th }} \text { time) }\end{array}$ & 25 & 26 & 27 \\
\hline $\begin{array}{l}\text { 28(PWIM } 3 \\
7^{\text {th }} \text { time) }\end{array}$ & $\begin{array}{l}\text { 29(no PWIM } \\
\text { because of } \\
\text { unit test) }\end{array}$ & $\begin{array}{l}30 \text { (no PWIM } \\
\text { because of unit } \\
\text { test) }\end{array}$ & $\begin{array}{l}1 \text { (no } \\
\text { PWIM even } \\
\text { I was there) }\end{array}$ & 1 & 2 & 3 \\
\hline $\begin{array}{l}4 \text { (PWIM } 1 \\
2^{\text {nd }} \text { time) }\end{array}$ & 5 & $\begin{array}{l}\text { 6(PWIM } 13^{\text {rd }} \\
\text { Time } \\
\text { posttest) }\end{array}$ & 7 & 8 & 9 & 10 \\
\hline
\end{tabular}




\section{Appendix DD}

Implementation Dates of PWIM for the $7^{\text {th }}$ Graders

\begin{tabular}{|c|c|c|c|c|c|c|}
\hline M & $\mathrm{T}$ & $\mathrm{W}$ & $\operatorname{Tr}$ & $\mathrm{F}$ & $\mathrm{Sa}$ & $\mathrm{Su}$ \\
\hline 2 & $\begin{array}{l}3 \text { (meet } \\
\text { vice-principal } \\
\text { Li and teacher } \\
\text { Lily) }\end{array}$ & 4 & $\begin{array}{l}5 \quad \text { (Meet } \\
\text { teacher Lily } \\
\& \quad \text { train } \\
\text { PWIM for } \\
\text { PWIM } \\
\text { the } 1^{\text {st }} \text { time) }\end{array}$ & 6 & 7 & $\begin{array}{l}8 \\
\text { (PWIM } \\
\text { training } \\
--\quad \text { Lily } \\
\& \quad \text { Ivy } \\
\text { for the } \\
2^{\text {nd }} \\
\text { time) }\end{array}$ \\
\hline 9 & $\begin{array}{l}10 \quad \text { (pretest } \\
\text { G7C10) }\end{array}$ & $\begin{array}{l}11 \text { (PWIM } \\
\text { visit } 1^{\text {st }} \text { pic } \\
1^{\text {st }} \text { time) }\end{array}$ & $\begin{array}{l}12 \text { (pretest } \\
\text { G7C16,no } \\
\text { PWIM) }\end{array}$ & $\begin{array}{l}13 \text { (PWIM } \\
\text { only } \\
\text { revision, no } \\
\text { new words) }\end{array}$ & 14 & 15 \\
\hline $\begin{array}{l}16 \text { (no class } \\
\text { because of } \\
\text { physical } \\
\text { check) }\end{array}$ & $\begin{array}{l}17 \text { (PWIM } 2^{\text {nd }} \\
\text { visit PWIM } \\
1^{\text {st }} \text { pic } 3^{\text {rd }} \\
\text { time) }\end{array}$ & 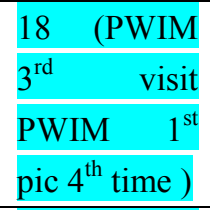 & 19 & 20 & 21 & $\begin{array}{l}22 \quad \text { (no } \\
\text { PWIM } \\
\text { 1) }\end{array}$ \\
\hline $\begin{array}{ll}23 & \text { (PWIM } \\
1) & \end{array}$ & $\begin{array}{l}24 \text { (PWIM } 1 \\
5^{\text {th }} \text { time) }\end{array}$ & $\begin{array}{l}25 \text { (PWIM } 1 \\
6^{\text {th }} \text { time) }\end{array}$ & $\begin{array}{l}26 \quad \text { (no } \\
\text { PWIM } \\
\text { because of } \\
\text { unit test) }\end{array}$ & $\begin{array}{l}27 \quad \text { (no } \\
\text { PWIM } \\
\text { because of } \\
\text { explaining } \\
\text { the test) }\end{array}$ & 28 & $\begin{array}{l}29 \\
(\mathrm{PWIM} \\
17^{\text {th }} \\
\text { time })\end{array}$ \\
\hline $\begin{array}{l}30 \text { (PWIM } \\
18^{\text {th }} \text { time) }\end{array}$ & 1 & 2 & 3 & 4 & 5 & 6 \\
\hline 7 & $\begin{array}{l}8 \text { (PWIM } 19^{\text {th }} \\
\text { time-last } \\
\text { time ) }\end{array}$ & $\begin{array}{l}\text { 9(PWIM2 } 1^{\text {st }} \\
\text { time) }\end{array}$ & $\begin{array}{l}10 \text { (no } \\
\text { PWIM } \\
\text { because of } \\
\text { physical } \\
\text { tests) }\end{array}$ & $\begin{array}{l}11 \text { (no } \\
\text { PWIM } \\
\text { because of } \\
\text { unit } \\
\text { revision) }\end{array}$ & $\begin{array}{l}12 \quad \text { (no } \\
\text { PWIM } \\
\text { because } \\
\text { some } \\
\text { principal } \\
\text { will } \\
\text { attend the } \\
\text { class) }\end{array}$ & 13 \\
\hline $\begin{array}{l}14 \text { PWIM } 2 \\
2^{\text {nd }} \text { time }\end{array}$ & $\begin{array}{l}\text { 15(no PWIM } \\
\text { because of } \\
\text { unit test) }\end{array}$ & $\begin{array}{l}\text { 16(no PWIM } \\
\text { because of } \\
\text { public class } \\
\text { within } \\
\text { English } \\
\text { teachers' } \\
\text { team) }\end{array}$ & $\begin{array}{l}17 \text { (PWIM } 2 \\
3^{\text {rd }} \text { time) }\end{array}$ & $\begin{array}{l}\text { 18(PWIM2 } \\
4^{\text {th }} \text { time) }\end{array}$ & 19 & 20 \\
\hline
\end{tabular}




\begin{tabular}{|l|l|l|l|l|l|l|}
\hline $\begin{array}{l}\text { 21(PWIM2 } \\
5^{\text {th }} \text { time) }\end{array}$ & $\begin{array}{l}\text { 22(PWIM2 } \\
6^{\text {th }} \text { time) }\end{array}$ & $\begin{array}{l}\text { 23(PWIM2 } \\
7 \text { th time) }\end{array}$ & $\begin{array}{l}\text { 24(no } \\
\text { PWIM } \\
\text { because of } \\
\text { Sports Fair) }\end{array}$ & $\begin{array}{l}\text { 25((no } \\
\text { PWIM } \\
\text { because of } \\
\text { Sports Fair) }\end{array}$ & 26 & 27 \\
\hline $\begin{array}{l}\text { 28(PWIM3 } \\
1^{\text {st }} \text { time) }\end{array}$ & $\begin{array}{l}29 \text { (PWIM3 } \\
2^{\text {nd }} \text { time) }\end{array}$ & $\begin{array}{l}30 \text { (no PWIM } \\
\text { because of } \\
\text { unified test) }\end{array}$ & $\begin{array}{lll}31 \text { (no time } \\
\text { for PWIM) }\end{array}$ & $\begin{array}{l}1 \text { (no time } \\
\text { for PWIM) }\end{array}$ & 2 & 3 \\
\hline $\begin{array}{l}4 \text { (PWIM 3 } 3 \\
3^{\text {rd }} \text { time) }\end{array}$ & $\begin{array}{l}5 \text { (posttest) } \\
\text { 6(mid-term) }\end{array}$ & (mid-term) & 8 (mid-term) & 9 & $10)$ \\
\hline
\end{tabular}


XUAN JIANG

Born, Lianyungang, Jiangsu, P.R.China

\section{EDUCATION AND EXPERIENCES}

1999-2003

2003-2010

2007-2009

2008-2009

2010-2013

$2010-2014$
B.A., English

Southwest University of Political Science and Law

Chongqing, China

B.A., Law

Southwest University of Political Science and Law Chongqing, China

(Assistant) Lecturer, College Comprehensive English Suzhou Institute of Construction and Communications Suzhou, China

M.A., Foreign Linguistics \& Literature Soochow University

Suzhou, China

M.Ed., Teachers of English to Speakers of Other Languages (TESOL)

Queensland University of Technology

Brisbane, Australia

Educational Specialist, Curriculum and Instruction-NCATE Florida International University

Miami, Florida

Ph.D., Curriculum and Instruction-TESOL

Florida International University

Miami, Florida

Teaching/Research/Graduate Assistant

Florida International University

Miami, Florida 


\section{PUBLICATIONS AND PRESENTATIONS (SELECTED)}

Jiang, X., \& Perkins, K. (May, 2012). Examining the effectiveness of the Picture Word Inductive Model. Paper presented at the Sunshine State TESOL 2012 conference. Orlando, FL.

Jiang, X., \& Perkins, K. (2013). A conceptual paper on the application of the picture word inductive model using Bruner's constructive view of learning and cognitive load theory. Interdisciplinary Journal of Teaching and Learning, 3(1), 8-17. Retrieved from http://www3.subr.edu/coeijtl/files/Download/IJTL\%20Vol.\%203\%2C\%20No.\%201\% 2C\%20Spring $\% 202013 \% 20-\% 20$ Jiang $\% 20 \% 26 \% 20$ Perkins $\% 20 \% 28$ pp. $\% 208-17 \% 29$ . $\mathrm{pdf}$

Jiang, X. (2011).Challenges for college-level learners of academic English writing in China. In M. S. Plakhotnik, S. M. Nielsen, \& D. M. Pane (Eds.), Proceedings of the Tenth Annual College of Education \& GSN Research Conference (pp. 95-100). Miami: Florida International University. http://coeweb.fiu.edu/research conference/

Jiang, X. (2012). [Review of the book The handbook of scholarly writing and publishing by Tonette S. Rocco \& Tim Hatcher]. Journal of Linguistics and Language Teaching, 3(2), 351-358.

Jiang, X. (March, 2014). Young English Learners' Perception of the Use of the Picture-Word Inductive Model in their English Classes in China. Paper presented at 2014 Annual Scholarly Forum. Miami, FL: Florida International University.

Jiang, X. (May, 2014,). A Quasi-Experiment Study of Vocabulary Learning through Use of the Picture-Word Inductive Model for Young English Learners in China. Paper presented at the Sunshine State TESOL 2014 conference. St. Petersburg, FL.

Jiang, X. (2014). Chinese biology teaching assistants' perception of their English proficiency: An exploratory case study. The Qualitative Report, 19(42), 1-24. Retrieved from http://www.nova.edu/ssss/QR/QR19/jiang42.pdf

Sanders-Reio, J., Reio, T. G., Jr., Newman, I., \& Jiang, X. (April, 2012). The relations between students' beliefs about writing, writing apprehension, and their use of writing strategies. Paper presented at the 2012 annual meeting of the American Educational Research Association, Vancouver, BC, CN. 